\title{
International Union of Basic and Clinical Pharmacology. XCII. Urotensin II, Urotensin II-Related Peptide, and Their Receptor: From Structure to Function
}

Hubert Vaudry, Jérôme Leprince, David Chatenet, Alain Fournier, David G. Lambert, Jean-Claude Le Mével, Eliot H. Ohlstein, Adel Schwertani, Hervé Tostivint, and David Vaudry

Institut National de la Santé et de la Recherche Médicale, U982, Institute for Research and Innovation in Biomedicine, Mont-Saint-Aignan, France (H.V., J.L., D.V.), University of Rouen, Mont-Saint-Aignan, France (H.V., J.L., D.V.); Institut National de la Recherche ScientifiqueInstitut Armand Frappier, Laval, Québec, Canada (D.C., A.F.); International Associated Laboratory Samuel de Champlain, University of Rouen, Mont-Saint-Aignan, France (H.V., J.L., D.C., A.F., D.V.); Department of Cardiovascular Sciences, Division of Anaesthesia, Critical Care and Pain Management, University of Leicester, Robert Kilpatrick Clinical Sciences Building, Leicester Royal Infirmary, Leicester, United Kingdom (D.G.L.); Institut National de la Santé et de la Recherche Médicale, U1101, Laboratoire de Traitement de l'Information

Médicale, Laboratoire de Neurophysiologie, Université Européenne de Bretagne, Brest, France (J.-C.L.M.); AltheRx Pharmaceuticals, Malvern, Pennsylvania (E.H.O.); Division of Cardiology, Montreal General Hospital, McGill University Health Center, Montreal, Québec, Canada (A.S.); and Centre National de la Recherche Scientifique, Unité Mixte de Recherche 7221, Evolution des Régulations Endocriniennes, Muséum National d'Histoire Naturelle, Paris, France (H.T.)

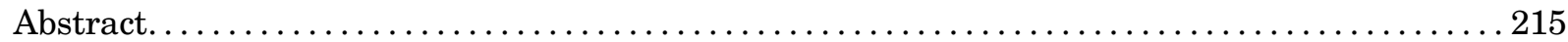

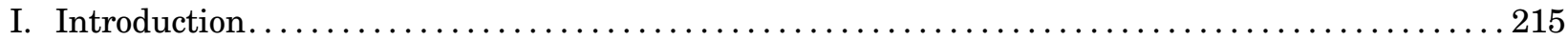

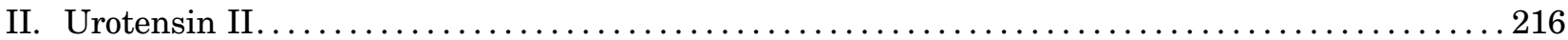

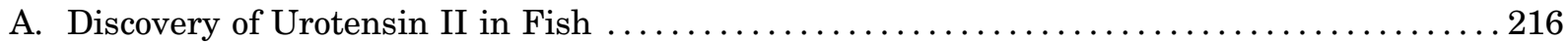

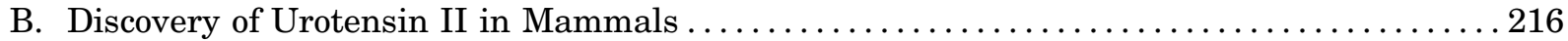

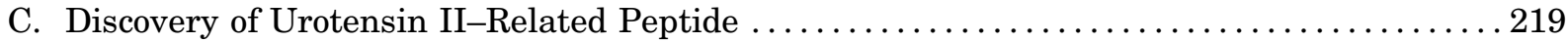

D. Secondary Structure of Urotensin II and Urotensin II-Related Peptide .............. 219

E. Structure of the Urotensin II and Urotensin II-Related Peptide Precursors and

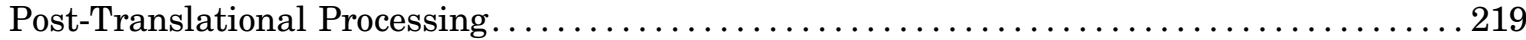

F. The Urotensin II and Urotensin II-Related Peptide Genes . . . . . . . . . . . . . . 221

G. Distribution of Urotensin II and Urotensin II-Related Peptide in the Central Nervous System . 221

H. Distribution of Urotensin II and Urotensin II-Related Peptide in Peripheral Organs ...... 222

I. Urotensin II and Urotensin II-Related Peptide in Tumor Cells . . . . . . . . . . . . . . 223

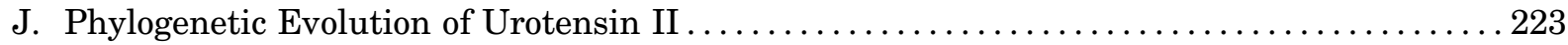

1. Discovery of Two Novel Urotensin II-Related Peptide-Like Genes in Teleosts. . . . . . . 223

2. Origin and Evolution of the Urotensin II Gene Family in Vertebrates...............224

3. Evolutionary Relationships between Peptides of the Urotensin II and

Somatostatin Families. . . . . . . . . . . . . . . . . . . . . . . . . . . . . . . . . . . . . . . 224

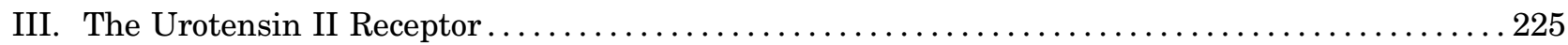

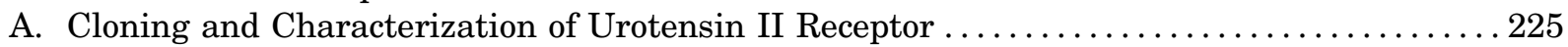

B. Signaling Mechanisms ................................................. 227

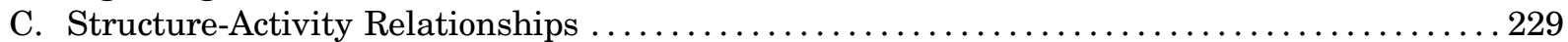

D. Design of Nonpeptidic Urotensin II Receptor Agonists and Antagonists . . . . . . . . . . . . 232

E. Distribution of Urotensin II Receptor in the Central Nervous System ................ 234

This work was supported by grants from the Institut National de la Santé et de la Recherche Médicale (INSERM, U982); the European Regional Development Fund (project PeReNE); an INSERM-Fonds de la Recherche en Santé du Québec exchange program (to A.F. and D.V.); the British Heart Foundation and British Journal of Anaesthesia (to D.G.L.); and the Région Haute-Normandie (to H.V., J.L., and D.V.).

Address correspondence to: Dr. Hubert Vaudry, Institut National de la Santé et de la Recherche Médicale U982, Institute for Research and Innovation in Biomedicine, International Associated Laboratory Samuel de Champlain, University of Rouen, 76821 Mont-Saint-Aignan, France. E-mail: hubert.vaudry@univ-rouen.fr

D.V. and H.V. are Affiliated Professors at the Institut National de la Recherche Scientifique-Institut Armand-Frappier.

dx.doi.org/10.1124/pr.114.009480. 
F. Distribution of Urotensin II Receptor in Peripheral Organs . . . . . . . . . . . . . . 238

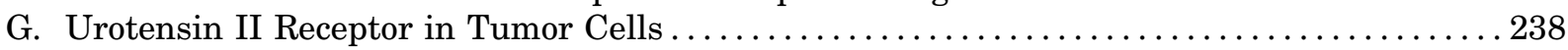

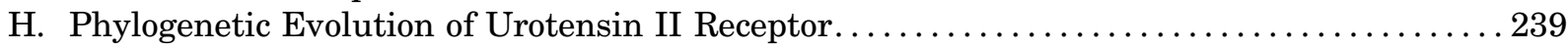

IV. Biologic and Pharmacologic Effects of Urotensin II and Urotensin II-Related Peptide....... 239

A. Effects of Urotensin II/Urotensin II-Related Peptide in the Central Nervous System . . . . . 239

1. Action on Rapid Eye Movement Sleep................................... 239

2. Action on Food Intake and Energy Homeostasis. .......................... 240

3. Action on Cardiovascular Activity. . . . . . . . . . . . . . . . . . . . . . . . . . . . 241

4. Action on Locomotor Activity...................................... 241

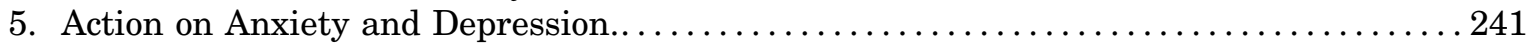

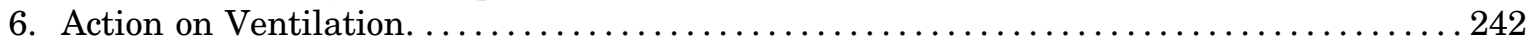

7. Neuroendocrine Actions........................................ 242

B. Effect of Urotensin II/Urotensin II-Related Peptide on the Cardiovascular System . . . . . . 244

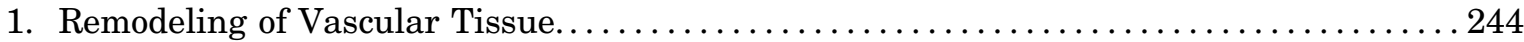

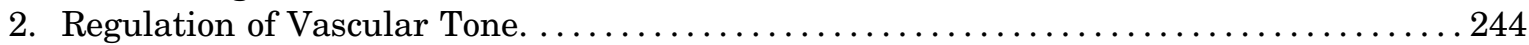

3. Regulation of Myocardial Contractility. ............................... 246

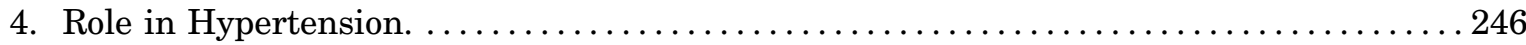

5. Role in Atherosclerosis........................................... 246

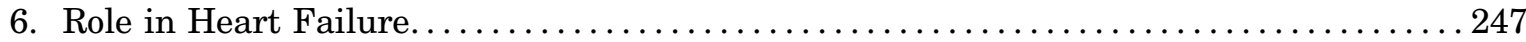

C. Effect of Urotensin II/Urotensin II-Related Peptide on the Urogenital Tract . . . . . . . . . . 248

D. Effect of Urotensin II/Urotensin II-Related Peptide on the Gastrointestinal Tract........ 248

E. Effect of Urotensin II/Urotensin II-Related Peptide on the Pancreas................. 249

F. Effect of Urotensin II/Urotensin II-Related Peptide on the Liver . . . . . . . . . . . . . 250

G. Effect of Urotensin II/Urotensin II-Related Peptide on the Adrenal Gland ............. 250

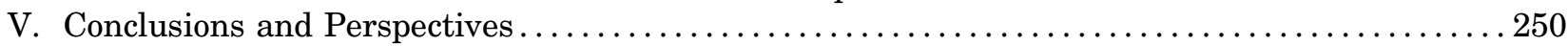

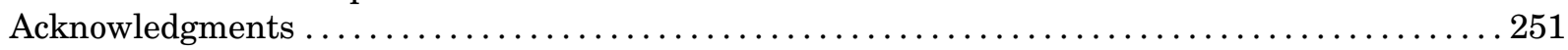

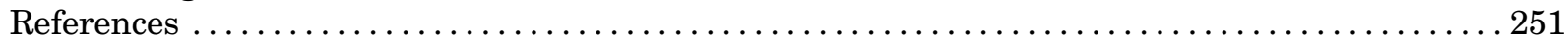

\begin{abstract}
Urotensin II (UII) is a cyclic neuropeptide that was first isolated from the urophysis of teleost fish on the basis of its ability to contract the hindgut. Subsequently, UII was characterized in tetrapods including humans. Phylogenetic studies and synteny analysis indicate that UII and its paralogous peptide urotensin II-related peptide (URP) belong to the somatostatin/ cortistatin superfamily. In mammals, the UII and URP genes are primarily expressed in cholinergic neurons of the brainstem and spinal cord. UII and URP mRNAs are also present in various organs notably in the cardiovascular, renal, and endocrine systems. UII and URP activate a common $G$ protein-coupled receptor, called UT, that exhibits relatively high sequence identity
\end{abstract}

with somatostatin, opioid, and galanin receptors. The UT gene is widely expressed in the central nervous system (CNS) and in peripheral tissues including the retina, heart, vascular bed, lung, kidney, adrenal medulla, and skeletal muscle. Structure-activity relationship studies and NMR conformational analysis have led to the rational design of a number of peptidic and nonpeptidic UT agonists and antagonists. Consistent with the wide distribution of UT, UII has now been shown to exert a large array of biologic activities, in particular in the CNS, the cardiovascular system, and the kidney. Here, we review the current knowledge concerning the pleiotropic actions of UII and discusses the possible use of antagonists for future therapeutic applications.

\section{Introduction}

In 1980, Howard Bern and his coworkers published an article, now a citation classic, in which they reported the characterization of a novel regulatory peptide from the fish urophysis that they called urotensin II (UII) (Pearson et al., 1980). Because the urophysis is a neurohemal organ that is exclusively present in teleosts (Bern et al., 1985), it had long been thought that UII only existed in fish. However, subsequent studies have led to the identification of UII orthologs in amphibians (Conlon et al., 1992b) and mammals, including humans (Coulouarn et al., 1998). Soon after, a UII receptor was

ABBREVIATIONS: ACAT-1, acyltransferase-1; ACTH, adrenocorticotropin; CHF, congestive heart failure; CHO, Chinese hamster ovary; CNS, central nervous system; CSF, cerebrospinal fluid; CTF-prohUII, C-terminal fragment of human pro-UII; 3D, three-dimensional; ECL, extracellular loop; FLIPR, fluorometric imaging plate reader; GPCR, G protein-coupled receptor; HCC, human corpus cavernosum; HPLC, high-performance liquid chromatography; HTS, high-throughput screening; $\mathrm{IP}_{3}$, inositol-1-4-5 triphosphate; LDL, low-density lipoprotein; MAPK, mitogen-activated protein kinase; NO, nitric oxide; PLC, phospholipase C; PPT, pedunculopontine tegmental nucleus; 2R, two wholeduplication rounds; REM, rapid eye movement; ROS, reactive oxygen species; RT-PCR, reverse-transcription polymerase chain reaction; SHR, spontaneously hypertensive rats; SNPs, single nucleotide polymorphisms; T2DM, type 2 diabetes mellitus; UCA, urocontrin A; UII, urotensin II; URP, urotensin II-related peptide; UT, UII receptor; WKY, Wistar-Kyoto rats. 
identified, called UT, which is widely expressed in the central nervous system (CNS) and in various peripheral organs, notably in the cardiovascular system and in the kidney (Ames et al., 1999; Liu et al., 1999; Mori et al., 1999; Nothacker et al., 1999). More recently, the existence of a UII paralog called urotensin II-related peptide (URP) was characterized in the brain of rodents (Sugo et al., 2003). Consistent with the widespread distribution of UT, it has been shown that UII exerts a number of biologic effects including regulation of behaviors and neuroendocrine activities, as well as central and peripheral control of blood pressure and heart rate (Douglas et al., 2004a; Vaudry et al., 2010). Clinical studies have provided evidence that UII and UT are implicated in various pathologies, including cardiovascular diseases (Douglas et al., 2002; Ng et al., 2002; Richards et al., 2002; You et al., 2012; Watson et al., 2013), renal diseases (Totsune et al., 2001), and diabetes (Wenyi et al., 2003; Sidharta et al., 2009). The various activities of UII and the potential implication of the urotensinergic system in various pathologies have prompted academic laboratories and pharmaceutical companies to design specific agonists and antagonists that are currently used for basic research and may lead to therapeutic applications (Leprince et al., 2008; Maryanoff and Kinney, 2010; Tsoukas et al., 2011; Merlino et al., 2013).

\section{Urotensin II}

\section{A. Discovery of Urotensin II in Fish}

Teleost fish possess a singular neurosecretory system located in the caudal region of the spinal cord. This system consists of two rows of magnocellular secretory neurons, termed Dahlgren cells (Dahlgren, 1914), symmetrically arranged in the ventral horn of the spinal cord, that project their axons into a neurohemal organ called the urophysis (Enami, 1959). The caudal neurosecretory system of teleosts is thus anatomically and functionally similar to the hypothalamo-neurohypophysial neurosecretory system (Bern et al., 1985; McCrohan et al., 2007).

Early studies have shown that urophysial extracts contain substances that exhibit various pharmacological activities both in fish and in mammals (Chan, 1975). Two laboratories have concurrently undertaken the purification and isolation of the bioactive peptides, collectively named urotensins, that are responsible for the observed pharmacologic effects. Thus, the group of Karl Lederis characterized urotensin I, a 41-amino acid peptide from an extract of the urophysis of the white sucker Catostomus commersonii (Lederis et al., 1982), that was found to be a paralog of corticotropin-releasing hormone (Vale et al., 1981), while the group of Howard Bern characterized UII, a 12-amino acid peptide, from an extract of the urophysis of the goby Gillichthys mirabilis (Pearson et al., 1980), that was found to exhibit some structural similarity to somatostatin (Brazeau et al., 1973).

The sequence of UII has been relatively well preserved in all fish species studied (Vaudry et al., 2010), suggesting that the peptide exerts important biologic functions. As a matter of fact, in fish, UII induces a general spasmogenic activity that has been documented in various tissue preparations including the trout (Salmo gairdneri) urinary bladder, the trout posterior intestine, the guppy (Poecilia reticulata) oviduct, the goby sperm duct, the eel (Anguilla rostrata) caudal lymph heart (Bern et al., 1985), and the dogfish (Scyliorhinus canicula) vascular ring (Hazon et al., 1993). In unanesthetized trout (Oncorhynchus mykiss), intra-arterial administration of UII causes an increase in aortic blood pressure and a decrease in heart rate (Le Mével et al., 2008). In fish, UII also contributes to the control of hydromineral balance through a direct action on ion transport across the skin, gill, intestine, and urinary bladder (Marshall, and Bern, 1979, 1981; Loretz and Bern, 1981; Loretz et al., 1982, 1983, 1985; Mainoya and Bern, 1982, 1984; Lu et al., 2008). Finally, UII participates in the neuroendocrine regulation of prolactin secretion in tilapia (Oreochromics mossambicus; Grau et al., 1982; Rivas et al., 1986) and cortisol secretion in the trout (Arnold-Reed and Balment, 1994) and the European flounder (Platichtys flesus; Kelsall and Balment, 1998).

\section{B. Discovery of Urotensin II in Mammals}

Because the urophysis is a neurosecretory organ that is exclusively found in teleosts, it has long been thought that UII was present only in fish and not in other vertebrates. Surprisingly however, biochemical experiments have shown the occurrence of specific binding sites for goby UII in rat arteries (Itoh et al., 1987, 1988), and pharmacological studies have revealed that fish UII exerts various effects in mammals such as relaxation of the mouse anococcygeus muscle (Gibson et al., 1984) and endothelium-independent contraction of the rat aorta (Gibson, 1987). Goby UII also induces a marked increase of intracellular calcium concentration $\left(\left[\mathrm{Ca}^{2+}\right]_{\mathrm{i}}\right)$ in rat aorta cells (Gibson et al., 1988). The observation that fish UII possessed significant biologic activity in rodents strongly suggested that an homologous peptide might exist in mammals. In fact, immunohistochemical studies have shown the presence of UII-immunoreactive neurons in the brain and anterior spinal cord of fish (Yulis and Lederis, 1986, 1988), indicating that UII could be produced not only in the caudal neurosecretory organ but also in extra-urophysial neurons.

The first unequivocal evidence for the occurrence of UII in tetrapods was provided by the purification of a UII-immunoreactive peptide from an extract of the whole brain of the European green frog Rana ridibunda (Conlon et al., 1992b), now renamed Pelophylax ridibundus (Conlon et al., 2009). Structural characterization of the isolated peptide showed that frog UII encompasses 
13 amino acids (Conlon et al., 1992b) instead of 12 amino acids as in all fish UII sequences identified to date (Lihrmann et al., 2013). However, the cyclic region that is essential for the biologic activity of the peptide (Itoh et al., 1987) is identical in fish and amphibian sequences (Fig. 1). Unlike many other neuropeptides, UII is not found in hypothalamic neurons, but is almost exclusively produced in motoneurons of the frog brainstem and spinal cord (Chartrel et al., 1996). The identification of UII in the frog brain confirmed that 1) UII is produced in extra-urophysial nervous tissues and 2) urotensinergic systems exist in vertebrate phyla outside the fish lineage (Conlon et al., 1997; Conlon, 2008; Vaudry et al., 2010). This finding thus paved the way for the discovery of UII and its receptor in mammals.

The cDNA encoding the UII precursor has been cloned from a frog brain library (Coulouarn et al., 1998). Frog UII cDNA has then been used to identify an expressed sequence tag from bulk human colon tumors and subsequently to clone the human preproUII cDNA (Coulouarn et al., 1998). The existence of a Lys-Lys-Arg cleavage motif in the $\mathrm{C}$-terminal region of the precursor (see section II.E) predicts that human UII is an 11-amino acid peptide with a cyclic hexapeptide motif (Cys-Phe-Trp-Lys-Tyr-Cys) identical to that of fish and frog UII (Fig. 2, compound 1), explaining why fish UII can excite mammalian UT (Gibson et al., 1984, 1988; Gibson, 1987). Characterization of the cDNAs encoding the rat, mouse (Coulouarn et al., 1999) and porcine prepro-UII (Mori et al., 1999) rapidly ensued. The way UII was identified in mammals is thus a remarkable illustration of the power of the comparative approach for the discovery of novel human neuropeptides (Conlon, 2000). Of note, urotensin I, the other regulatory peptide initially characterized from the fish urophysis (Lederis et al., 1982), led to the discovery of the urocortin peptides (Vaughan et al., 1995). Other mammalian neuropeptides characterized through a similar comparative strategy are: melanin-concentrating hormone (Kawauchi et al., 1983; Vaughan et al., 1989), cortistatin (Vaudry et al., 1992; de Lecea et al., 1996), secretoneurin (Vaudry and Conlon, 1991; Kirchmair et al., 1993), gonadotropininhibitory hormone (Tsutsui et al., 2000; Kriegsfeld et al., 2006), 26RFa/QRFP (Chartrel et al., 2003), and adrenomedullin 2 (Takei et al., 2004a,b).

The amino acid sequence of UII has now been determined in a number of vertebrate species from lamprey to human (Fig. 1). As shown in Fig. 1, the

\begin{tabular}{|c|c|c|c|c|}
\hline & Species & Sequence and origin ${ }^{1}$ & & $\begin{array}{c}\text { Reference/Accession } \\
\text { number }\end{array}$ \\
\hline \multicolumn{5}{|l|}{ UII } \\
\hline Lamprey & $\begin{array}{l}\text { Lampetra fluviatilis } \\
\text { Petromyzon marinus }\end{array}$ & $\begin{array}{l}\text { H-Asn-Asn-Phe-Ser-Asp-Cys-Phe-Trp-Lys-Tyr-Cys-Val-OH } \\
\text { H-Asn-Asn-Phe-Ser-Asp-Cys-Phe-Trp-Lys-Tyr-Cys-Val-OH }\end{array}$ & $\begin{array}{l}\mathrm{P} \\
\mathrm{P}\end{array}$ & $\begin{array}{l}\text { Waugh et al., } 1995 \\
\text { Waugh et al., } 1995\end{array}$ \\
\hline $\begin{array}{l}\text { Dogfish } \\
\text { Skate }\end{array}$ & $\begin{array}{l}\text { Scyliorhinus canicula } \\
\text { Raja rhina }\end{array}$ & $\begin{array}{l}\text { H-Asn-Asn-Phe-Ser-Asp-Cys-Phe-Trp-Lys-Tyr-Cys-Val-OH } \\
\text { H-Asn-Asn-Phe-Ser-Asp-Cys-Phe-Trp-Lys-Tyr-Cys-Val-OH }\end{array}$ & $\begin{array}{l}\mathrm{P} \\
\mathrm{P}\end{array}$ & $\begin{array}{l}\text { Conlon et al., } 1992 \mathrm{~b} \\
\text { Waugh and Conlon, } 1993\end{array}$ \\
\hline $\begin{array}{l}\text { Paddlefish } \\
\text { Sturgeon }\end{array}$ & $\begin{array}{l}\text { Polyodon spathula } \\
\text { Acipenser ruthenus }\end{array}$ & $\begin{array}{l}\text { H-Gly-Ser-Thr-Ser-Glu-Cys-Phe-Trp-Lys-Tyr-Cys-Val-OH } \\
\text { H-Gly-Ser-Thr-Ser-Glu-Cys-Phe-Trp-Lys-Tyr-Cys-Val-OH }\end{array}$ & $\begin{array}{l}\mathrm{P} \\
\mathrm{P}\end{array}$ & $\begin{array}{l}\text { Waugh et al., } 1995 \\
\text { Mc Master et al., } 1992\end{array}$ \\
\hline $\begin{array}{l}\text { Burton's haplo } \\
\text { Carp } \alpha\end{array}$ & $\begin{array}{l}\text { Haplochromis burtoni } \\
\text { Cyprinus carpio }\end{array}$ & $\begin{array}{l}\text { H-Gly-Gly-Asn-Ser-Glu-Cys-Phe-Trp-Lys-Tyr-Cys-Val-OH } \\
\text { H-Gly-Gly-Gly-Ala-Asp-Cys-Phe-Trp-Lys-Tyr-Cys-Val-OH }\end{array}$ & $\begin{array}{l}\mathrm{D} \\
\mathrm{P}\end{array}$ & $\begin{array}{l}\text { XP_005930789 } \\
\text { Ichikawa et al., } 1984\end{array}$ \\
\hline Carp $\beta 1$ & Cyprinus carpio & H-Gly-Gly-Asn-Thr-Glu-Cys-Phe-Trp-Lys-Tyr-Cys-Val-OH & $P$ & Ichikawa et al., 1984 \\
\hline Carp $\beta 2$ & Cyprinus carpio & H-Gly-Ser-Asn-Thr-Glu-Cys-Phe-Trp-Lys-Tyr-Cys-Val-OH & $\mathrm{P}$ & Ichikawa et al., 1984 \\
\hline Carp $\gamma$ & Cyprinus carpio & H-Gly-Gly-Gly-Ala-Asp-Cys-Phe-Trp-Lys-Tyr-Cys-Ile-OH & C & Ohsako et al., 1986 \\
\hline Cichlid & Pundamilia nyererei & H-Gly-Gly-Asn-Ser-Glu-Cys-Phe-Trp-Lys-Tyr-Cys-Val-OH & D & XP_005731732 \\
\hline Codfish & Gadus morhua & H-Gly-Gly-Asn-Thr-Glu-Cys-Phe-Trp-Lys-Tyr-Cys-Val-OH & $\mathrm{D}$ & ENS̄GMOP00000021176 \\
\hline Eel & Anguilla japonica & H-Gly-Ser-Gly-Ser-Glu-Cys-Phe-Trp-Lys-TYr-Cys-Val-OH & $\mathrm{C}$ & Nobata et al., 2011 \\
\hline Flounder & Platichthys flesus & H-Ala-Gly-Thr-Thr-Glu-Cys-Phe-Trp-Lys-Tyr-Cys-Val-OH & $\mathrm{P}$ & Conlon et al., 1990 \\
\hline Fugu & Takifugu rubripes & H-Thr-Gly-Asn-Asn-Glu-Cys-Phe-Trp-Lys-Tyr-Cys-Val-OH & $\mathrm{C}$ & CAl53670 \\
\hline Grouper & Epinephelus coioides & H-Ala-Gly-Asn-Ser-Glu-Cys-Phe-Trp-Lys-Tyr-Cys-Val-OH & $\mathrm{C}$ & ACN65410 \\
\hline Goby & Gillichthys mirabilis & H-Ala-Gly-Thr-Ala-Asp-Cys-Phe-Trp-Lys-Tyr-Cys-Val-OH & $\mathrm{P}$ & Pearson et al., 1980 \\
\hline Killifish & Fundulus heteroclitus & H-Asn-Asp-Asn-Ser-Glu-Cys-Phe-Trp-Lys-Tyr-Cys-Val-OH & $\mathrm{c}$ & Evans et al., 2011 \\
\hline Medaka & Oryzias latipes & H-Ser-Gly-Asn-Thr-Glu-Cys-Phe-Trp-Lys-Tyr-Cys-Val-OH & D & XP_004070888 \\
\hline Platyfish & Xiphophorus maculatus & H-Asn-Gly-Asn-Ser-Glu-Cys-Phe-Trp-LYs-Tyr-Cys-Val-OH & $\mathrm{D}$ & $\mathrm{XP}-005801770$ \\
\hline Stickleback & Gasterosteus aculeatus & H-Ala-Gly-Asn-Ser-Glu-Cys-Phe-Trp-Lys-Tyr-Cys-Val-OH & $\mathrm{D}$ & ENSGACP00000016360 \\
\hline Sucker A & Catostomus commersoni & H-Gly-Ser-Gly-Ala-Asp-Cys-Phe-Trp-Lys-Tyr-Cys-Val-OH & $\mathrm{P}$ & Mc Master et al., 1983 \\
\hline Sucker B & Catostomus commersoni & H-Gly-Ser-Asn-Thr-Glu-Cys-Phe-Trp-Lys-Tyr-Cys-Val-OH & $\mathrm{P}$ & Mc Master et al., 1983 \\
\hline Tetraodon & Tetraodon nigroviridis & H-His-Gly-Asn-Asp-Glu-Cys-Phe-Trp-Lys-Tyr-Cys-Val-OH & D & ENSTNIP00000002161 \\
\hline Tilapia & Oreochromis niloticus & H-Gly-Gly-Asn-Ser-Glu-Cys-Phe-Trp-Lys-Tyr-Cys-Val-OH & $\mathrm{D}$ & XP_003438987 \\
\hline Trout & Oncorhynchus mykiss & H-Gly-Gly-Asn-Ser-Glu-Cys-Phe-Trp-Lys-Tyr-Cys-Val-OH & $\mathrm{P}$ & Waugh et al., 1993 \\
\hline Zebrafish $\alpha$ & Danio rerio & H-Gly-Gly-Gly-Ala-Asp-Cys-Phe-Trp-Lys-Tyr-Cys-Val-OH & $\mathrm{C}$ & Tostivint et al., 2006 \\
\hline Zebrafish $\beta$ & Danio rerio & H-Gly-Ser-Asn-Thr-Glu-Cys-Phe-Trp-Lys-Tyr-Cys-Val-OH & $\mathrm{C}$ & Tostivint et al., 2006 \\
\hline Coelacanth & Latimeria chalumnae & H-Glu-Asn-Gln-Ser-Glu-Cys-Phe-Trp-LYs-Tyr-Cys-Val-OH & $\mathrm{D}$ & Tostivint et al., 2013 \\
\hline Clawed frog & $\begin{array}{l}\text { Xenopus laevis } \\
\text { Xenopus (Silurana) tropicalis }\end{array}$ & $\begin{array}{l}\text { H-Gly-Asn-Leu-Ser-Glu-Cys-Phe-Trp-Lys-Tyr-Cys-Val-OH } \\
\text { H-Gly-Asn-Leu-Ser-Glu-Cys-Phe-Trp-Lys-Tyr-Cys-Val-OH }\end{array}$ & $\begin{array}{l}\text { C } \\
\mathrm{D}\end{array}$ & $\begin{array}{l}\text { Konno et al., } 2013 \\
\text { XP_002933899 }\end{array}$ \\
\hline European frog & Pelophylax ridibundus & H-Ala-Gly-Asn-Leu-Ser-Glu-Cys-Phe-Trp-Lys-Tyr-Cys-Val-OH & $\mathrm{P}$ & Conlon et al., 1992a \\
\hline Alligator & Alligator mississippiensis & H-Gly-Asn-Pro-Ser-Glu-Cys-Phe-Trp-Lys-Tyr-Cys-Val-OH & $\mathrm{D}$ & XP_006267924 \\
\hline & Alligator sinensis & H-Gly-Asn-Pro-Ser-Glu-Cys-Phe-Trp-Lys-Tyr-Cys-Val-OH & D & $\mathrm{XP}_{-}^{-} 006031433$ \\
\hline Turtle & Chelonia mydas & H-Gly-Asn-Leu-Ser-Glu-Cys-Phe-Trp-Lys-Tyr-Cys-Val-OH & $\mathrm{D}$ & EMP35266 \\
\hline & Pelodiscus sinensis & H-Gly-Asn-Leu-Ser-Glu-Cys-Phe-Trp-Lys-Tyr-Cys-Val-OH & $\mathrm{D}$ & XP_006118029 \\
\hline Budgerigar & Melopsittacus undulatus & H-Gly-Asn-Leu-Ser-Glu-Cys-Phe-Trp-Lys-Tyr-Cys-Val-OH & D & XP_005143668 \\
\hline Chicken & Gallus gallus & H-Gly-Asn-Leu-Ser-Glu-Cys-Phe-Trp-Lys-Tyr-Cys-Val-OH & $\mathrm{C}$ & Tostivint et al., 2006 \\
\hline Flycatcher & Ficedula albicollis & H-GlY-Asn-Leu-Ser-Glu-Cys-Phe-Trp-Lys-TYr-Cys-Val-OH & $\mathrm{D}$ & XP_005057716 \\
\hline Ground-finch & Geospiza fortis & H-Gly-Asn-Leu-Ser-Glu-Cys-Phe-Trp-LYs-Tyr-Cys-Val-OH & $\mathrm{D}$ & XP_005427513 \\
\hline Ground-tit & Pseudopodoces humilis & H-GlY-Asn-Leu-Ser-Glu-Cys-Phe-Trp-Lys-Tyr-Cys-Val-OH & $\mathrm{D}$ & XP_005528378 \\
\hline Mallard & Anas platyrhynchos & H-Gly-Asn-Leu-Ser-Glu-Cys-Phe-Trp-Lys-Tyr-Cys-Val-OH & $\mathrm{D}$ & EOÁ97941 \\
\hline Rock pigeon & Columba livia & H-GlY-Asn-Leu-Ser-Glu-Cys-Phe-Trp-Lys-TYr-Cys-Val-OH & D & Shapiro et al., 2013 \\
\hline Saker falcon & Falco cherrug & H-Gly-Asn-Leu-Ser-Glu-Cys-Phe-Trp-Lys-Tyr-Cys-Val-OH & $\mathrm{D}$ & XP_005437787 \\
\hline Sparrow & Zonotrichia albicollis & H-Gly-Asn-Leu-Ser-Glu-Cys-Phe-Trp-Lys-Tyr-Cys-Val-OH & D & XP_-005493007 \\
\hline Turkey & Meleagris gallopavo & H-GlY-Asn-Leu-Ser-Glu-Cys-Phe-Trp-Lys-Tyr-Cys-Val-OH & $\mathrm{D}$ & XP_003212227 \\
\hline Zebra finch & Taeniopygia guttata & H-Gly-Asn-Leu-Ser-Glu-Cys-Phe-Trp-Lys-Tyr-Cys-Val-OH & $\mathrm{D}$ & XP_002195510 \\
\hline Platypus & O. anatinus & <Gln-Ser-Lys-Lys-His-Val-Pro-Ser-Ser-Asn-Cys-Phe-Trp-Lys-Tyr-Cys-Val-OH & $\mathrm{D}$ & ENSOANP000000026867 \\
\hline Alpaga & Vicugna pacos & H-Gly-Pro-Pro-Ser-Glu-Cys-Phe-Trp-Lys-Tyr-Cys-Val-OH & D & XP_006196676 \\
\hline
\end{tabular}

Fig. 1. Alignment of UII and URP sequences. The conserved cyclic hexapeptide is indicated in bold characters. 


\begin{tabular}{|c|c|c|c|c|}
\hline Antelope & Pantholops hodgsonii & H-Gly-Pro-Ser-Ser-Glu-Cys-Phe-Trp-Lys-Tyr-Cys-Val-OH & D & XP_005956450 \\
\hline Baboon & Papio anubis & H-Glu-Thr-Pro-Asp-Cys-Phe-Trp-Lys-Tyr-Cys-Val-OH & D & $X P-003891103$ \\
\hline \multirow[t]{2}{*}{ Chimpanzee } & Pan paniscus & H-Glu-Thr-Pro-Asp-Cys-Phe-Trp-Lys-Tyr-Cys-Val-OH & $\mathrm{D}$ & $X P-003822185$ \\
\hline & Pan troglodytes & H-Glu-Thr-Pro-Asp-Cys-Phe-Trp-Lys-Tyr-Cys-Val-OH & $\mathrm{D}$ & XP_001157612 \\
\hline Camel & Camelus ferus & H-Gly-Pro-Pro-Ser-Glu-Cys-Phe-Trp-Lys-Tyr-Cys-Val-OH & $\mathrm{D}$ & XP_006194843 \\
\hline Cat & Felis catus & H-Gly-Ser-Pro-Ser-Glu-Cys-Phe-Trp-Lys-Tyr-Cys-Val-OH & $\mathrm{D}$ & $\mathrm{XP}-003989612$ \\
\hline Cattle & Bos taurus & H-Gly-Pro-Ser-Ser-Glu-Cys-Phe-Trp-Lys-Tyr-Cys-Val-OH & $\mathrm{D}$ & XP_582447 \\
\hline Dog & Canis lupus familiaris & H-His-Gly-Pro-Ser-Ser-Glu-Cys-Phe-Trp-Lys-Tyr-Cys-Val-OH & $\mathrm{D}$ & XP_005620655 \\
\hline Dolphin & Tursiops truncatus & H-Gly-Thr-Pro-Ser-Glu-Cys-Phe-Trp-Lys-Tyr-Cys-Val-OH & $\mathrm{D}$ & XP_004328272 \\
\hline Ferret & Mustela putorius & H-Gly-Ser-Pro-Ser-Glu-Cys-Phe-Trp-Lys-Tyr-Cys-Val-OH & $\mathrm{D}$ & $\mathrm{XP}-004768825$ \\
\hline Galago & Otolemur garnettii & H-Gly-Thr-Pro-Ser-Glu-Cys-Phe-Trp-Lys-Tyr-Cys-Val-OH & $\mathrm{D}$ & $\mathrm{XP}-003793290$ \\
\hline Gibbon & Nomascus leucogenys & H-Glu-Thr-Pro-Asp-Cys-Phe-Trp-Lys-Tyr-Cys-Val-OH & $\mathrm{D}$ & XP_003274324 \\
\hline Goat & Capra hircus & H-Gly-Pro-Ser-Ser-Glu-Cys-Phe-Trp-Lys-Tyr-Cys-Val-OH & $\mathrm{D}$ & $\mathrm{XP}-005690796$ \\
\hline Gorilla & Gorilla gorilla gorilla & H-Glu-Thr-Pro-Asp-Cys-Phe-Trp-Lys-Tyr-Cys-Val-OH & $\mathrm{D}$ & $\mathrm{XP}-004024635$ \\
\hline Hamster & Cricetulus griseus & $<$ Gln-His-Lys-Gln-His-Gly-Ala-Val-Ser-Glu-Cys-Phe-Trp-Lys-Tyr-Cys-Ile-OH & $\mathrm{D}$ & $\mathrm{XP}-003515833$ \\
\hline Horse & Equus caballus & H-Gly-Pro-Pro-Pro-Glu-Cys-Phe-Trp-Lys-Tyr-Cys-Val-OH & $\mathrm{D}$ & $\mathrm{XP}-005607680$ \\
\hline Human & Homo sapiens & H-Glu-Thr-Pro-Asp-Cys-Phe-Trp-Lys-Tyr-Cys-Val-OH & $\mathrm{C}$ & Coulouarn et al., 1998 \\
\hline Jerboa & Jaculus jaculus & $<$ Gln-His-Lys-Gln-Gln-Gly-Thr-Ala-Ser-Asp-Cys-Phe-Trp-Lys-Tyr-Cys-Ile-OH & $\mathrm{D}$ & XP 004657735 \\
\hline Killer whale & Orcinus orca & H-GlY-Thr-Pro-Ser-Glu-Cys-Phe-Trp-Lys-Tyr-Cys-Val-OH & $\mathrm{D}$ & XP_004272397 \\
\hline Macaque & Macaca fascicularis & H-Glu-Thr-Pro-Asp-Cys-Phe-Trp-Lys-Tyr-Cys-Val-OH & $\mathrm{D}$ & XP_005544950 \\
\hline Manatee & T. manatus latirostris & $<$ Gln-Tyr-Lys-Gln-His-Glu-Thr-Pro-Ala-Glu-Cys-Phe-Trp-Lys-Tyr-Cys-Val-OH & $\mathrm{D}$ & XP_004385186 \\
\hline Marmoset & $\begin{array}{l}\text { Callithrix jacchus } \\
\text { ans }\end{array}$ & H-Glu-Thr-Pro-Asp-Cys-Phe-Trp-Lys-Tyr-Cys-Val-OH & $\mathrm{D}$ & XP-002750284 \\
\hline Mouse & Mus musculus & $<$ Gln-His-Lys-Gln-His-Gly-Ala-Ala-Pro-Glu-Cys-Phe-Trp-Lys-Tyr-Cys-Ile-OH & $\mathrm{c}$ & Coulouarn et al., 1999 \\
\hline Orang-utan & Pongo abelii & H-Glu-Thr-Pro-Asp-Cys-Phe-Trp-Lys-Tyr-Cys-Val-OH & $\mathrm{D}$ & XP_002811599 \\
\hline Porcine A & Sus scrofa & H-Gly-Pro-Thr-Ser-Glu-Cys-Phe-Trp-Lys-Tyr-Cys-Val-OH & $\mathrm{P}$ & Mori et al., 1999 \\
\hline Porcine B & Sus scrofa & H-Gly-Pro-Pro-Ser-Glu-Cys-Phe-Trp-Lys-Tyr-Cys-Val-OH & $\mathrm{P}$ & Mori et al., 1999 \\
\hline Rat & Rattus norvegicus & $<$ Gln-His-Gly-Thr-Ala-Pro-Glu-Cys-Phe-Trp-Lys-Tyr-Cys-Ile-OH & $\mathrm{c}$ & Coulouarn et al., 1999 \\
\hline Rhesus monkey & Macaca mulatta & H-Glu-Thr-Pro-Asp-Cys-Phe-Trp-Lys-Tyr-Cys-Val-OH & $\mathrm{c}$ & Elshourbagy et al., 2002 \\
\hline Rhinoceros & Ceratotherium simum simum & H-Gly-Ser-Pro-Pro-Glu-Cys-Phe-Trp-Lys-Tyr-Cys-Val-OH & $\mathrm{D}$ & XP_004425595 \\
\hline Sheep & Ovis aries & H-Gly-Pro-Ser-Ser-Glu-Cys-Phe-Trp-Lys-Tyr-Cys-Val-OH & $\mathrm{D}$ & $\mathrm{XP}-004013800$ \\
\hline Shrew & Tupaia chinensis & H-Val-Thr-Pro-Glu-Cys-Phe-Trp-Lys-Tyr-Cys-Val-OH & D & XP_006145447 \\
\hline Squirrel monkey & Saimiri boliviensis boliviensis & H-Glu-Thr-Pro-Asp-Cys-Phe-Trp-Lys-Tyr-Cys-Val-OH & $\mathrm{D}$ & XP_003939655 \\
\hline & Bos mutus & H-Gly-Pro-Ser-Ser-Glu-Cys-Phe-Trp-Lys-Tyr-Cys-Val-OH & $\mathrm{D}$ & $\mathrm{XP}-005892753$ \\
\hline Zebra mbuna & Maylandia zebra & H-Gly-Gly-Asn-Ser-Glu-Cys-Phe-Trp-Lys-Tyr-Cys-Val-OH & D & XP_004546380 \\
\hline \multicolumn{5}{|l|}{ URP } \\
\hline Fugu & Takifugu rubripes & H-Ser-Glu-Pro-Cys-Phe-Trp-Lys-Tyr-Cys-Val-OH & $\mathrm{D}$ & Quan et al., 2012 \\
\hline Medaka & Oryzias latipes & H-Gly-Glu-Pro-Cys-Phe-Trp-Lys-Tyr-Cys-Val-OH & $\mathrm{c}$ & Quan et al., 2012 \\
\hline Stickleback & Gasterosteus aculeatus & H-Gly-Glu-Pro-Cys-Phe-Trp-Lys-Tyr-Cys-Val-OH & $\mathrm{D}$ & Quan et al., 2012 \\
\hline Tetraodon & Tetraodon nigroviridis & H-Gly-Glu-Pro-Cys-Phe-Trp-Lys-Tyr-Cys-Val-OH & $\mathrm{D}$ & Quan et al., 2012 \\
\hline Tilapia & Oreochromis niloticus & H-Gly-Glu-Pro-Cys-Phe-Trp-Lys-Tyr-Cys-Val-OH & $\mathrm{D}$ & Quan et al., 2012 \\
\hline Zebrafish & Danio rerio & H-Asp-Asp-Thr-Cys-Phe-Trp-Lys-Tyr-Cys-Val-OH & $\mathrm{c}$ & Quan et al., 2012 \\
\hline Clawed frog & Xenopus laevis & H-Ala-Cys-Phe-Trp-Lys-Tyr-Cys-Val-OH & c & Konno et al. 2013 \\
\hline & Xenopus (Silurana) tropicalis & H-Ala-Cys-Phe-Trp-Lys-Tyr-Cys-Val-OH & $\mathrm{C}$ & NP_001120467 \\
\hline Alligator & $\begin{array}{l}\text { Alligator mississippiensis } \\
\text { Alligator sinensis }\end{array}$ & $\begin{array}{l}\text { H-Ala-Cys-Phe-Trp-Lys-Tyr-Cys-Val-OH } \\
\text { H-Ala-Cys-Phe-Trp-Lys-Tyr-Cys-Val-OH }\end{array}$ & $\begin{array}{l}D \\
D\end{array}$ & $\begin{array}{l}\text { XP_006268854 } \\
\text { XP } 006030210\end{array}$ \\
\hline Chicken & Gallus gallus & $\mathrm{H}-\mathrm{Al}$ a-Cys-Phe-Trp-Lys-Tyr-Cys-Ile-OH & c & Tostivint et al 2006 \\
\hline Rock pigeon & Columba livia & $\begin{array}{l}\text { H-Ala-Cys-Phe-Trp-Lys-Tyr-Cys-Ile-OH } \\
\text { Hal - The }\end{array}$ & $\mathrm{D}$ & EMC79212 \\
\hline Turkey & Meleagris gallopavo & H-Ala-Cys-Phe-Trp-Lys-Tyr-Cys-Ile-OH & $\mathrm{D}$ & XP_003209174 \\
\hline Zebra finch & Taeniopygia guttata & H-Ala-Cys-Phe-Trp-Lys-Tyr-Cys-Ile-OH & D & XP_002190569 \\
\hline Alpaga & Vicugna pacos & H-Ala-Cys-Phe-Trp-Lys-Tyr-Cys-Val-OH & D & XP_006201020 \\
\hline Baboon & Papio anubis & H-Ala-Cys-Phe-Trp-Lys-Tyr-Cys-Val-OH & $\mathrm{D}$ & XP_003895325 \\
\hline Camel & Camelus ferus & H-Ala-Cys-Phe-Trp-Lys-Tyr-Cys-Val-OH & $\mathrm{D}$ & XP_006188931 \\
\hline Cat & Felis catus & H-Ala-Cys-Phe-Trp-Lys-Tyr-Cys-Val-OH & $\mathrm{D}$ & ENSFCAP00000010986 \\
\hline Cattle & Bos taurus & H-Ala-Cys-Phe-Trp-Lys-Tyr-Cys-Val-OH & $\mathrm{D}$ & XP 871317 \\
\hline \multirow{2}{*}{ Chimpanzee } & Pan paniscus & H-Ala-Cys-Phe-Trp-Lys-Tyr-Cys-Val-OH & $\mathrm{D}$ & $X P_{-}-003804509$ \\
\hline & Pan troglodytes & H-Ala-Cys-Phe-Trp-Lys-Tyr-Cys-Val-OH & $\mathrm{D}$ & JAĀ39878 \\
\hline Dog & Canis lupus familiaris & H-Ala-Cys-Phe-Trp-Lys-Tyr-Cys-Val-OH & D & XP_850358 \\
\hline Galago & Otolemur garnettii & H-Ala-Cys-Phe-Trp-Lys-Tyr-Cys-Val-OH & D & XP_003792747 \\
\hline Giant panda & Ailuropoda melanoleuca & H-Ala-Cys-Phe-Trp-Lys-Tyr-Cys-Val-OH & $\mathrm{D}$ & XP_002922874 \\
\hline Gorilla & Gorilla gorilla gorilla & H-Ala-Cys-Phe-Trp-Lys-Tyr-Cys-Val-OH & $\mathrm{D}$ & XP_004038262 \\
\hline Guinea pig & Cavia porcellus & H-Ala-Cys-Phe-Trp-Lys-Tyr-Cys-Val-OH & $\mathrm{D}$ & XP_005006976 \\
\hline Hamster & Mesocricetus auratus & H-Ala-Cys-Phe-Trp-Lys-Tyr-Cys-Val-oH & $\mathrm{D}$ & $X P-005071750$ \\
\hline Horse & Equus caballus & H-Ala-Cys-Phe-Trp-Lys-Tyr-Cys-Val-OH & $\mathrm{D}$ & XP_001500234 \\
\hline Human & Homo sapiens & H-Ala-Cys-Phe-Trp-Lys-Tyr-Cys-Val-OH & $\mathrm{C}$ & Sugo et al., 2003 \\
\hline Jerboa & Jaculus jaculus & H-Ala-Cys-Phe-Trp-Lys-Tyr-Cys-Val-OH & $\mathrm{D}$ & XP_004654321 \\
\hline Killer Whale & Orcinus orca & H-Ala-Cys-Phe-Trp-Lys-Tyr-Cys-Val-OH & $\mathrm{D}$ & XP-004278804 \\
\hline Macaque & Macaca fascicularis & H-Ala-Cys-Phe-Trp-Lys-Tyr-Cys-Val-OH & $\mathrm{D}$ & XP_005545453 \\
\hline Mouse & Mus musculus & H-Ala-Cys-Phe-Trp-Lys-Tyr-Cys-Val-oH & $\mathrm{C}$ & Sugo et al., 2003 \\
\hline Orang-utan & Pongo abelii & H-Ala-Cys-Phe-Trp-Lys-Tyr-Cys-Val-OH & $\mathrm{D}$ & XP 002814464 \\
\hline Rat & Rattus norvegicus & H-Ala-Cys-Phe-Trp-Lys-Tyr-Cys-Val-OH & $\mathrm{P}$ & Sugo et al., 2003 \\
\hline Rhesus monkey & Macaca mulatta & H-Ala-Cys-Phe-Trp-Lys-Tyr-Cys-Val-OH & $\mathrm{D}$ & XP 001094399 \\
\hline Rhinoceros & Ceratotherium simum simum & $\mathrm{H}$-Ala-Cys-Phe-Trp-Lys-Tyr-Cys-Val-OH & $\mathrm{D}$ & XP 004424629 \\
\hline Yak & Bos mutus & H-Ala-Cys-Phe-Trp-Lys-Tyr-Cys-Val-OH & $\mathrm{D}$ & XP_005901255 \\
\hline Walrus & Odobenus rosmarus divergens & H-Ala-Cys-Phe-Trp-Lys-Tyr-Cys-Val-OH & $\mathrm{D}$ & XP_-004391905 \\
\hline URP1 & & & & \\
\hline Spotted gar & Lepisosteus oculatus & H-Ala-Cys-Phe-Trp-Lys-Tyr-Cys-Val-Thr-Asn-OH & $\mathrm{D}$ & Tostivint et al., 2013 \\
\hline & Anguilla japonica & H-Ala-Cys-Phe-Trp-Lys-Tyr-Cys-Val-Thr-Asn-OH & c & Nobata et al., 2011 \\
\hline Medaka & Oryzias latipes & H-Ala-Cys-Phe-Trp-Lys-Tyr-Cys-Val-Thr-Asn-OH & $\mathrm{D}$ & XP 004073138 \\
\hline Salmon & Salmo salar & H-Ala-Cys-Phe-Trp-Lys-Tyr-Cys-Val-Thr-Asn-OH & $\mathrm{D}$ & CA063448 \\
\hline Trout & Salvelinus fontinalis & H-Ala-Cys-Phe-Trp-Lys-Tyr-Cys-Val-Thr-Asn-OH & $\mathrm{D}$ & EV393063 \\
\hline Zebrafish & Danio rerio & H-Ala-Cys-Phe-Trp-Lys-Tyr-Cys-Val-Thr-Asn-OH & $\mathrm{D}$ & $\mathrm{EH} 467261$ \\
\hline Coelacanth & Latimeria chalumnae & H-Ala-Cys-Phe-Trp-Lys-Tyr-Cys-Val-Thr-Asn-OH & D & Tostivint et al., 2013 \\
\hline URP2 & & & & \\
\hline Spotted gar & Lepisosteus oculatus & H-Val-Cys-Phe-Trp-Lys-Tyr-Cys-Ser-Gln-Asn-OH & $\mathrm{D}$ & Tostivint et al., 2013 \\
\hline & & & $\mathrm{D}$ & XP_004086076 \\
\hline Tetraodon & Tetraodon nigroviridis & H-Val-Cys-Phe-Trp-Lys-Tyr-Cys-Ser-Gln-Asn-OH & $\mathrm{D}$ & CAG 04941 \\
\hline Zebrafish & Danio rerio & H-Val-Cys-Phe-Trp-Lys-Tyr-Cys-Ser-Gln-Asn-OH & C & Parmentier et al., 2011 \\
\hline UII-like peptide & & & & \\
\hline Aplysia & Aplysia californica & H-Ser-Gly-Gly-Met-Ser-Leu-Cys-Leu-Trp-Lys-Val-Cys-Pro-Ala-Ala-Pro-Trp-Leu-Ile-Se & $\mathrm{C}$ & Romanova et al. 2012 \\
\hline
\end{tabular}

${ }^{1} \mathrm{P}$, purification; C, cDNA cloning; D, genomic data; $<\mathrm{Gln}$, pyroglutamic acid

Fig. 1. Continued.

sequence of the N-terminal region of UII is quite variable, and the predicted length of the peptide ranges from 11 amino acids for human UII to 17 amino acids for mouse UII. In contrast, the primary structure of the cyclic hexapeptide has been totally preserved from fish to mammals. Immunohistochemical studies had long suggested the existence of UII-like peptides in the CNS of the marine mollusc Aplysia californica (González et al., 


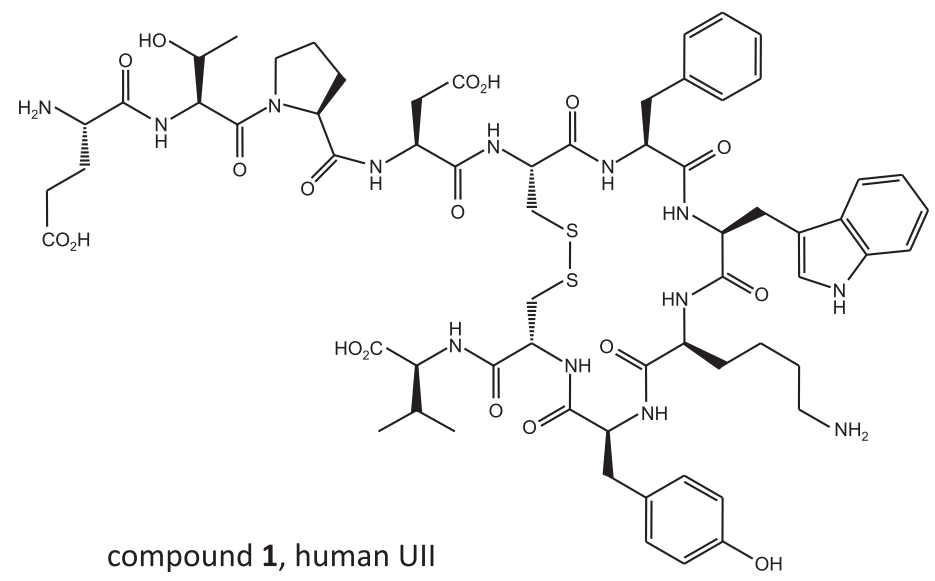

compound 2, rat (mammalian) URP

Fig. 2. Chemical structures of human urotensin II (compound 1) and mammalian URP (compound 2).

1992) and, recently, a peptide exhibiting structural similarity to vertebrate UII has been characterized in this gastropod (Romanova et al., 2012), suggesting that a urotensinergic system may also exist in protostomes (see section II.J.3).

\section{Discovery of Urotensin II-Related Peptide}

By combining high-performance liquid chromatography (HPLC) analysis with radioimmunoassay detection, Sugo et al. (2003) have isolated from a rat brain extract, an 8-amino-acid peptide that they named URP (Fig. 2, compound 2). The primary structure of URP is highly similar to that of the C-terminal octapeptide region of UII. The sequence of URP has now been determined in representative species of teleost fish (Quan et al., 2012), amphibians (Konno et al., 2013), birds (Tostivint et al., 2006), and mammals (Dubessy et al., 2008), and it appears that the structure of the peptide has been strongly preserved during vertebrate evolution (Vaudry et al., 2010). As for UII, the sequence of the cyclic hexapeptide of URP is identical in all species investigated so far (Fig. 1).

\section{Secondary Structure of Urotensin II and Urotensin II-Related Peptide}

Conformational analysis of goby (Bhaskaran et al., 1994) and human (Flohr et al., 2002; Lescot et al., 2007) UII and human URP (Chatenet et al., 2004) in solution has been determined by nuclear magnetic resonance spectroscopy and restrained molecular dynamics. The solution structure of the cyclic UII hexapeptide is welldefined, whereas the flanking linear segments appear to be flexible (Bhaskaran et al., 1994; Flohr et al., 2002; Lescot et al., 2007). However, no canonical turn motifs involving intramolecular hydrogen bonds are observed in the cyclic part of goby and human UII at $300 \mathrm{~K}$ (Bhaskaran et al., 1994; Flohr et al., 2002). At a lower temperature $(280 \mathrm{~K})$, the hydrogen/deuterium exchange time of the amide protons of residues $\mathrm{Tyr}^{9}$ and $\mathrm{Cys}^{10}$ is longer than that of the other amide protons, suggesting the presence of a local stabilized structure (Lescot et al., 2007). The optimal proximity between the $\mathrm{NH}$ of $\mathrm{Tyr}^{9}$ and the carbonyl group of $\operatorname{Trp}^{7}$ and between the amide proton of $\mathrm{Cys}^{10}$ and the $\mathrm{C}=\mathrm{O}$ moiety of $\mathrm{Lys}^{8}$ in combination with the $(\varphi, \psi)$ dihedral angle values indicates the occurrence of a distended inverse $\gamma$-turn centered on Lys $^{8}$ together with a standard inverse $\gamma$-turn centered on $\mathrm{Tyr}^{9}$ (Lescot et al., 2007). In sodium dodecylsulfate micelles used as a membrane mimetic environment, human UII exhibits two distinct conformations that exchange slowly at $300 \mathrm{~K}$, i.e., a major population that encompasses an unprecedented type $\mathrm{II}^{\prime} \beta$-hairpin motif due to the presence of a $\beta$-turn from $\mathrm{Phe}^{6}$ to $\mathrm{Tyr}^{9}$ and a minor population of random structures (Carotenuto et al., 2004a). Identification of the structural characteristics of UII in water at $280 \mathrm{~K}$ or in a membrane-like environment has served as conformational templates to generate three-dimensional three-point pharmacophores (Flohr et al., 2002; Carotenuto et al., 2004a; Lescot et al., 2007) for virtual screening of small-molecule libraries or ligand-based drug design (see section IV.A) .

Nuclear Overhauser effect observed between the amide proton of $\mathrm{Tyr}^{6}$ and the $\mathrm{H} \beta$ of $\operatorname{Trp}^{4}$ and the $(\varphi, \psi)$ dihedral angle values reveal that, in water, the structure of URP at $280 \mathrm{~K}$ consists of an inverse $\gamma$-turn that extends from $\operatorname{Trp}^{4}$ to $\mathrm{Tyr}^{6}$ (Chatenet et al., 2004). In very much the same way as for human UII (Lescot et al., 2007), all the side-chains adopt a preferential orientation, and URP presents a hydrophobic surface formed by the $\mathrm{Phe}^{3}$, Trp ${ }^{4}, \mathrm{Tyr}^{6}$, and $\mathrm{Val}^{8}$ residues (Chatenet et al., 2004). The main difference between the solution structures of human UII and URP lies in the important variation in the position of the lysine side-chain (Lescot et al., 2007).

\section{E. Structure of the Urotensin II and Urotensin II-Related Peptide Precursors and \\ Post-Translational Processing}

The cDNAs encoding the UII and URP precursors have been characterized in a number of vertebrate 
species from fish to mammals (Ohsako et al., 1986; Coulouarn et al., 1998; Vaudry et al., 2010) (Fig. 1). In all species, UII and URP precursors exhibit a similar organization with a predicted 19- to 28-amino-acid signal peptide (Petersen et al., 2011) and a 78 to 127 amino acid N-terminal flanking peptide, the UII or URP bioactive sequence being located at the $\mathrm{C}$-terminal extremity of the precursor (Fig. 3). However, comparison of the cDNA sequences of, e.g., human (Coulouarn et al., 1998), porcine (Mori et al., 1999), mouse (Coulouarn et al., 1999; Elshourbagy et al., 2002), and carp prepro-UII (Ohsako et al., 1986) reveals that the dibasic motifs that constitute potential cleavage sites by prohormone convertases (Artenstein and Opal, 2011; Seidah et al., 2013) have been poorly conserved. For instance, in human, the existence of a $\mathrm{Lys}^{91} \mathrm{Lys}^{92}-\mathrm{Arg}^{93}$ tribasic motif (Coulouarn et al., 1998) suggests that the UII precursor can produce an 11-residue form of UII. In the mouse precursor, this cleavage site does not exist and processing is thought to occur at the $\mathrm{Arg}^{105}$-Lys ${ }^{106}$ dibasic site (Coulouarn et al., 1999), thus generating a 17-residue mature form of UII (Fig. 1). In the case of the URP precursor, a Lys-Arg canonical cleavage motif has been strongly preserved from fish to mammals (Coulouarn et al., 1998; Lu et al., 2006) so that the conserved cyclic hexapeptide is flanked at its $\mathrm{N}$-terminal position by a single residue (Figs. 1 and 2).

Porcine kidney tissue exhibits urotensin II-converting enzyme activity as shown by a mass spectrometryassisted enzyme-screening system (Schlüter et al., 2003). Incubation of a 25-amino-acid C-terminal fragment of human pro-UII (CTF-prohUII) with recombinant furin gives rise to a mature 11-amino acid form of UII (Russell et al., 2004). Permeabilized epicardial mesothelial cells can also process CTF-prohUII to generate human UII, and conversion of CTF-prohUII to human UII is reduced in conditions known to inhibit furin activity (Russell et al., 2004). These observations provide evidence for the existence of intracellular furin-like urotensin II-converting enzyme activity in human epicardial mesothelial cells.

The amino acid sequence of UII has been determined in dogfish (Conlon et al., 1992a), flounder (Conlon et al., 1990), frog (Conlon et al., 1992b), and pig (Mori et al., 1999) confirming that the peptide is generated through cleavage at the $\mathrm{Arg}^{115}-\mathrm{Lys}^{116}-\mathrm{Arg}^{117}$ site of the flounder precursor (Lu et al., 2006), at the $\mathrm{Lys}^{112}-\mathrm{Lys}^{113}-\mathrm{Arg}^{114}$

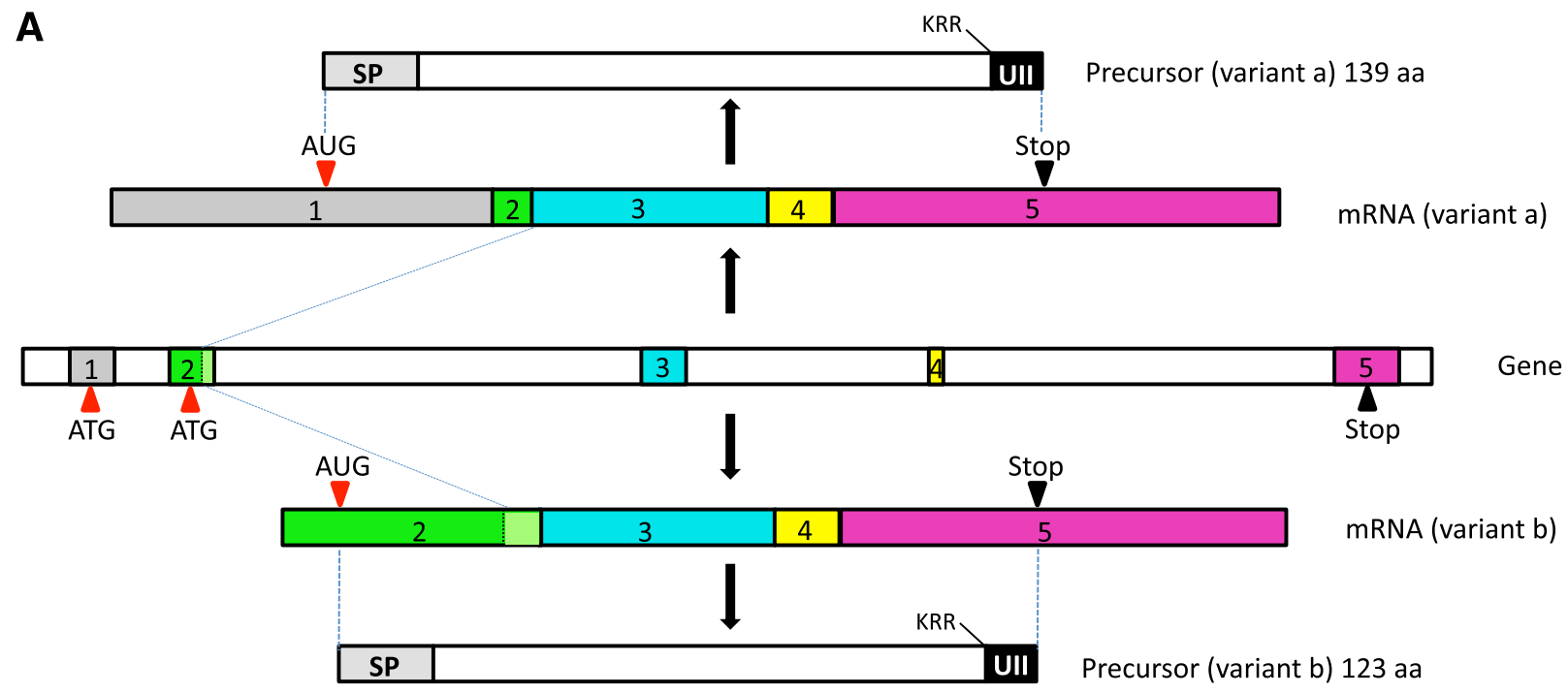

B

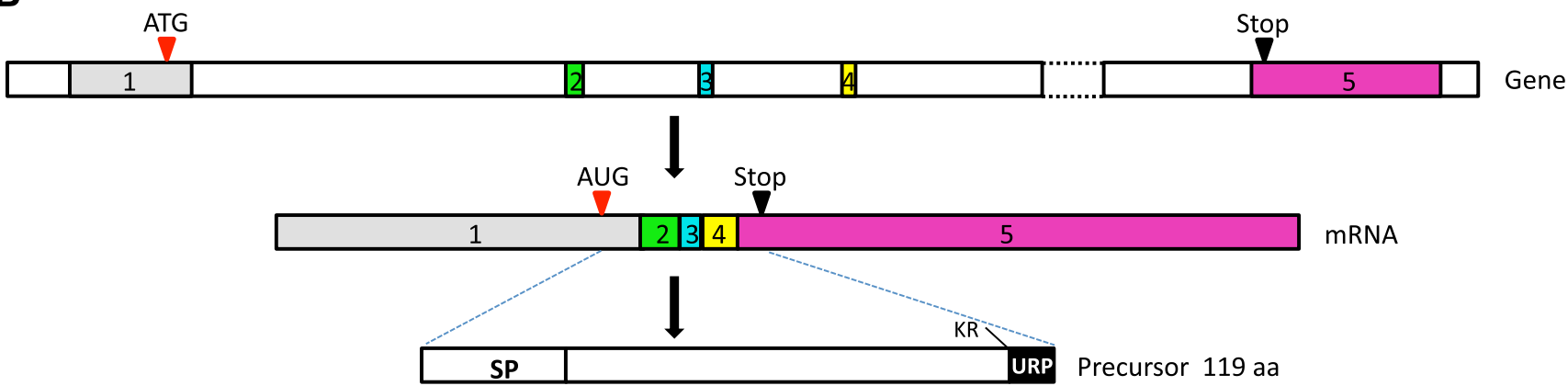

Fig. 3. Structure of the human prepro-UII and prepro-URP genes. (A) The prepro-UII gene comprises five exons and encodes two precursor isoforms (variants $\mathrm{a}$ and $\mathrm{b}$ ) that only differ at their N-terminal extremity, the UII sequence being located at the C-terminal extremity. Each isoform generates the same mature UII peptide through proteolytic cleavage at a tribasic site (KKR). (B) The prepro-URP gene comprises five exons. The URP sequence is located at the C-terminal extremity of the URP precursor and the mature peptide is generated by proteolytic cleavage at a dibasic site (KR). SP, signal peptide; ATG/AUG, initiation codon; Stop, termination codon. (Adapted from Lihrmann et al., 2013.) 
site of the frog precursor (Coulouarn et al., 1998), and at the Lys $^{107}$-Lys $^{108}$-Arg ${ }^{109}$ site of the porcine precursor (Mori et al., 1999). HPLC analysis of human brainstem and spinal cord extracts has revealed that the major UII-immunoreactive peptide coelutes with synthetic 11-residue human UII (Chartrel et al., 2004), whereas in mouse brain extracts it coelutes with synthetic 17-residue mouse UII (Dubessy et al., 2008). These findings strongly suggest that endoproteolytic processing occurs at the $\mathrm{Lys}^{91}$-Lys ${ }^{92}-\mathrm{Arg}^{93}$ site of the human UII precursor and at the $\mathrm{Arg}^{105}$-Lys $^{106}$ site of the mouse UII precursor.

To date, the amino acid sequence of the URP peptide has only been determined in rat (Sugo et al., 2003). In that case, cleavage of the precursor occurs at a Lys ${ }^{109}$ $\mathrm{Arg}^{110}$ site (Sugo et al., 2003). The strong conservation of this dibasic site across vertebrate species supports the notion that all URP precursors undergo similar endoproteolytic cleavage.

\section{F. The Urotensin II and Urotensin II-Related Peptide Genes}

In human, the gene encoding the UII precursor, also named uts2, is composed of five exons. Two distinct precursor isoforms with 139 (isoform a) and 124 (isoform b) amino acids have been characterized that likely result from alternative initiation at two distinct AUG codons (Coulouarn et al., 1998; Ames et al., 1999; Lihrmann et al., 2013). These two isoforms only differ in their $\mathrm{N}$-terminal extremity and thus give rise to the same mature UII peptide, the coding sequence of UII being located in the last exon. In all other vertebrate species studied so far (mouse, rat, pig, monkey, chicken, and zebrafish), only isoform $b$ has been identified. In the zebrafish Danio rerio, two UII genes, UII $\alpha$ and UII $\beta$, that exhibit the same organization, have been identified (Tostivint et al., 2006). The uts2d gene encoding the prepro-URP comprises five exons in all vertebrate species examined. In tetrapods, the coding sequence of URP is located in the fifth exon (Lihrmann et al., 2013), whereas, in teleosts, it is split between exons 4 and 5 (Quan et al., 2012). As mentioned above (see section II.J), two additional paralogous genes of the UII family have been characterized in actinopterygians and sarcopterygians and have been called URP1 and URP2 (Nobata et al., 2011; Tostivint et al., 2013, 2014). In zebrafish, both URP1 and URP2 genes contain five exons and, for each gene, the coding sequence of the mature peptide is located on the last exon (Parmentier et al., 2011).

\section{G. Distribution of Urotensin II and Urotensin II-Related Peptide in the Central Nervous System}

UII was initially isolated and characterized from the urophysis of teleost fish (Pearson et al., 1980). The axon terminals releasing UII into the urophysis originate from Dahlgren cells, i.e., large cholinergic neurons that are located in the caudal region of the ventral horn of the spinal cord of teleosts (Enami, 1959). Immunohistochemical labeling has confirmed that UII is primarily located in neurosecretory cells of the ventral spinal cord (Owada et al., 1985; Oka et al., 1989; Parmentier et al., 2006). However, subsequent studies have shown that UII is also present in the fish brain (Waugh and Conlon, 1993), and the expression of UII mRNA in fish brain has been confirmed by reverse-transcription polymerase chain reaction (RT-PCR; Lu et al., 2006; Sun et al., 2014). In various species of freshwater and seawater fish, UII is found in cerebrospinal fluid (CSF)-contacting neurons located within the ventral ependyma bordering the central canal along the entire length of the spinal cord and medulla (Yulis and Lederis 1986, 1988). These UII-containing neurons project their axons toward the external surface of the spinal cord, and ascending fibers innervate various regions of the brain (Yulis and Lederis, 1986, 1988). Although nonteleost fish do not possess an authentic urophysis, they do exhibit a neurohemal area apposed to the ventral spinal cord that extends along several spinal cord segments (Fridberg and Bern, 1968). UII-immunoreactive cell bodies actually occur in the caudal spinal cord of representative species of nonteleost fish, including chondrichthyes (cartilaginous fish) and dipnoans (lungfish) but not agnatha (jawless fish) (Onstott and Elde, 1986).

In the CNS of tetrapods, UII is primarily expressed in motoneurons of the brainstem and spinal cord. Specifically, in the European green frog, UII immunoreactivity is found in neurons of the hypoglossal nucleus of the medulla oblongata, which controls tongue muscles, and in a subpopulation of motoneurons of the spinal cord, particularly abundant in the caudal region (Chartrel et al., 1996). In the brain of rodents, UII is primarily expressed in brainstem nuclei including the dorsal motor nucleus of the vagus, the hypoglossal nucleus, the trigeminal motor nucleus, the facial motor nucleus, the abducens nucleus, and the trigeminal motor nucleus (Coulouarn et al., 1999; Dun et al., 2001; Dubessy et al., 2008). Although the expression pattern of URP largely overlaps with that of UII, differential levels of expression occur in most brainstem nuclei. For instance, the expression of URP is substantially higher than that of UII in the abducens nucleus, the dorsal motor nucleus of the vagus, the Edinger-Westphal nucleus, the locus coerulus, the lateral superior olive, the raphe obscursus nucleus, the reticular nucleus, and the paragigantocellular nucleus (Dubessy et al., 2008). Reciprocally, the UII gene, but not the URP gene, is expressed in the medial vestibular nucleus (Dubessy et al., 2008). In mouse and rat, UII is expressed in a subset of spinal motoneurons, the density of UII-positive neurons being higher in the lumbar and sacral regions than in the cervical segment (Coulouarn et al., 1998, 1999; Ames et al., 1999; Dun et al., 2001; Pelletier et al., 2002, 2005; Egginger et al., 2006; Dubessy et al., 2008). A majority of mouse spinal motoneurons simultaneously express UII 
and URP mRNAs as well as androgen receptor mRNA (Pelletier et al., 2005). Similarly, a vast majority of rat motoneurons that express UII mRNA are also androgen receptor immunopositive (Pelletier et al., 2002). Consistent with these observations, in mouse and rat, androgens downregulate UII and/or URP gene expression most likely through a direct action at the level of motoneurons (Pelletier et al., 2002, 2005). Developmental studies show that UII mRNA is expressed in the rat spinal cord as early as embryonic day 10, i.e., during terminal mitosis of motoneurons (Phelps et al., 1988; Chen and Chiu, 1992), suggesting that UII could play a role in motoneuron differentiation, survival, and/or programmed cell death (Coulouarn et al., 2001). In human, UII-immunoreactive material is present in both the brainstem and spinal cord (Chartrel et al., 2004). In the human spinal cord, UII is contained in a subpopulation of ventral horn motoneurons (Chartrel et al., 2004).

\section{H. Distribution of Urotensin II and Urotensin II-Related Peptide in Peripheral Organs}

In mammals, early studies have shown that the UII gene is widely expressed outside the CNS, notably in the cardiovascular, renal, and endocrine systems (Coulouarn et al., 1998; Ames et al., 1999; Matsushita et al., 2001; Douglas et al., 2002; Dschietzig et al., 2002; Elshourbagy et al., 2002). It was subsequently found that URP mRNA is also present in various organs and that, in peripheral tissues as in the CNS, the UII and URP genes are differentially expressed (Sugo et al., 2003; Dubessy et al., 2008). For instance, in mouse, whereas the UII and URP genes are equally expressed in skeletal muscle, UII expression predominates in the vagina, uterus, and testis, and inversely, only URP expression occurs in the thymus, heart, colon, and seminal vesicles (Dubessy et al., 2008). Measurement of the arteriovenous gradient of UII/URP concentration in sheep indicates that the heart, liver, and kidney release UII and/or URP in the circulation (Charles et al., 2005).

In the cardiovascular system, UII mRNA is expressed in vascular smooth muscle cells (Douglas et al., 2002), endothelial cells (Totsune et al., 2003; McDonald et al., 2007), and cardiac fibroblasts (Tzanidis et al., 2003). In the human heart, UII mRNA is found in the right atrium and ventricular septum (Matsushita et al., 2001). UII and URP levels are upregulated in various cardiovascular diseases, including systemic and pulmonary hypertension, atherosclerosis, and congestive heart failure. In particular, UII and URP mRNA expression is higher in the atrium of spontaneously hypertensive rats (SHR) compared with age-matched Wistar-Kyoto rats (WKY) (Hirose et al., 2009). In human, plasma UII/URP is significantly elevated in congestive heart failure (Ng et al., 2002; Richards et al., 2002; Russell et al., 2003; Russell, 2008). Although in patients with acute heart failure both plasma UII and URP levels are elevated, URP concentrations are 10-fold higher than those of UII (Jani et al., 2013). To date, little is known regarding the regulatory mechanisms underlying overexpression of UII and/or URP in cardiovascular disease.

The renal system is another important site of UII production. UII and URP mRNAs are present in the human kidney (Coulouarn et al., 1998; Nothacker et al., 1999; Matsushita et al., 2001; Totsune et al., 2001, 2003; Sugo et al., 2003) but are virtually absent in the kidney of monkey (Elshourbagy et al., 2002), rat (Sugo et al., 2003), and mouse (Elshourbagy et al., 2002; Dubessy et al., 2008). The UII peptide is localized in epithelial cells of kidney tubules and collecting ducts notably in the distal convoluted tubules (Shenouda et al., 2002; Langham et al., 2004; Maguire et al., 2004; Balat et al., 2007). UII immunoreactivity is also present in renal capillary endothelial cells (Shenouda et al., 2002). The occurrence of substantial urinary UII concentrations in healthy individuals whose plasma UII levels are undetectable (Matsushita et al., 2001) indicates that UII is released by the human kidney. Consistent with this notion, in sheep, plasma UII concentrations are higher in the renal vein than in the renal artery (Charles et al., 2005), thus identifying the kidney as a source of circulating UII. In SHR, URP but not UII mRNA is elevated in kidney compared with WKY rats (Hirose et al., 2009; Forty and Ashton, 2013), suggesting a potential role for URP in spontaneous hypertension.

The liver is also a documented site of UII and/or URP production in human (Coulouarn et al., 1998; Totsune et al., 2001; Sugo et al., 2003), monkey (Elshourbagy et al., 2002), and sheep (Charles et al., 2005). In cirrhotic patients, UII mRNA expression is increased in liver (Liu et al., 2010a) and plasma UII concentration is elevated, particularly in the hepatic vein compared with the hepatic portal vein (Heller et al., 2002). In patients with chronic liver disease, elevated serum UII is associated with disease severity and the extent of portal hypertension (Kemp et al., 2007).

The UII gene is expressed in various endocrine glands including the pituitary, pancreas, and adrenal in human and rat (Coulouarn et al., 1998; Totsune et al., 2001; Sugo et al., 2003), whereas the URP gene is expressed in the testis, ovary, and placenta in human (Sugo et al., 2003) and testis and seminal vesicle in mouse (Dubessy et al., 2008). In contrast, UII is not expressed in monkey endocrine glands (Elshourbagy et al., 2002). UII and/or URP are also produced in other organs, such as the thymus, lung, spleen, stomach, and intestine (Coulouarn et al., 1998, 1999; Totsune et al., 2001, 2003; Elshourbagy et al., 2002; Sugo et al., 2003; Maguire et al., 2004; Dubessy et al., 2008), but marked species differences occur even between phylogenetically related animals.

In the European flounder, UII mRNA is expressed in the rectum, intestine, and bladder (Lu et al., 2006). The 
UII gene is also expressed in flounder and grouper endocrine glands, including pituitary, head kidney (where the interrenal tissue is located), and ovary (Lu et al., 2006; Sun et al., 2014).

Plasma UII/URP concentrations are in the same range in human $(2.5-24 \mathrm{fmol} / \mathrm{ml}$; Totsune et al., 2004), rat $(2.9 \mathrm{fmol} / \mathrm{ml}$; Prosser et al., 2006), sucker (40 fmol/ml; Kobayashi et al., 1986), goldfish Carassius auratus (16 fmol/ml; Kobayashi et al., 1986), and flounder (5-8 $\mathrm{fmol} / \mathrm{ml}$; Lu et al., 2006).

\section{Urotensin II and Urotensin II-Related Peptide in Tumor Cells}

The initial characterization of human prepro-UII cDNA was performed by analysis of a cDNA library obtained from colon tumors (Coulouarn et al., 1998). Subsequent studies revealed that various human cell lines, such as T98G glioblastoma cells, IMR-32 neuroblastoma cells, BeWo choriocarcinoma cells, SW-13 adrenocortical carcinoma cells, DLD-1 colorectal adenocarcinoma cells, and HeLa cervical cancer cells, express UII mRNA, whereas NB69 neuroblastoma cells do not (Takahashi et al., 2001). In addition, SW-13 adrenocortical carcinoma cells secrete a mature form of UII (Takahashi et al., 2001) that may act as a tumor growth-stimulating factor (Takahashi et al., 2003). UII mRNA is also expressed in adrenal tumors, including adrenocortical adenomas, adrenocortical carcinomas, pheochromocytomas, ganglioneuroblastomas, and neuroblastomas, but UII immunoreactivity is present in only a small proportion of these tumor tissues (Takahashi et al., 2003; Zeng et al., 2006). The occurrence of elevated UII mRNA has been confirmed in human adrenal tumors compared with non-neoplastic adrenal tissue (Morimoto et al., 2008), suggesting the involvement of UII in adrenal tumor growth and steroidogenesis. UII mRNA and UII immunoreactivity are also present in the human lung adenocarcinoma cell line A549 (Wu et al., 2010). Synthetic UII stimulates A549 cell proliferation in vitro and accelerates growth of A549 tumor xenografts in nude mice (Wu et al., 2010). Immunoreactive UII and URP are present in interstitial nodular lesions of lungs from patients with lymphangioleiomyomatosis, a rare disease characterized by abnormal proliferation of smooth muscle-like cells in the pulmonary interstitium (Kristof et al., 2010). UII promotes lung adenocarcinoma growth via a mechanism involving activation of the nuclear factor $\kappa \mathrm{B}$ pathway and a proinflammatory microenvironment (Zhou et al., 2012).

\section{J. Phylogenetic Evolution of Urotensin II}

1. Discovery of Two Novel Urotensin II-Related Peptide-Like Genes in Teleosts. Until recently, the UII family was thought to be composed of only two members, namely UII and URP. As mentioned above (see section II.A), UII was initially discovered in teleosts (Pearson et al., 1980) and subsequently characterized in amphibians (Conlon et al., 1992b) and mammals
(Coulouarn et al., 1998, 1999). Conversely, URP was first identified in mammals (Sugo et al., 2003) and later in birds (Tostivint et al., 2006) and amphibians (Konno et al., 2013). Hence, it was logical to search for the existence of URP in fish. Using degenerated primers designed from the amino acid sequence of mammalian URP, Nobata et al. (2011) successfully amplified a cDNA encoding for a novel URP-like peptide in the Japanese eel. A blast search revealed the occurrence of the same peptide, now called URP1, in several other teleost species including the Brook trout, the Atlantic salmon, and the zebrafish. However, it also appeared that teleosts possess a second URP-like peptide named URP2 (Nobata et al., 2011; Parmentier et al., 2011). Recently, the URP1 and URP2 genes were also identified in the spotted gar, a nonteleost ray finned fish (Tostivint et al., 2013). As shown in Fig. 1, URP1 and URP2 exhibit very similar structures. Like tetrapod URP, fish URP1/2 possess a nonpolar residue (instead of an acidic residue for UII) upstream the cyclic region. In contrast, at their C-terminal extremity, fish URP1 and URP2 exhibit a 3-residue tail, whereas all tetrapod URPs carry a single hydrophobic residue at their $\mathrm{C}$ terminus. It has thus been hypothesized that the URP1 and URP2 genes were two co-orthologs of the tetrapod URP gene, in very much the same manner as the zebrafish and sucker UII $\alpha$ (also called UIIA) and UII $\beta$ (also called UIIB) genes (Nobata et al., 2011), which are the two counterparts of the tetrapod UII gene. However, this view was recently invalidated by synteny analysis (Parmentier et al., 2011). Using this approach, it was found that the URP1 and URP2 genes, although present only in fish, emerged long before the tetrapod/fish split and thus represent two distinct paralogous genes, in addition to the UII and URP genes. As mentioned in section II.C, a true ortholog of the URP gene does also exist in teleosts and was recently characterized (Quan et al., 2012; Tostivint et al., 2014). As in tetrapods, teleost URPs possess a single residue extension at their $\mathrm{C}$ terminus. In contrast, teleost URPs exhibit a 3-residue extension at their $\mathrm{N}$ terminus, whereas most tetrapod URPs carry only one residue at their N-terminal end (Fig. 1).

In zebrafish, URP mRNA is primarily localized in motoneurons of the brainstem and spinal cord (submitted manuscript), as previously reported in tetrapods (Coulouarn et al., 1998, 1999; Dubessy et al., 2008; Konno et al., 2013), indicating that the expression pattern of the URP gene has been strongly conserved during vertebrate evolution. In contrast, the expression patterns of the URP1 and URP2 genes differ markedly from that of the URP gene. Although most URP1- and URP2-expressing cells are found in the spinal cord, these cells are located in close contact with the ventral aspect of the central canal (Parmentier et al., 2011; unpublished data). URP1 and URP2 mRNAs colocalize in the same cells that also express the glutamate decarboxylase gene, identifying them as 
CSF-contacting neurons (Vigh and Vigh-Teichmann, 1998). It is likely that these URP1- and URP2-expressing neurons correspond to the extra-urophysial UII system previously described by Yulis and Lederis $(1986,1988)$.

2. Origin and Evolution of the Urotensin II Gene Family in Vertebrates. The UII gene family thus appears to encompass four distinct paralogous genes, namely the UII, URP, URP1, and URP2 genes. Synteny analysis has revealed that the four chromosomal regions comprising the UII/URP genes are highly conserved across species. Indeed, all these regions contain paralogs from at least 10 other gene families and thus clearly represent a tetraparalogon (Fig. 4). These observations support the view that the UII gene family has been actually shaped through the two whole-duplication rounds $(2 \mathrm{R})$ that occurred during early vertebrate evolution (Van de Peer et al., 2010) (Fig. 5). They also indicate that the original quartet of the UII/URP genes has been fully preserved in teleosts (Parmentier et al., 2011) and suggest that the existence of only two members of the UII/URP gene family in tetrapods can be ascribed to the loss of the URP1 and URP2 genes specifically in this lineage (Parmentier et al., 2011) (Fig. 5). Synteny analysis also shows that the two copies of the UII gene in teleosts, UII $\alpha$ (or UIIA) and UII $\beta$ (or UIIB), probably emerged through the teleost-specific wholegenome duplication (also called 3R) (Fig. 5).

UII has been identified in all vertebrate classes, including agnathans (Waugh et al., 1995). In contrast, UII-like sequences have not been detected in the sea lamprey (Petromyzon marinus; Decatur et al., 2013) and in nonvertebrate chordates, such as tunicates or amphioxus. The existence of a UII-like peptide was recently reported in the marine mollusc Aplysia californica (Romanova et al., 2012), and UII has been found to potentiate $\mathrm{GABA}_{\mathrm{A}}$ receptor-mediated chloride current in Aplysia neurons (Sawada and Ichinose, 1999), suggesting that UII is an ancient peptide that existed before the emergence of vertebrates. However, two observations cast doubt on this hypothesis: 1 ) the sequence of the Aplysia UII-like peptide is not located at the $\mathrm{C}$ terminus of its precursor, as for all other members of the UII/URP family; and 2) although several other protostomian species do possess an orthologous UII-like precursor gene, they are apparently devoid of UT-like gene (personal communication).

3. Evolutionary Relationships between Peptides of the Urotensin II and Somatostatin Families. UII was initially described as a somatostatin-like peptide on the basis of its structural similarities with somatostatin (Pearson et al., 1980). UII and somatostatin actually share several features including a disulfide bridge and a common motif, Phe-Trp-Lys, which is essential for their biologic activity (Fig. 6). Moreover, the general organization of the UII and somatostatin precursors is very similar (Tostivint et al., 2008). From these observations, it was tempting to assume that UII

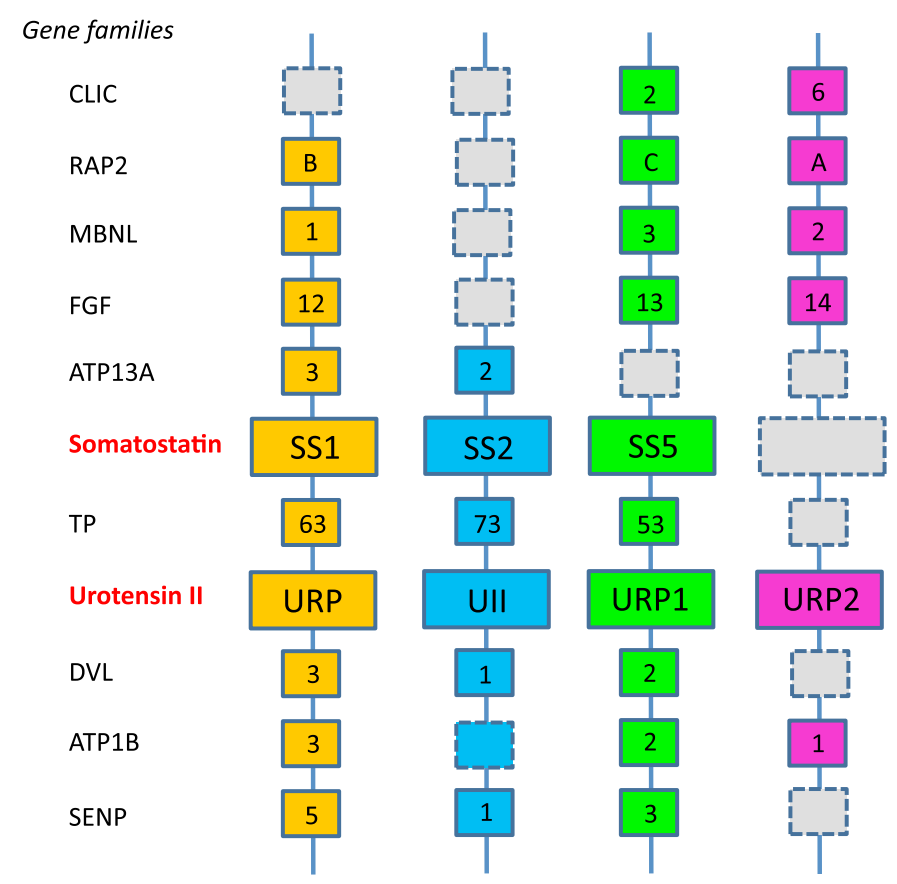

Fig. 4. Schematic representation of the putative ancestral tetraparalogon bearing genes of the UII and somatostatin families. The other families displayed are as follows: ATPB1B, ATPase, $\mathrm{Na}^{+} / \mathrm{K}^{+}$transporting, $\beta$ polypeptide; ATP13A, ATPase type 13A; CLIC, chloride intracellular channel; DVL, dishevelled homolog 1 (Drosophila); FGF, fibroblast growth factor; MBNL, muscleblind-like splicing regulator 2; RAP2, member of RAS oncogene family; SENP, SUMO1/sentrin specific peptidase; TP, tumor protein. The gray dashed boxes represent lost genes. The color code is the same as in Fig. 3. (Adapted from Parmentier et al., 2011.)

and somatostatin originate from a common ancestral gene. However, it has long been considered that UII and somatostatin were not phylogenetically related (Conlon et al., 1997).

The evolutionary history of the somatostatin gene family was recently clarified (Tostivint et al., 2004, 2006, 2008, 2013, 2014; Liu et al., 2010b). It has been established that, in vertebrates, the current family diversified from four ancestral genes that arose through $2 \mathrm{R}$, namely SS1, SS2 (also called cortistatin in mammals), SS5 and a fourth putative gene that was apparently lost early during evolution. Interestingly, synteny analysis shows that the UII and SS2 genes, and the URP and SS1 genes are closely linked on the same chromosome in all species investigated so far (Tostivint et al., 2006), whereas, in teleosts, the URP1 and SS5 genes are located on the same block of doubly conserved synteny (Parmentier et al., 2011) (Fig. 4). These observations indicate that the UII- and somatostatin-related genes belong to the same tetraparalogon and thus evolved in parallel. In addition, these data suggest that the UII and somatostatin ancestral genes probably arose through tandem duplication of a single ancestral gene (Tostivint et al., 2006; Parmentier et al., 2011). It is likely that this duplication occurred long before the emergence of vertebrates. Worthy of note, a somatostatin-related peptide, called allatostatin $\mathrm{C}$, is present in arthropods (Mirabeau and Joly, 2013). 
Molluscs

Aplysia californica
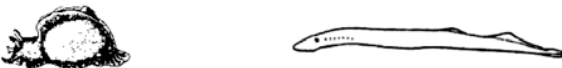

UII-like

UII
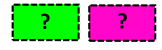
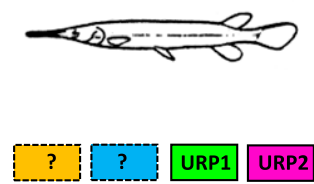

Lepisosteus oculatus

Actinopterygians

Tetrapods

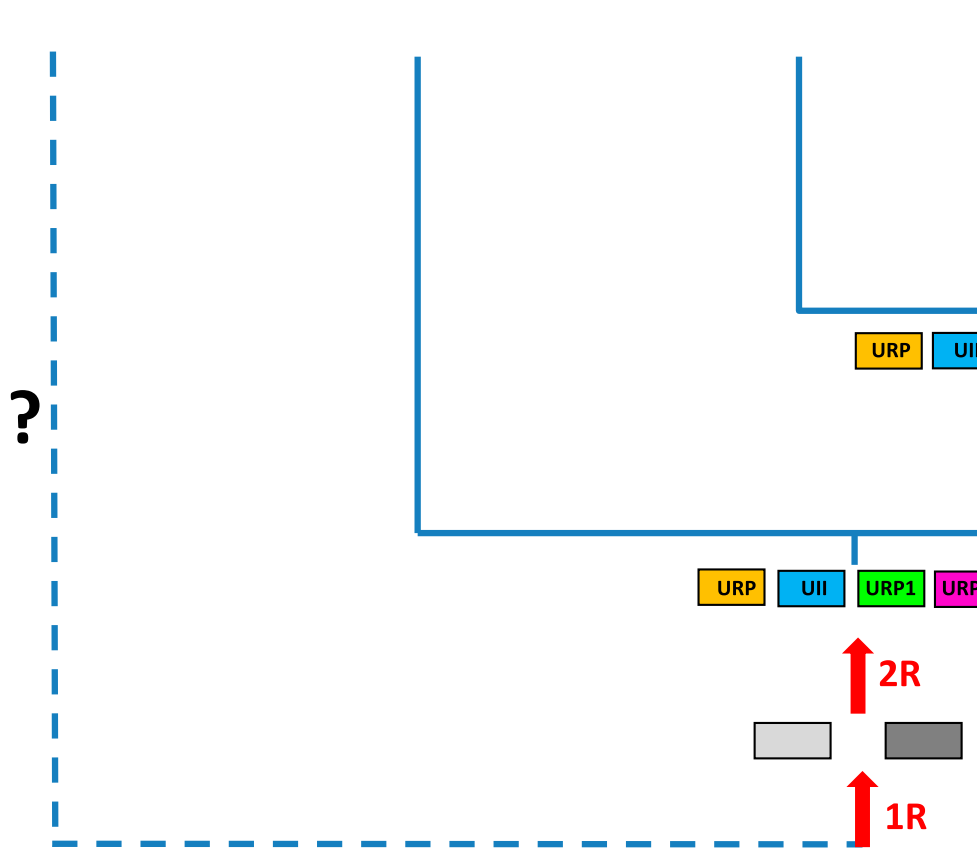

Ancestral UII

Fig. 5. A proposed evolutionary model for the evolution of the UII gene family. The names of the different paralogous genes are given in the boxes. Crossed-out boxes represent lost genes. $\mathrm{R}$, rounds of whole-genome duplication. ? denotes genes that have not been detected, either because of incomplete genome assembly in the relevant species or because these genes have been lost during evolution. (Adapted from Tostivint et al., 2014.)

\section{The Urotensin II Receptor}

A. Cloning and Characterization of Urotensin II Receptor

Although UII/URP and somatostatin/cortistatin share substantial structural similarities, UII and URP are poor agonists of somatostatin receptors (Malagon et al., 2008; Nothacker et al., 1999), indicating that the biologic effects of UII and URP are mediated through distinct receptors. Thus, soon after the identification of human UII, four independent laboratories using a reverse pharmacology

hUII

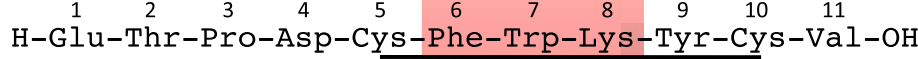

URP

H-Ala-Cys-Phe-Trp-Lys-Tyr-Cys-Val-OH

SST

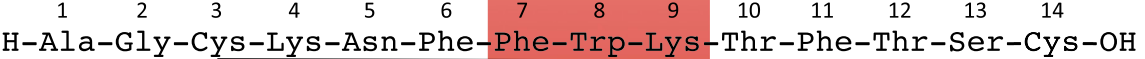

Fig. 6. Amino acid sequences of human urotensin II (hUII), human urotensin II-related peptide and somatostatin (SST). All three peptides exhibit a disulfide bridge and a conserved Phe-Trp-Lys motif (red box). 
strategy reported that the orphan receptor GPR14 previously characterized in rat (Marchese et al., 1995), also called SENR (sensory epithelial neuropeptide-like receptor) previously characterized in bovine (Tal et al., 1995), was indeed the UII receptor (Ames et al., 1999; Liu et al., 1999; Mori et al., 1999; Nothacker et al., 1999). In contrast to most neuropeptides that usually possess several receptor isoforms, GPR14/SENR, now renamed UII receptor (UT) (Alexander et al., 2011), is the only high affinity receptor for UII/URP known so far, at least in mammals (see section III.G). This intronless class A (rhodopsin family) G protein-coupled receptor (GPCR) exhibits the highest degree of identity with the somatostatin receptors $\mathrm{SST}_{2}(26 \%)$ and $\mathrm{SST}_{4}(27 \%)$ and the $\mu, \delta$, and $\kappa$ opioid receptors (25-27\%) (Marchese et al., 1995; Fredriksson and Schiöth, 2005; http://www.iuphardb.org/DATABASE/FamilyMenuForward?familyId=65). Human UT encompasses 389 amino acids and possesses 75\% identity with rat GPR14 (Marchese et al., 1995; Ames et al., 1999). As all class A GPCRs, UT is characterized by a short N-terminal segment, an Asp residue in transmembrane domain 2 (TMD2) that is essential for ligand binding, a D/ERY motif at the junction between TMD3 and the second intracellular loop 2 (ICL2), a $\mathrm{NP}(\mathrm{XX}) \mathrm{Y}$ motif in TMD7 that is required for receptor internalization and 12 potential Ser/Thr phosphorylation sites in the intracellular loop 3 and the cytoplasmic tail (Fig. 7). Conserved $\mathrm{Cys}^{123} / \mathrm{Cys}^{199}$ residues, which likely form a disulfide bridge, are present in the first and second extracellular loops (ECL1 and ECL2), respectively.
Two putative $N$-glycosylation sites are also observed in the N-terminal extracellular domain (Fig. 7). A putative palmitoylation site $\left(\mathrm{Cys}^{339}\right)$ is present in rat UT (Marchese et al., 1995) but absent in human UT (Ames et al., 1999).

Because UT exhibits relatively high sequence identity with opioid receptors (Fredriksson and Schiöth, 2005), a $\delta$-opioid receptor model was used to build the first threedimensional (3D) molecular model of rat UT (Kinney et al., 2002). Thus, goby UII was docked into this homology model by imposing the alignment of the Lys ${ }^{9}$ residue of UII toward the Asp ${ }^{130}$ residue of TMD3 of rat UT. Although all the conformational space available in the binding pocket was not explored, the hypothetical docking position suggests interactions between UT and the key side chains of the $\mathrm{Tyr}^{8}, \mathrm{Lys}^{9}$, and $\mathrm{Tyr}^{10}$ residues of UII (Kinney et al., 2002). Subsequently, a human homology model, based on the X-ray structure of rhodopsin, has been constructed. Because the Lys ${ }^{9}$ residue of UII was also aligned to the $\mathrm{Asp}^{130}$ residue of UT, this latter model yielded very similar information on the putative ligand binding pocket (Lavecchia et al., 2005). Photolabeling experiments combined with site-directed mutagenesis indicate that the $\mathrm{Phe}^{6}$ residue of UII interacts with the Met ${ }^{184}$ and/or Met ${ }^{185}$ residues of TMD4 of UT, confirming the existence of a relatively deep binding pocket (Boucard et al., 2003). Surface plasmon resonance assays show that UII and URP interact with ECL2 and ECL3 but not ECL1, whereas the antagonist urantide only binds ECL2 (Boivin et al., 2006). Docking studies confirm that UT agonists and antagonists

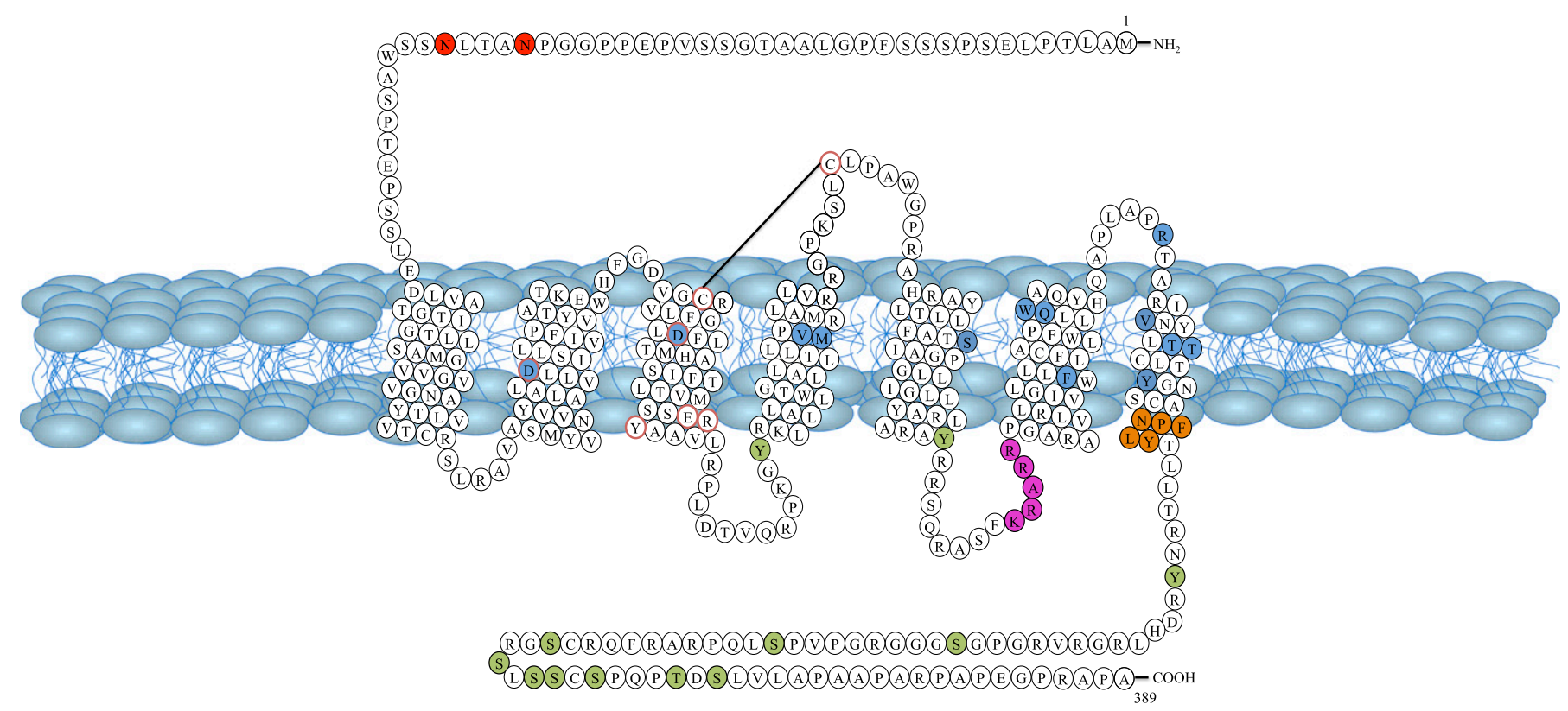

Conserved residues among family A of GPCRs

Internalization motif

Putative nuclear localization signal sequence
N-glycosylation sites

Phosphorylation sites

Residues potentially involved in UT/UII binding

Fig. 7. Amino acid sequence and membrane topology of the human UII receptor. (Adapted from Kim et al., 2010, and Chatenet et al., 2013c.) 
differentially bind a UT model (Grieco et al., 2009). Solution structure of the human $\mathrm{UT}_{(281-300)}$ segment by high-resolution NMR and molecular modeling in the presence of UII also shows the occurrence of physical interactions between UII and ECL3 (Boivin et al., 2008). In dodecylphosphocholine micelles mimicking a membrane environment, the human $\mathrm{UT}_{(281-300)}$ sequence exhibits a type III $\beta$-turn $\left(\mathrm{Gln}^{285}-\mathrm{Leu}^{288}\right)$ followed by an $\alpha$-helical structure $\left(\mathrm{Ala}^{289}-\mathrm{Leu}^{299}\right)$ that includes a stretch of TMD7 (Boivin et al., 2008). The presence of a binding site in rat UII ECL3 is confirmed by photolabeling data (Holleran et al., 2007). However, it is not yet established whether this is a transient surface interaction that precedes a deeper set of interactions into the TMD bundle leading to receptor activation. This contact may participate to the primary recognition process of UT by UII and thus to the selectivity of the ligand, or it may constitute an allosteric site of interaction. By using the substituted-cysteine accessibility method (Javitch et al., 2002), it was recently demonstrated that several TMD3, TMD4, TMD5, TMD6, and TMD7 residues of rat UT participate to the formation of the receptor binding pocket (Holleran et al., 2009; Sainsily et al., 2013). However, there are still numerous unsolved questions regarding the molecular interactions between UT and its natural ligands. Clearly, crystal structure characterization of UT and UT-UII complex is required to elucidate the detailed mechanisms of binding and activation of the receptor.

\section{B. Signaling Mechanisms}

Initial studies conducted in UT-transfected cells and thoracic aorta segments indicate that UT is primarily coupled to phospholipase C (PLC) activation through the pertussis toxin-insensitive $\mathrm{G}$ protein $\mathrm{G} \alpha_{\mathrm{q} / 11}$ (Fig. 8). Upon UII binding to UT, activation of PLC causes hydrolysis of phosphatidylinositol-4-5 bisphosphate (PIP2) to inositol-1-4-5 triphosphate ( $\left.\mathrm{IP}_{3}\right)$ and diacylglycerol (Saetrum Opgaard et al., 2000) (Fig. 9A). The involvement of PLC in UT signaling has been confirmed in cultured rat cortical astrocytes (Castel et al., 2006; Jarry et al., 2010). $\mathrm{IP}_{3}$ binds to the $\mathrm{IP}_{3}$ receptor, a calcium channel on the membrane of the endoplasmic reticulum, resulting in an increase in cytoplasmic calcium levels (Parys and de Smedt, 2012) (Fig. 9B). UII-induced intracellular calcium mobilization has now been documented in a number of cell types, including the porcine renal epithelial cell line LLCPK1 (Matsushita et al., 2003), human aorta endothelial cells (Brailoiu et al., 2008), and rat aorta vascular smooth muscle cells (Rodríguez-Moyano et al., 2013). In endothelium-denuded rat aorta, protein kinase $\mathrm{C}$ mediates the synergistic action of UII and angiotensin II (Wang et al., 2007). In addition, in rat spinal cord cholinergic neurons, UII causes calcium influx from the extracellular space via $\mathrm{N}$-type $\mathrm{Ca}^{2+}$ channels, and this effect is mediated through the protein kinase A pathway (Filipeanu et al., 2002), whereas in arterial smooth muscle cells, UII stimulates $\mathrm{Ca}^{2+}$ influx via L-type $\mathrm{Ca}^{2+}$ channels (Sauzeau et al., 2001) indicating that, depending on the cell type, UII-induced $\mathrm{Ca}^{2+}$ entry occurs through various types of voltage-operated $\mathrm{Ca}^{2+}$ channels. Of note, UII provokes membrane depolarization in cholinergic neurons from the ventral tegmentum (Clark et al., 2005) that is likely involved in the UII-evoked control of rapid eye movements (de Lecea and Bourgin, 2008).

$\mathrm{UT}$ is also coupled to $\mathrm{G} \alpha_{\mathrm{i} / \mathrm{o}}$, leading to activation of the mitogen-activated protein kinase (MAPK) pathway (Fig. 8). Thus, UII stimulates P38MAPK and extracellular signal-regulated kinase 1/2 in UT-transfected cell lines (Ziltener et al., 2002), cardiac myocytes (Zou et al., 2001; Onan et al., 2004b), vascular smooth muscle cells (Watanabe et al., 2001b; Tamura et al., 2003), airway smooth muscle cells (Chen et al., 2004), endothelial cells (Matsushita et al., 2003; Guidolin et al., 2010), and endothelium-denuded rat aorta (Tasaki et al., 2004). UII also stimulates proliferation of endothelial progenitor cells through activation of p38 and p44/42 MAPK (Xu et al., 2012). The stimulatory effect of UII on P38MAPK and extracellular signal-regulated kinase $1 / 2$ in neonatal rat cardiomyocytes and cardiac fibroblasts depends on transactivation of epidermal growth factor receptor (Onan et al., 2004b; Chen et al., 2008; Liu et al., 2009). UT stimulates phosphorylation of C-Jun N-terminal protein kinase in cardiac side population cells and inhibits proliferation of these stem/ progenitor cells (Gong et al., 2011). UII-induced activation of the small GTPase RhoA and its downstream effector Rho-kinase mediates the contractile activity of the peptide on rat vascular rings (Sauzeau et al., 2001), its mitogenic effect on rat vascular smooth muscle cells (Sauzeau et al., 2001), its chemoattractant activity on human monocytes (Segain et al., 2007), and its stimulatory effect on collagen synthesis and migration of adventitial fibroblasts (Zhang et al., 2008). UII increases phosphorylation of both Akt and its downstream target glycogen synthase kinase-3 in rat cardiomyocytes (Gruson et al., 2010a). In these cells, UII also phosphorylates $\beta$-catenin (Gruson et al., 2010a). Because the Akt/glycogen synthase kinase-3 signaling pathway plays a pivotal role in cardiomyocyte hypertrophy (Sugden et al., 2008), these observations suggest that UT antagonists may prove useful for the treatment of cardiac hypertrophy.

A possible implication of phospholipase $\mathrm{A}_{2}$ in the contractile effect of UII has long been postulated (Gibson, 1987) (Fig. 8). As a matter of fact, UII increases the release of arachidonic acid from UT-transfected Chinese hamster ovary (CHO) cells (Mori et al., 1999), and the effect of UII on CHO and human embryonic kidney cells are attenuated by a phospholipase $\mathrm{A}_{2}$ inhibitor (Lehner et al., 2007). In addition, UII-induced contractions of guinea pig ileum or frog systemic arch, bladder, and ileum are blocked by the cyclooxygenase inhibitor indomethacin (Yano et al., 1994, 1995; Horie 


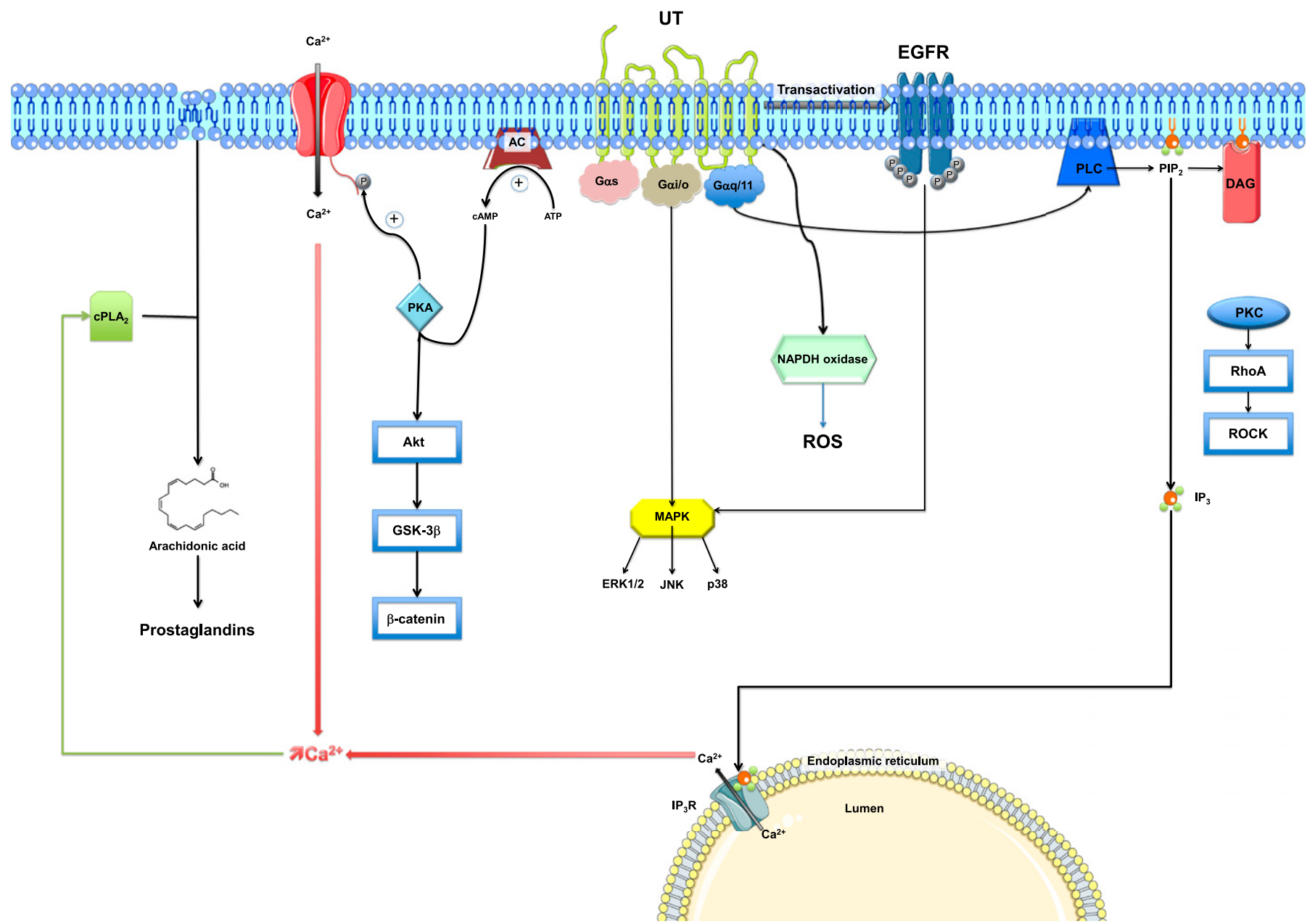

Fig. 8. Signaling pathways associated with UT after UII or URP activation. AC, adenylyl cyclase; Akt, protein kinase B; cAMP, cyclic adenosine monophosphate; EGFR, epidermal growth factor receptor; ERK1/2, extracellular signal-reduced kinase 1/2; GSK-3 $\beta$, glycogen synthase kinase-3 $\beta$; JNK, c-Jun N-terminal kinase; P38, P38 mitogen-activated protein kinases; PIP ${ }_{2}$, phosphatidylinositol 4,5-bisphosphate; PKA, protein kinase A; PKC, protein kinase C; $\mathrm{PLA}_{2}$, phospholipase $\mathrm{A}_{2}$; RhoA, Ras homolog gene family, member A; ROCK, Rho kinase; ROS, reactive oxygen species.

et al., 2005). Similarly, UII- and URP-induced vasodilation in the rat heart is significantly attenuated by indomethacin (Prosser et al., 2006), suggesting that the biologic actions of UII are mediated, at least in part, through stimulation of prostaglandin synthesis. However, prostaglandins are apparently not involved in the vasoconstrictive effects of UII in dogfish (Hazon et al., 1993), rat (Gibson, 1987; Itoh et al., 1987), and rabbit aorta (Saetrum Opgaard et al., 2000). In the isolated rat heart, nitric oxide (NO) and prostacyclin modulate the constrictor response to UII (Gray et al., 2001).

UII stimulates the expression of the NADPH oxidase subunits P22phox and NOX4 and potently activates the production of reactive oxygen species (ROS) in human pulmonary artery smooth muscle cells (Djordjevic et al., 2005) (Fig. 8), suggesting that the peptide may play a role in pulmonary hypertension through activation of NADPH oxidases. Generation of ROS also plays an important role in UII signaling in cardiac fibroblasts (Chen et al., 2008). In fact, UII-mediated ROS generation inhibits Src homology 2-containing tyrosine phosphatase activity, thereby facilitating epidermal growth factor receptor transactivation (Liu et al., 2009).

Most studies related to UT-associated intracellular signaling pathways have been conducted with UII. Although UII and URP produce similar biologic actions, there is now evidence that the two peptides may interact distinctively with UT and exert differential effects (Chatenet et al., 2013a,b,c). For instance, in rat astrocytes, pertussis toxin, which inhibits Gi/o-mediated processes, significantly decreases UII-evoked incorporation of $\left[{ }^{3} \mathrm{H}\right]$ inositol into phosphatidyl-inositol phosphates but does not affect URP-induced $\left[{ }^{3} \mathrm{H}\right]$ inositol incorporation (Jarry et al., 2010). Morever, URP accelerates the dissociation rate of membrane-bound $\left[{ }^{125}\right.$ I]UII, whereas UII has no noticeable effect on [ $\left.{ }^{125} \mathrm{I}\right]$ URP dissociation kinetics (Chatenet et al., 2013b). It thus appears that, although both UII and URP can activate UT, they may exert differential modulatory effects. 


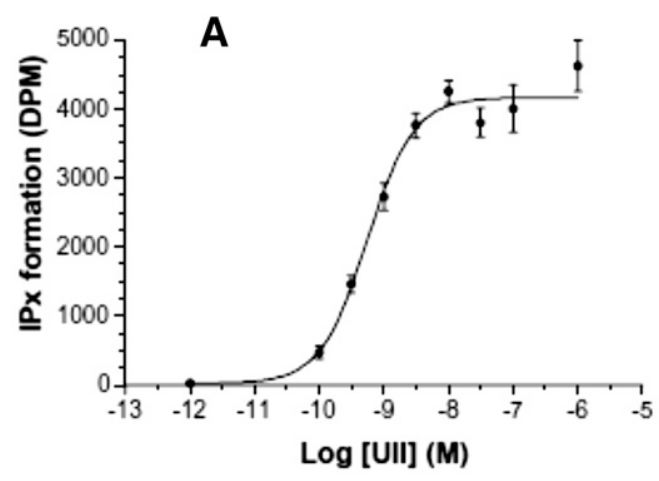

B

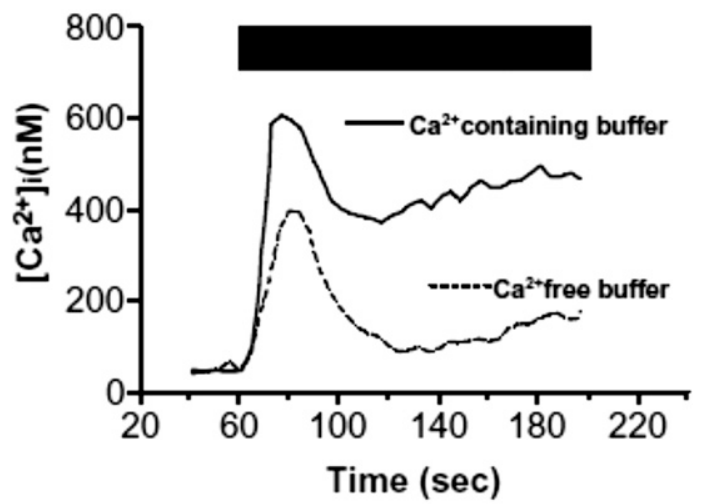

C

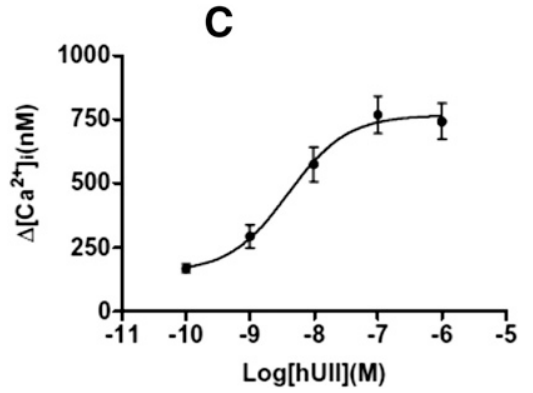

Fig. 9. Effect of human UII on inositol phosphate turnover and intracellular calcium concentration $\left(\left[\mathrm{Ca}^{2+}\right]_{i}\right)$ in human UT-transfected CHO cells. (A) In cells labeled with $\left[{ }^{3} \mathrm{H}\right]$ inositol, graded concentrations of UII, in the presence of $\mathrm{Li}$ block, induces a dose-dependent increase of inositol phosphate (IPx) formation. DPM, disintegrations per minute. (B) Time course effect of UII $\left(100 \mathrm{nM}\right.$, black bar) on $\left[\mathrm{Ca}^{2+}\right]_{\mathrm{i}}$ in Fura 2-loaded cells. In the presence of extracellular $\mathrm{Ca}^{2+}$, a biphasic response in observed, i.e., a peak originating from intracellular calcium stores (as a consequence of IP formation) and a plateau phase caused by an entry of extracellular $\mathrm{Ca}^{2+}$. In the absence of extracellular $\mathrm{Ca}^{2+}$, the response is monophasic with the plateau-phase missing. (C) Effect of graded concentrations of UII on the peak $\left[\mathrm{Ca}^{2+}\right]_{i}$ response. [Reprinted from McDonald et al. (2007). Used with permission.]

\section{Structure-Activity Relationships}

The in vitro activity of UII and URP analogs has been measured by two complementary approaches, i.e., displacement of $\left.{ }^{125} \mathrm{I}\right] \mathrm{UII}$ binding and measurement of $\left[\mathrm{Ca}^{2+}\right]_{\mathrm{i}}$ in UT-transfected cells. Functional characterization of the spasmogenic effect of the designed compounds has been determined using various ex vivo paradigms (Leprince et al., 2008). The most common test consists in measuring the contractile response of de-endothelialized aortic rings from the proximal portion of the rat aortic arch (Itoh et al., 1987; Douglas et al., 2000a; Rossowski et al., 2002; Brkovic et al., 2003; Labarrère et al., 2003; Clozel et al., 2004; Ishihata et al., 2006). Deletion of $\mathrm{N}$ - or C-terminal amino acids of UII indicates that the $\mathrm{C}$-terminal cyclic octapeptide $\mathrm{UII}_{(4-11)}$ (Fig. 10, compound 3) represents the minimal sequence of UII with full biologic activity (Itoh et al., 1987; Perkins et al., 1990; Kinney et al., 2002; Brkovic et al., 2003; Labarrère et al., 2003). Consistent with this observation, the primary structure of this C-terminal sequence has been highly conserved across the vertebrate phylum, whereas the $\mathrm{N}$-terminal linear fragment is quite variable, both in length and amino acid composition (Fig. 1). It should also be recalled that the sequence of the C-terminal octapeptide of UII is almost identical to that of URP. Alanine and D-amino acid scanning studies of UII and URP converge to demonstrate that the -Phe-Trp-LysTyr- motif within the cyclic sequence is the core of the bioactivity with different contributions on UT binding and activation (Flohr et al., 2002; Kinney et al., 2002; Brkovic et al., 2003; Labarrère et al., 2003; Chatenet et al., 2004). In particular, the Tyr residue is clearly involved in UT binding and the Lys residue in UT activation, whereas the Phe residue plays a dual role (Chatenet et al., 2006). The importance of the disulfide bridge in UII has been known for a long time (McMaster et al., 1986). Reduced goby UII or linear UII analogs in which the cystine moiety is replaced with two isosteric serine residues, two S-substituted cysteines, or two alanines are weak agonists or devoid of contractile activity (McMaster et al., 1986; Flohr et al., 2002; Brkovic et al., 2003; Labarrère et al., 2003; Guerrini et al., 2005). Similarly, replacement of the disulfide bond by a lactam bridge of various sizes yields less active or inactive analogs (Grieco et al., 2002b). Concurrently, the cysteine-free head-to-tail cyclic hexapeptide -Ala-Phe-Trp-Lys-Tyr-Aladisplays a lower affinity compared with UII (Foister et al., 2006). Replacement of the Tyr residue of this cyclic hexapeptide with a $\beta$-naphtalene moiety enhances binding affinity but impairs selectivity for UT versus somatostatin receptors (Foister et al., 2006). N-terminal acylation is well tolerated and does not impair the binding affinity and the functional activity of UII and URP (Coy et al., 2002; Brkovic et al., 2003; Labarrère et al., 2003; Chatenet et al., 2004; Song et al., 2006b). However, capping of the $\mathrm{N}$-terminal function may improve the stability of the analogs against proteolysis (Perkins et al., 1990; Kinney et al., 2002; Labarrère et al., 2003). Similarly, amidation of the C-terminal Val residue does not significantly affect the ability of UII to contract rat thoracic aortic rings (Coy et al., 2002; Brkovic et al., 2003; Labarrère et al., 2003).

Several structure-activity relationship studies have focused on the optimization of the Trp-Lys-Tyr triad for the development of UT ligands with potent agonistic or antagonistic activities. In URP as in UII, the 


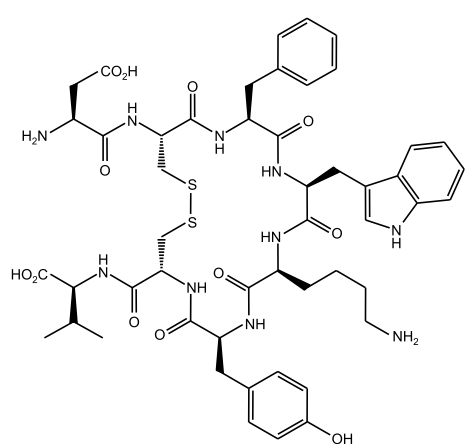

compound 3, human UII $(4-11)$

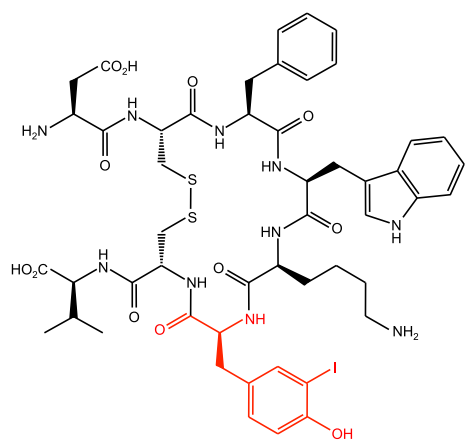

compound 6, human [3-iodo-Tyr ${ }^{6} \mathrm{UII}_{(4-11)}$

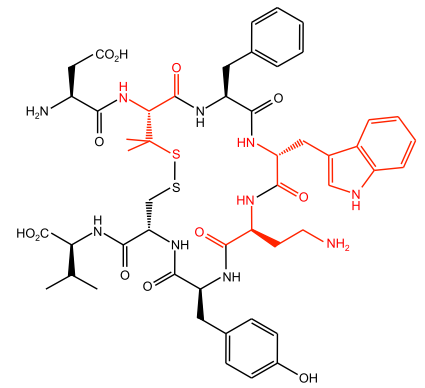

compound 9, UFP-803

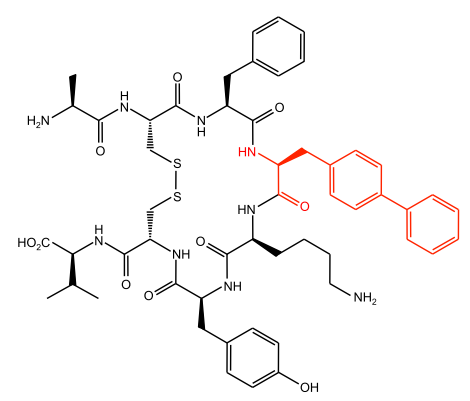

compound 12, urocontrin

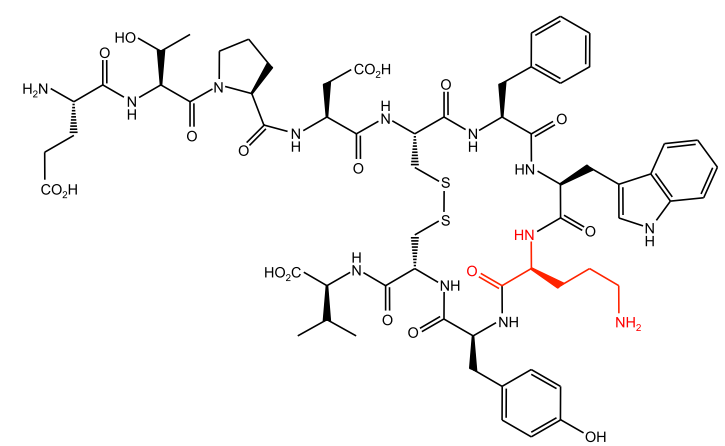

compound 4, human [Orn $\left.{ }^{8}\right]$ UII

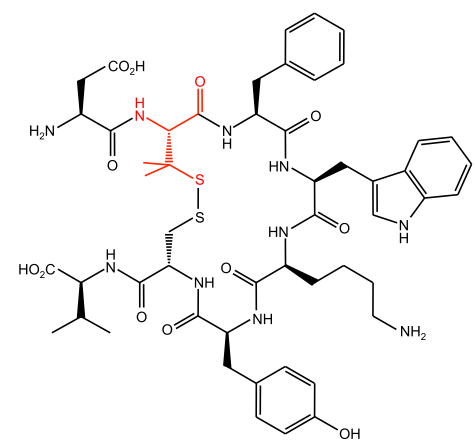

compound 7, human $\left[\mathrm{Pen}^{5}\right] \mathrm{UII}_{(4-11)}$

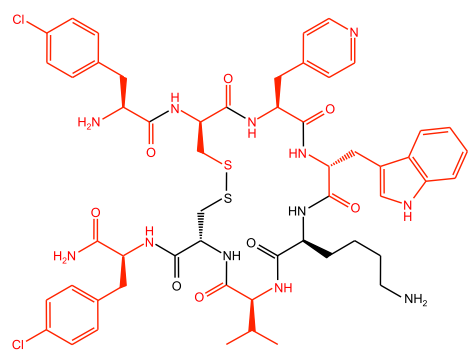

compound 10, SB-710411

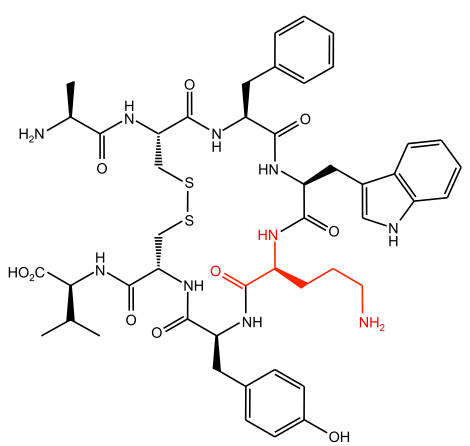

compound 5, mammalian [Orn 5 ]URP

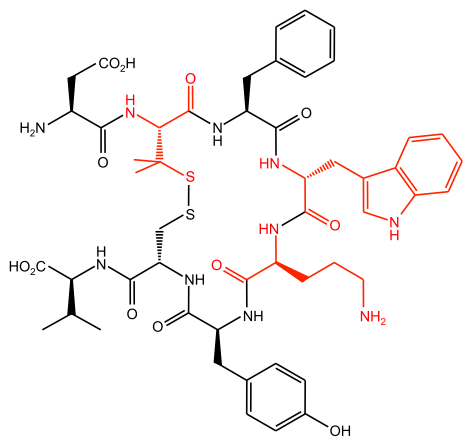

compound 8 , urantide

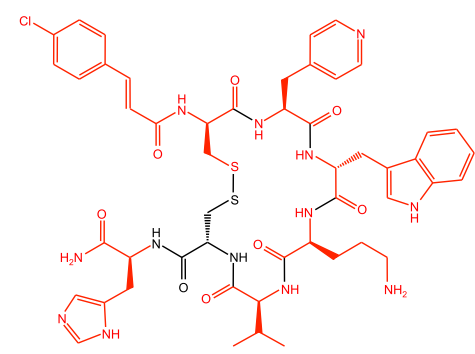

compound 11, GSK-248451

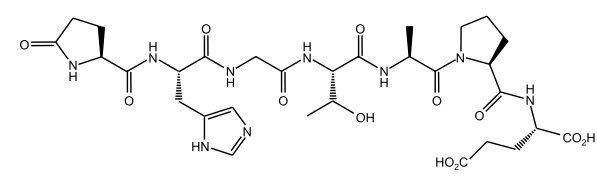

compound 14, rat UIII 1 (1-7)

Fig. 10. Chemical structures of various pepditic ligands of UT. The residue(s) modified from the original scaffold are indicated in red.

tryptophan residue appears to be relatively tolerant to stereoisomer substitution (Flohr et al., 2002; Brkovic et al., 2003; Labarrère et al., 2003; Chatenet et al., 2004; Guerrini et al., 2005). For instance, [DTrp $\left.{ }^{4}\right]$ URP retains substantial binding affinity on human UT-transfected cells and a weak ability to contract de-endothelialized aortic rings. However, [DTrp $\left.{ }^{4}\right] \mathrm{URP}$ totally suppresses the
UII-evoked contractile response (Chatenet et al., 2004), indicating that this compound behaves as a partial agonist of UT. Replacement of the Trp residue with tetrahydroisoquinoline-1-carboxylic acid (Tiq) or L-1,2,3,4tetrahydronorharman-3-carboxylic acid (Tpi) in URP yields two potent UT receptor agonists, $\left[\mathrm{Tiq}^{4}\right] \mathrm{URP}$ and $\left[\mathrm{Tpi}^{4}\right] \mathrm{URP}$ (Chatenet et al., 2013a), suggesting that the indole ring 
of the Trp residue is not critical for receptor interaction (binding) and could in fact be involved in the intramolecular stabilization of the bioactive conformation of URP (Chatenet et al., 2013a). On the basis of the structural similarities existing between UII and somatostatin on the one hand (Pearson et al., 1980) and between UT and SST4 on the other hand (Marchese et al., 1995), it has been hypothesized that the interactions of UII with UT may be similar to those previously reported for somatostatin with $\mathrm{SST}_{4}$ (Kinney et al., 2002). In particular, it has been proposed that the lateral amine function of the Lys residue of UII may establish a physical interaction with the carboxyl group of the Asp ${ }^{130}$ moiety of TMD3 of UT (Kinney et al., 2002; Lavecchia et al., 2005) that is likely involved in receptor activation (see section III.A). Thus, analogs with a reduced distance between the side-chain $\mathrm{NH}_{2}$ group and the peptide backbone in positions 8 and 5 of UII and URP, respectively, which should limit receptor activation, may exhibit antagonistic properties. Indeed, UII-related compounds containing ornithine, 2,4-diaminobutyric acid (Dab), or 2,3-diaminopropionic acid instead of the lysine residue display significant attenuation of the effects of UII. In particular, [Orn ${ }^{8}$ ]UII (Fig. 10, compound 4) induces a rightward shift of the concentrationresponse curve of UII on rat aortic strip contraction (Camarda et al., 2002a) and prevents UII-evoked plasma extravasation in mice (Vergura et al., 2004). However, $\left[\mathrm{Orn}^{8}\right]$ UII stimulates calcium mobilization in human and rat UT-transfected cells (Camarda et al., 2002a), indicating that this compound also acts as a partial UT agonist. Conversely, the [Orn $\left.{ }^{5}\right]$ URP analog (Fig. 10, compound 5), which retains high binding affinity (Chatenet et al., 2004), behaves as a pure selective antagonist in both rat aortic ring contraction and astrocyte $\left[\mathrm{Ca}^{2+}\right]_{\mathrm{i}}$ mobilization assays (Diallo et al., 2008; http://www.iuphar-db.org/ DATABASE/FamilyMenuForward?familyId=65).

To date, only a few peptidic UT superagonists have been designed (Leprince et al., 2008). Consistent with the observation that radio-iodinated UII ([ $\left.\left.{ }^{125} \mathrm{I}\right] \mathrm{UII}\right)$ possesses high affinity for native UT (Maguire et al., 2000) and UT-transfected cells (Nothacker et al., 1999), it was found that [3-iodo-Tyr $\left.{ }^{6}\right] \mathrm{UII}_{(4-11)}$ (Fig. 10, compound 6) is five times more potent than UII and $\mathrm{UII}_{(4-11)}$ in causing rat aortic ring contraction (Labarrère et al., 2003). Similarly, substitution of the tyrosine residue with hindered aromatic amino acids such as (2-naphtyl)L-alanine and biphenylalanine increases the binding affinity and/or the biologic activity of the analogs, probably through an enhancement of the hydrophobic interactions within the binding pocket (Kinney et al., 2002). In contrast, double iodination of the $\mathrm{Tyr}^{9}$ sidechain, to produce [3,5-diiodo-Tyr $\left.{ }^{9}\right] \mathrm{UII}_{(4-11)}$, does not modify the potency of the peptide to mobilize $\left[\mathrm{Ca}^{2+}\right]_{\mathrm{i}}$ in HEK293 cells expressing rat UT but causes a marked decrease of the efficacy, indicating that the diiodinated analog behaves as a partial agonist (Batuwangala et al., 2009b). One of the most effective cycle modifications on activity is the single replacement of the Cys ${ }^{5}$ residue of $\mathrm{UII}_{(4-11)}$ with a penicillamine, which yields $\left[\mathrm{Pen}^{5}\right] \mathrm{UII}_{(4-11)}$, also named P5U (Fig. 10, compound 7), an analog that exhibits an affinity 3 times as high as that of UII and an increased potency in the isolated rat thoracic aorta assay (Grieco et al., 2002a; Patacchini et al., 2003). Finally, replacement of the $\mathrm{Tyr}^{9}$ residue in the P5U sequence with the benzothiazolyl-alanine or the (3,4-Cl)Phe moities leads to analogs with $\mathrm{pEC}_{50}$ values at least $1.4 \mathrm{log}$ higher than that of P5U being the most potent UT agonists discovered to date (Carotenuto et al., 2014).

Several peptidic antagonists have been designed by combining multiple point modifications. For instance, urantide $\left(\left[\operatorname{Pen}^{5}, \mathrm{DTrp}^{7}, \mathrm{Orn}^{8}\right] \mathrm{UII}_{(4-11)}\right.$; Fig. 10, compound 8) acts as a UT antagonist in the rat aorta bioassay (Patacchini et al., 2003; Camarda et al., 2004) but stimulates $\mathrm{Ca}^{2+}$ mobilization in $\mathrm{CHO}$ cells transfected with human UT (Camarda et al., 2004; Grieco et al., 2005). Another analog, UFP-803 ([Pen $\left.{ }^{5}, \mathrm{DTrp}^{7}, \mathrm{Dab}^{8}\right] \mathrm{UII}_{(4-11)}$; Fig. 10, compound 9), which does not evoke any contraction of thoracic aorta rings, shifts to the right the UII concentration-response curve (Camarda et al., 2006). However, UFP-803 is about 10 -fold less potent than urantide to antagonize UII-induced contraction (Patacchini et al., 2003; Camarda et al., 2004, 2006). The cyclic somatostatin analog SB-710411, i.e., Cpa-c[DLys-PalDTrp-Lys-Val-Cys]Cpa- $\mathrm{NH}_{2}$ (Cpa: 4-chlorophenylalanine; Pal: 3-pyridylalanine; Coy et al., 2000; Fig. 10, compound 10) inhibits UII-induced contraction of isolated rat aorta (Behm et al., 2002) but exerts agonistic activity in monkey arteries (Behm et al., 2004b). Rather than a species-dependent process, these divergent responses may be ascribed to an assay-dependent phenomenon inasmuch as $\left[\mathrm{Orn}^{8}\right]$ UII behaves as an antagonist in the rat aorta assay and as an agonist at the recombinant rat UII (Camarda et al., 2002a). These discordant behaviors can be accounted for by different UT expression levels and/or different signal transduction-coupling efficiency. It should be noted, however, that another somatostatin analog, GSK-248451 (Cin-c[DLys-Pal-DTrp-Orn-Val-Cys]His- $\mathrm{NH}_{2}$; Cin: 4-chlorocinnamoyl; Fig. 10, compound 11), acts as a potent UT antagonist in both native mammalian tissues and recombinant cell systems (Behm et al., 2006).

Functional studies have shown that UII and URP exert both common and specific biologic activities (see section III.B). Until recently, none of the UT agonists and antagonists (either peptidic or nonpeptidic) could selectively mimic/block the effects of UII or URP. However, two recent reports describe the design of allosteric modulators of UT, i.e., urocontrin ([Bip $\left.{ }^{4}\right] \mathrm{URP}$; Bip: 4,4'biphenylalanine; Fig. 10, compound 12) and urocontrin A (UCA; [Pep $\left.{ }^{4}\right]$ URP; Pep: 4-(phenylethynyl)-phenylalanine; Fig. 10, compound 13) and rat UII (1-7) $_{\text {(Fig. 10, compound }}$ 14), that can discriminate the biologic activities exerted by 
UII and URP both ex vivo and in vivo (Chatenet et al., 2013a,b,c). In particular, in the rat and monkey aortic ring contraction assays, UCA decreases the maximum response to human UII but has no noticeable effect on URP-induced vasoconstriction (Chatenet et al., 2013b). Reciprocally, the N-terminal region of rat UII, i.e., rat $\mathrm{UII}_{(1-7)}$, significantly reduces the contractile activity of URP but does not affect that of rat UII (Chatenet et al., $2013 \mathrm{~b})$. The antagonistic activity of UCA can be ascribed to an allosteric mechanism, because this compound inhibits UII and URP binding by means of a noncompetitive process.

\section{Design of Nonpeptidic Urotensin II Receptor Agonists and Antagonists}

Over the past 15 years, the design of agonists and antagonists of UII and URP has been carried out to facilitate the delineation of their physiologic roles and to explore new therapeutic strategies. Structure-activity relationship studies (Flohr et al., 2002; Kinney et al., 2002; Brkovic et al., 2003; Labarrère et al., 2003; Chatenet et al., 2004; Guerrini et al., 2005; Leprince et al., 2008; Merlino et al., 2013) led to the discovery of peptide-derived analogs acting as potent agonists or antagonists (Behm et al., 2002; Grieco et al., 2002a; Herold et al., 2003; Patacchini et al., 2003; Carotenuto et al., 2004b; Grieco et al., 2005; Carotenuto et al., 2006; Chatenet et al., 2012, 2013a,b). However, those molecules are usually not considered as the best drug candidates, because their pharmacodynamic and pharmacokinetic properties (bioavailability, metabolic stability, biodistribution) are not optimal. Therefore, the identification and evaluation of nonpeptidic urotensinergic compounds were achieved following approaches based on analysis of the molecular arrangements of UIIand URP-related ligands or the 3D structure of the UT receptor, together with high-throughput screening (HTS).

Structure-activity relationship studies and NMR conformational evaluations (Bhaskaran et al., 1994; Flohr et al., 2002; Grieco et al., 2002b; Chatenet et al., 2004; Lescot et al., 2007) of UII, URP, and analogs, in conditions replicating UT-bound or -unbound ligand, have revealed that the endocyclic triad -Trp-Lys-Tyr- is the key pharmacophore (see sections II.D and III.C). The spatial parameters determined from these studies have been used to carry out virtual $3 \mathrm{D}$ screenings. For instance, a virtual screening performed by Flohr et al. (2002) on an Aventis chemolibrary, followed by a biologic testis using fluorometric imaging plate reader (FLIPR)-based functional assay, led to the identification of S6716 (Fig. 11, compound 15), a benzamidinederived antagonist with an $\mathrm{IC}_{50}$ of $400 \mathrm{nM}$. Similarly, a few years later, Lescot et al. (2007) established a pharmacophore template after NMR studies of UII and molecular dynamics calculations of nonpeptidic UII antagonists identified by Takeda Chemical Industries
(Osaka, Japan) and Actelion (Allschwil, Switzerland). Subsequently, a virtual screening of their compound database (6626 molecules) revealed six chemical substances that showed affinities in the low micromolar range, the best being compound $\mathbf{1 6}$ (Fig. $11 ; \mathrm{IC}_{50}: 1.4 \mu \mathrm{M}$ ). The 3D arrangement of UT was also used (Kinney et al., 2002; Lavecchia et al., 2005; Lescot et al., 2008b) to determine the particular physicochemical requirements of the binding pocket of the receptor and help for the design of new nonpeptidic UT ligands. Although appealing, this approach remains complex because GPCRs are dynamic biomolecules exhibiting conformational changes upon activation (Preininger et al., 2013). Nevertheless, the $3 \mathrm{D}$ information might be very useful for understanding the binding process of existing leads, as shown by docking studies performed with the nonpeptidic UII agonist AC-7954 (Lavecchia et al., 2005) (Fig. 11, compound 17; Acadia Pharmaceuticals, San Diego, CA; $\mathrm{EC}_{50}: 316 \mathrm{nM}$ for the racemic mixture) (Croston et al., 2002). Noteworthy, AC-7954 is the precursor of the potent UT agonists (+)-FL68 ( $\left.\mathrm{EC}_{50}: 50 \mathrm{nM}\right)$, a 6,7-dimethylated derivative of the lead compound (Lehmann et al., 2005), as well as (+)-FL104 (Fig. 11, compound 18, Acadia Pharmaceuticals; $\left.\mathrm{EC}_{50}: 32 \mathrm{nM}\right)$ and its optimized $(+)-(S)-$ naphtyl-containing derivative (Fig. 11, compound 19, Acadia Pharmaceuticals; $\mathrm{EC}_{50}: 23 \mathrm{nM}$ ) (Lehmann et al., 2006, 2009).

HTS is, by far, the most common strategy for discovering template candidates for a drug. This approach has been applied for identifying nonpeptidic UT ligands and many hits were obtained for both antagonists and agonists. Among the first series of antagonists to be reported, the aminoalkoxybenzylpyrrolidines, identified by GlaxoSmithKline (Brentford, UK), showed promising antagonistic properties (Dhanak et al., 2001; Jin et al., 2005). This series is illustrated by compound SB-436811 (Fig. 11, compound 20), an optimized hit that exhibits a good affinity for human UT $\left(K_{\mathrm{i}}: 200 \mathrm{nM}\right)$ but a weak binding potency on rat UT $\left(K_{\mathrm{i}}: 3.2 \mu \mathrm{M}\right)$. GlaxoSmithKline also described the preparation of sulfonamide derivatives (Dhanak et al., 2002; Douglas et al., 2005). In particular, the lead sulfonamide molecule, SB-611812 (Fig. 11, compound 21), which binds to rat UT $\left(K_{\mathrm{i}}: 121 \mathrm{nM}\right)$, antagonizes UII-elicited rat aortic contractions and exhibits very good pharmacokinetic properties $(\sim 100 \%$ oral bioavailability and a 5 -hour half-life), has been used in a rat congestive heart failure model. After 8 weeks of treatment, health improvement was observed, as demonstrated for instance by the decrease of right ventricular systolic pressure, cardiomyocyte hypertrophy, and lung edema, which altogether reduced the overall mortality (Bousette et al., 2006a). Further refinements within the sulfonamide series gave rise to the UT antagonist SB-706375 (Fig. 11, compound 22), which potently blocks UII binding (low nanomolar range) with a reversible mode of action, 


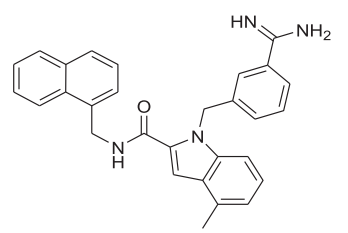

Compound 15 (S6716)

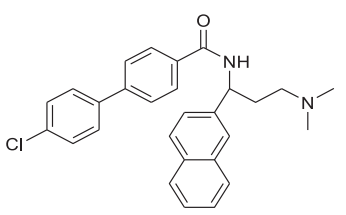

Compound 19

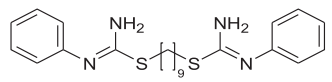

Compound 16

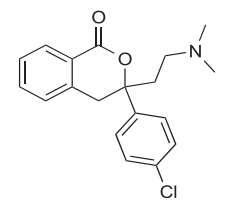

Compound 17 (AC-7954)

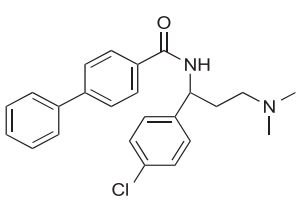

Compound 18 (FL104)

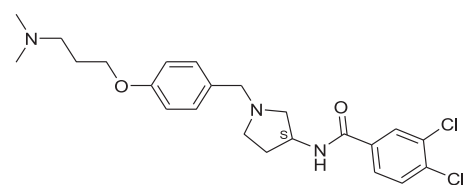

Compound 20 (SB-436811)

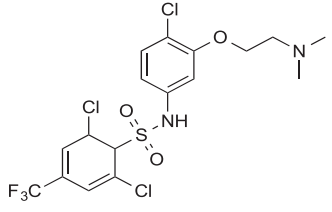

Compound 21 (SB-611812)

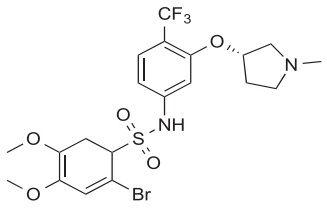

Compound 22 (SB-706375)

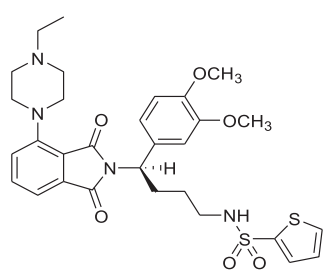

Compound 23 (JNJ-39319202)

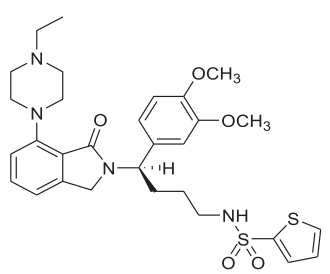

Compound 24

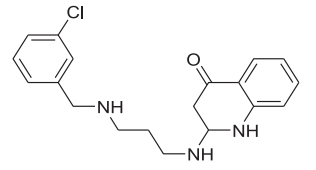

Compound 25

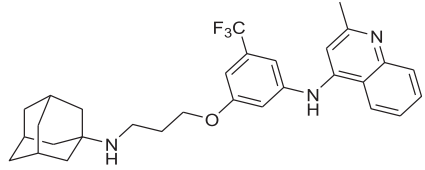

Compound 26

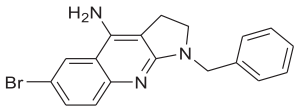

Compound 27

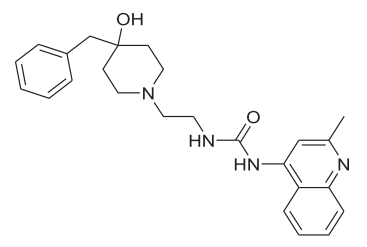

Compound 28 (Palosuran)

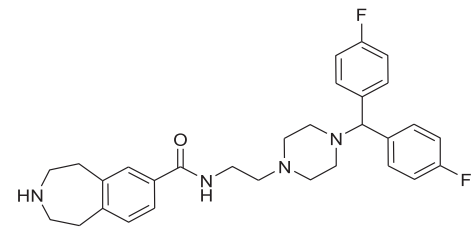

Compound 29

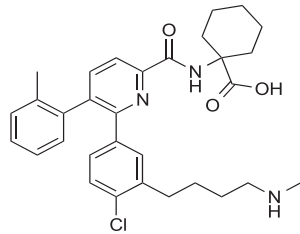

Compound $\mathbf{3 0}$

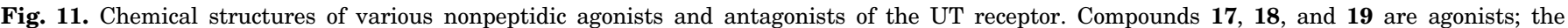
remaining compounds are antagonists.

and inhibits contraction of the rat isolated aorta, as well as intracellular calcium mobilization (Douglas et al., 2005). Likewise, the Johnson \& Johnson group, after applying an HTS protocol to a library of about 500,000 molecules, found new antagonist ligands based on the piperazinophtalimide chemotype (Lawson et al., 2009). Their lead compounds showed only a moderate antagonistic activity and were metabolically unstable. To improve the drug properties of their hits, they introduced various chemical groups in the scaffold and discovered JNJ-39319202 (Fig. 11, compound 23; rat and human IC $_{50}$ in FLIPR: 4.8 and $150 \mathrm{nM}$, respectively, and human UT $K_{\mathrm{i}}$ : $35 \mathrm{nM}$ ) (Lawson et al., 2009; Maryanoff and Kinney, 2010). Interestingly, this piperazinophtalimide derivative contains a sulfonamide function, which appears to enhance the interaction of the ligand with the UT receptor. In parallel, Lawson et al. (2009) explored a series of piperazinoisoindolinone-based derivatives that are molecules structurally close to the piperazinophtalimide-derived compounds. Their study showed that the removal of one carbonyl group in the phtalimide moiety does not much change the activity, because compound $\mathbf{2 4}$ exhibits singledigit nanomolar affinity and antagonistic potency (Lawson et al., 2009).

Quinolone and quinoline templates have been used by a few pharmaceutical companies [such as compound 25 from GlaxoSmithKline, compound 26 from Encysive Pharmaceuticals (Houston, TX), and compound $\mathbf{2 7}$ from Takeda] for the design of UT antagonists (Dhanak and Knight, 2002; Kessler and Wu, 2009; Tarui et al., 2001). These compounds show variable potencies. Similarly, Actelion carried out a structural study of 4-ureidoquinoline derivatives and, in 2004, the company reported the characterization of ACT-058362 (Fig. 11, compound 28), also known as palosuran (Clozel et al., 2004). This molecule exhibits high inhibitory binding potency on human UT receptor $\left(\mathrm{IC}_{50}: 3.6 \mathrm{nM}\right)$. In a functional FLIPR assay with human UT, an $\mathrm{IC}_{50}$ of $17 \mathrm{nM}$ 
was reported. By contrast, palosuran is poorly recognized by the rat UT. Hence, Actelion initiated human clinical trials with patients afflicted by hypertension and diabetic nephropathy. Yet, no significant changes in renal hemodynamic parameters, such as glomerular filtration rate and renal blood flow, were observed and the clinical trials were stopped in 2005 (Maryanoff and Kinney, 2010).

Finally, various optimized chemical substances, based on a benzazepine template (Fig. 11, compound 29 from Takeda), as well as on carboxamide cores, such as 5,6-bisaryl-2-pyrimidinecarboxamide, 5,6-bisaryl-2pyridinecarboxamide, and 5,6-bisaryl-2-pyrazinecarboxamide (for example, compound 30 from Sanofi-Aventis, Paris, France), were reported (Tarui et al., 2002; Altenburger et al., 2008, 2009, 2011). The corresponding compounds exhibited potent antagonistic properties, and thus Sanofi launched a phase I clinical trial with a 5,6-bisaryl-2-pyridinecarboxamide derivative (SAR101099). However, this trial was discontinued because of the lack of efficacy in diabetic nephropathy (en.sanofi.com/Images/29618_20120208-2011_Results_ EN.pdf).

This section represents a summary of nonpeptidic ligands for the urotensinergic system; more information can be obtained in the reviews from Cosenzi (2008), Lescot et al. (2008a), Maryanoff and Kinney (2010), and Merlino et al. (2013). Thus, the literature shows that most major pharmaceutical companies are involved in a research program aimed at designing highly potent agonists and antagonists of the UT receptor. So far, excellent ligands have been developed and some compounds have even been evaluated in clinical trials. However, mixed clinical results (Maryanoff and Kinney, 2010; Portnoy et al., 2013; en.sanofi.com/Images/ 29618_20120208-2011_Results_EN.pdf) were obtained, for instance by Actelion, Sanofi, and GlaxoSmithKline, and consequently, several trials were stopped. It was recently found that UII and URP exhibit not only common but also dissimilar biologic activities (Prosser et al., 2008; Jarry et al., 2010; Doan et al., 2012). Thus, ligands able to discriminate between the UII and URP effects have been developed (Chatenet et al., 2012, 2013a,b,c). Pharmacological studies using these compounds confirmed that the urotensinergic system is far more complex than initially thought. These observations might explain some of the failures of clinical trials and, therefore, this aspect should be considered when designing new UT ligands.

\section{E. Distribution of Urotensin II Receptor in the Central Nervous System}

The localization of UT mRNA has been determined in the brain and spinal cord by RT-PCR and in situ hybridization histochemistry (Liu et al., 1999; Clark et al., 2001; Gartlon et al., 2001; Totsune et al., 2001; Elshourbagy et al., 2002; Jégou et al., 2006; Dubessy et al., 2008), and the localization of UII binding sites has been studied by autoradiography using $\left[{ }^{125} \mathrm{I}\right] \mathrm{UII}$ or $\left[{ }^{125} \mathrm{I}\right] \mathrm{URP}$ as a radioligand (Maguire et al., 2000; Clark et al., 2001; Jégou et al., 2006; Bucharles et al., 2014). The distribution and relative density of UT mRNA and UII binding sites in the rat CNS are compared in Table 1.

High concentrations of UT mRNA are found in most regions of the CNS, including the cerebral cortex, olfactory bulb, hippocampus, amygdala, pineal gland, hypothalamus, tegmentum, brainstem, cerebellum, and spinal cord (Gartlon et al., 2001; Jégou et al., 2006). Expression of UII mRNA occurs in neurons (Jégou et al., 2006), astrocytes (Castel et al., 2006; Desrues et al., 2012), and endothelial cells (Spinazzi et al., 2006).

In rat, the expression of UT mRNA is particularly intense in the piriform cortex, the pineal gland, the arcuate nucleus of the hypothalamus, the choroid plexus, the locus coeruleus, the dorsal motor nucleus of the vagus nerve, the trigeminal nucleus, the facial nucleus, the medial superior olive, the medioventral periolivary nucleus, the nucleus of the trapezoid body, the pontine nuclei, and in the Purkinje cell and granule cell layers of the cerebellum (Jégou et al., 2006; Hunt et al., 2010). High levels of UT mRNA are also observed in the entorhinal cortex, the piriform cortex, the tenia tecta, in several regions of the amygdala including the nucleus of the lateral olfactory tract, the bed nucleus of the accessory olfactory tract, the anterior and posterolateral cortical amygdaloid nuclei, the medial amygdaloid nucleus and the posteromedial amygdalohippocampal transition area, in the parabigeminal nucleus, the medial habenular nucleus, the supraoptic and ventromedial hypothalamic nuclei, the area postrema, the dorsal laterodorsal and ventral tegmental nuclei, the interpeduncular nucleus, the nucleus of the solitary tract, the nucleus ambiguus, the nucleus abducens, the hypoglossal nucleus, the principal sensory nucleus, the lateral periolivary nucleus, the supragenuate nucleus, the inferior olivary complex, the magnocellular subdivision of the red nucleus, and layers 9 and 10 of the ventral horn of the spinal cord (Jégou et al., 2006; Hunt et al., 2010). In the mesopontine tegmentum area and the spinal cord, the UT gene is strongly expressed in motoneurons (Clark et al., 2001, 2005; Jégou et al., 2006; Bruzzone et al., 2010). The fact that UII induces an increase in $\left[\mathrm{Ca}^{2+}\right]_{i}$ in cultured rat motoneurons indicates that the UT mRNA is translated into functional UT receptor (Filipeanu et al., 2002).

Autoradiographic labeling with $\left[{ }^{125} \mathrm{I}\right] \mathrm{UII}$ confirmed the presence of UII binding sites in several areas of the rat brain that actively express the UT gene such as the endopiriform nucleus in the olfactory system, the subiculum complex in the hippocampal formation, the medial amygdaloid nucleus, the parabigeminal nucleus in the visual system, the medial aspect of the 
TABLE 1

Distribution of UT mRNA and UII binding sites on the rat brain

The distribution of ${ }^{125}$ I-labeled UII binding sites has been described in three reports: 1) Maguire et al., 2000; 2) Clark et al., 2001; 3) Jégou et al., 2006. [Reprinted from Jégou et. al. (2006). Used with permission.]

\begin{tabular}{|c|c|c|}
\hline Structure & GPR14 mRNA & UII Binding Sites \\
\hline Isocortex & +/++ & \\
\hline \multicolumn{3}{|l|}{ Allocortex } \\
\hline Cingulate cortex & +/++ & \\
\hline Insular cortex & + & \\
\hline Orbital cortex & + & \\
\hline Retrosplenial cortex & + & \\
\hline Entorhrinal cortex & $++/+++$ & \\
\hline \multicolumn{3}{|l|}{ Olfactory system } \\
\hline \multicolumn{3}{|l|}{ Main olfactory bulb } \\
\hline Mitral cell layer & ++ & \\
\hline Internal granular layer & ++ & \\
\hline Glomerular layer & + & \\
\hline Anterior olfactory nucleus & ++ & \\
\hline Dorsal endopiriform nucleus & ++ & Yes $(2,3)$ \\
\hline Piriform cortex & $+++/++++$ & \\
\hline Tenia tecta & +++ & \\
\hline Olfactory tubercle & +++ & \\
\hline Claustum & ++ & \\
\hline \multicolumn{3}{|l|}{ Basal ganglia } \\
\hline Caudate putamen & $+1-$ & \\
\hline Globus pallidus & - & \\
\hline Accumbens nucleus & $+1-$ & Yes (2) \\
\hline Ventral pallidum & $+1-$ & \\
\hline Islands of Calleja & - & \\
\hline \multicolumn{3}{|l|}{ Substantia nigra } \\
\hline Pars compacta & ++ & \\
\hline Pars reticularis & - & \\
\hline Subthalamic nucleus & +/++ & \\
\hline Ventral tegmental area & + & Yes (2) \\
\hline \multicolumn{3}{|l|}{ Septum } \\
\hline Lateral septal nucleus, dosal & + & Yes $(2,3)$ \\
\hline Lateral septal nucleus, intermediate & + & \\
\hline Lateral septal nucleus, ventral & + & \\
\hline Horizontal limb of the diagonal band of Broca & + & \\
\hline \multicolumn{3}{|l|}{ Hippocampal formation } \\
\hline \multicolumn{3}{|l|}{ Ammon's horn } \\
\hline Stratum oriens & Patchy labeling & \\
\hline Pyramidal cell layer & $+++/+++$ & \\
\hline Stratum radiatum & Patchy labeling & \\
\hline Dentate gyrus & $+++/++++$ & \\
\hline Subiculum complex & ++ & Yes (2) \\
\hline \multicolumn{3}{|l|}{ Amygdala } \\
\hline Nucleus of the lateral olfactory tract & +++ & \\
\hline Bed nucleus of the accessory olfactory tract & +++ & \\
\hline Anterior cortical amygdaloid nucleus & +++ & \\
\hline Posterolateral cortical amygdaloid nucleus & +++ & \\
\hline Posteromedìal cortical amygdaloid nucleus & ++ & \\
\hline Amygdalopiriform transition area & ++ & \\
\hline Medial amygdaloid nucleus & +++ & Yes (3) \\
\hline Posteromedial amygdalohippocampal transition area & +++ & \\
\hline Basolatetal amygdaloid complex & ++ & \\
\hline Basomedial amygdaloid complex & ++ & \\
\hline Central amygdaloid complex & ++ & \\
\hline Bed nucleus of the stria terminalis, lateral & + & Yes $(2,3)$ \\
\hline \multicolumn{3}{|l|}{ Visual system } \\
\hline Parabigeminal nucleus & +++ & Yes (3) \\
\hline Lateral geniculate nuclei, ventral and dorsal & $+1-$ & Yes $(2,3)$ \\
\hline Pretectum & + & Yes (3) \\
\hline Superior colliculus & + & \\
\hline \multicolumn{3}{|l|}{ Epithalamus } \\
\hline Pineal gland & ++++ & \\
\hline Habenular nucleus & & \\
\hline Medial & +++ & Yes (2) \\
\hline Lateral & ++ & \\
\hline Thalamus & & \\
\hline Paraventricular thalamic nucleus & ++ & \\
\hline Anterodorsal thalamic nucleus & ++ & \\
\hline Anteroventral thalamic nucleus & $+/++$ & Yes $(2,3)$ \\
\hline Centromedian thalamic nucleus & + & \\
\hline Reticular thalamic nucleus & + & \\
\hline Mediodorsal thalamic nucleus & + & \\
\hline Reuniens thalamic nucleus & + & \\
\hline
\end{tabular}


TABLE 1-Continued

\begin{tabular}{|c|c|c|}
\hline Structure & GPR14 mRNA & UII Binding Sites \\
\hline Rhomboid nucleus & + & \\
\hline Ventrolatetal thalamic nucleus & + & \\
\hline Ventroposterior lateral thalamic nucleus & + & \\
\hline Ventroposterior medial thalamic nucleus & + & \\
\hline Ventromedial thalamic nucleus & + & \\
\hline Posterior thalamic nuclear group & + & \\
\hline Paratenial thalamic nucleus & + & \\
\hline Zona incerta & ++ & \\
\hline \multicolumn{3}{|l|}{ Hypothalamus } \\
\hline Anterior hypothalamic area, anterior & + & \\
\hline Anterior hypothalamic area, posterior & ++ & \\
\hline Anterior medial preoptic nucleus & - & \\
\hline Anteroventral preoptic nucleus & - & \\
\hline Medial preoptic area & - & \\
\hline Medial preoptic nucleus & +/++ & Yes (2) \\
\hline Lateral preoptic area & - & \\
\hline Median preoptic nucleus & ++ & \\
\hline Lateroanterior hypothalamic nucleus & + & \\
\hline Magnocellular preoptic nucleus & - & \\
\hline Supachiasmatic nucleus & ++ & \\
\hline Supraoptic nucleus & +++ & \\
\hline Ventromedial hypothalamic nucleus & +++ & \\
\hline Lateral hypothalamic area & + & \\
\hline Posterior hypothalamic area & + & \\
\hline Dorsomedian hypothalamus, dorsal & + & \\
\hline Paraventricular nucleus, magnocellular part & ++ & \\
\hline Paraventricular nucleus, median parvocellular & + & \\
\hline Arcuate nucleus & $+++/++++$ & \\
\hline Mammillary nucleus, medial, lateral & ++ & \\
\hline \multicolumn{3}{|l|}{ Circumventricular organs } \\
\hline Area postrema & +++ & \\
\hline Choroid plexus & ++++ & \\
\hline
\end{tabular}

Reticular formation

Paramedian reticular nucleus

Medullary nucleus, ventral, dorsal Ventral

Dorsal

Lateral paragigantocellular nucleus

Rostroventrolateral reticular nucleus

Dorsal paragigantocellular nucleus

Gigantocellular reticular nucleus

Ventral

Alpha

Intermediate reticular nucleus

Parvocellular reticular nucleus

Pontine reticular nuclei

Periaqueducal gray

Cuneiform nucleus

Dorsal tegmental nucleus

Ventral tegmental nucleus

Laterodorsal tegmental nucleus

Microcellular tegmental nucleus

Pedunculopontine tegmental nucleus

Deep mesencephalic nucleus

Raphe complex

Dorsal raphe nucleus

Median raphe nucleus

Raphe pallidus nucleus

Interpeduncular nucleus

Locus coeruleus

Brainstem nuclei associated to autonomic functions

Nucleus of the solitary tract

Dorsal motor nucleus of the vagus

Ambiguus nucleus

Parabrachial nucleus

Medial

Lateral

Motor nuclei

Oculomotor nucleus

Trochlear nucleus

Trigeminal nucleus

Abducens nucleus

Facial nucleus

Hypoglossal nucleus

Patchy Labeling

Patchy Labeling

-

Patchy Labeling

$++$

Patchy Labeling

Patchy Labeling

Patchy Labeling $+$

Patchy Labeling

Patchy Labeling

$+$

$+$

+
+
+++
++2

$+++$

$+++$

$+$

Yes (2)

Yes $(2,3)$

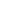

++
++

++
++

+4
++
+++++

$++++$

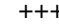

$+++/+++$

$+++$

$++$

$++$

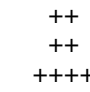

$++++$

$+++$

$+++/++++$

$+++$ 
TABLE 1-Continued

\begin{tabular}{|c|c|c|}
\hline Structure & GPR14 mRNA & UII Binding Sites \\
\hline Mesencephalic trigeminal nucleus & ++++ & \\
\hline Principal sensory nucleus, dorsomedial & $++/+++$ & \\
\hline \multicolumn{3}{|l|}{ Nucleus of the spinal tract } \\
\hline Oral & $+/++$ & \\
\hline Caudal & + & \\
\hline Interpolar part & + & \\
\hline External cuneate nucleus & ++ & \\
\hline Cuneate nucleus & - & \\
\hline Paratrigeminal nucleus & ++ & \\
\hline \multicolumn{3}{|l|}{ Auditory system } \\
\hline Lateral superior olive & ++ & \\
\hline Medial superior olive & ++++ & \\
\hline Medioventral periolivary nucleus & ++++ & \\
\hline Lateroventral periolivary nucleus & +++ & \\
\hline Nucleus of the trapezoid body & ++++ & \\
\hline Dorsal cochlear nucleus & ++ & \\
\hline \multicolumn{3}{|l|}{ Ventral cochlear nucleus } \\
\hline Anterior & ++ & \\
\hline Posterior & ++ & \\
\hline Ventral nucleus of the lateral lemniscus & $+/++$ & \\
\hline Inferior colliculus & + & \\
\hline Medial geniculate body & + & \\
\hline \multicolumn{3}{|l|}{ Vestibular system } \\
\hline Superior vestibular nucleus & + & \\
\hline Lateral vestibular nucleus & + & \\
\hline Medial vestibular nucleus & ++ & \\
\hline Prepositus hypoglossal nucleus & ++ & \\
\hline Supragenuate nucleus & +++ & \\
\hline \multicolumn{3}{|l|}{ Precerebellar nuclei } \\
\hline Pontine nuclei & ++++ & Yes $(2,3)$ \\
\hline Reticulotegmental nucleus of the pons & ++ & \\
\hline Inferior olivary complex & +++ & \\
\hline Lateral reticular nucleus & ++ & \\
\hline \multicolumn{3}{|l|}{ Red nucleus } \\
\hline Parvocellular & ++ & \\
\hline Magnocellular & +++ & \\
\hline \multicolumn{3}{|l|}{ Cerebellum } \\
\hline Purkinje cell layer & ++++ & Yes (3) \\
\hline Granular layer & ++++ & \\
\hline Molecular layer & - & \\
\hline Medial cerebellar nucleus & +/++ & \\
\hline Interposed cerebellar nucleus & +/++ & \\
\hline Lateral cerebellar nucleus & $+/++$ & \\
\hline \multicolumn{3}{|l|}{ Spinal cord } \\
\hline Layer 2-4 & ++ & \\
\hline Layer 5 & + & \\
\hline Layer 7-8 & $\begin{array}{l}\mathrm{T} \\
++\end{array}$ & \\
\hline Layer 9 & +++ & \\
\hline Layer 10 & $++/+++$ & \\
\hline
\end{tabular}

The symbols provide a semiquantitative evaluation of the density of UT mRNA: ++++, very high density; +++, high density; ++, moderate density; +, low density; —, no hybridization signal.

habenular nucleus, the medial preoptic nucleus, the laterodorsal tegmental nucleus in the reticular formation, the interpeduncular nucleus, the abducens nucleus, the pontine nuclei, and the Purkinje cell layer (Maguire et al., 2000; Clark et al., 2001; Jégou et al., 2006). However, a number of brain nuclei that are enriched with UT mRNA do not contain detectable amounts of UII binding sites. This mismatch suggests that, in certain brain regions, the UT protein may be occupied by endogenous UII or URP. Consistent with this notion, it has been shown that, in various tissues, UII binds tightly to its receptor in a quasi-irreversible manner (Qi et al., 2005; Song et al., 2006b; Du et al., 2010), and dissociation of UII from cat UT appears to be very slow (Aiyar et al., 2005) (Fig. 12). Alternatively, in brain regions that contain high concentrations of
UT mRNA but are devoid of UII binding sites, the receptors may be transported along the axons to distant projecting areas (Jégou et al., 2006). This latter hypothesis would also explain why UII binding sites are observed in a few brain regions that are virtually devoid of UT mRNA, e.g., the nucleus accumbens and the pedunculopontine tegmental nucleus (Jégou et al., 2006). A recent study has shown that the distribution of $\left[{ }^{125} \mathrm{I}\right]$ URP binding sites totally overlaps that of $\left[{ }^{125} \mathrm{I}\right] \mathrm{UII}$ (Bucharles et al., 2014). Intriguingly, UII and URP binding sites are observed along the wall of the fourth ventricle (Bucharles et al., 2014), suggesting that the urotensinergic system may regulate chemical communication between CSF and brain parenchyma.

In the mouse CNS, RT-PCR analysis revealed that the expression pattern of UT is globally similar to that 

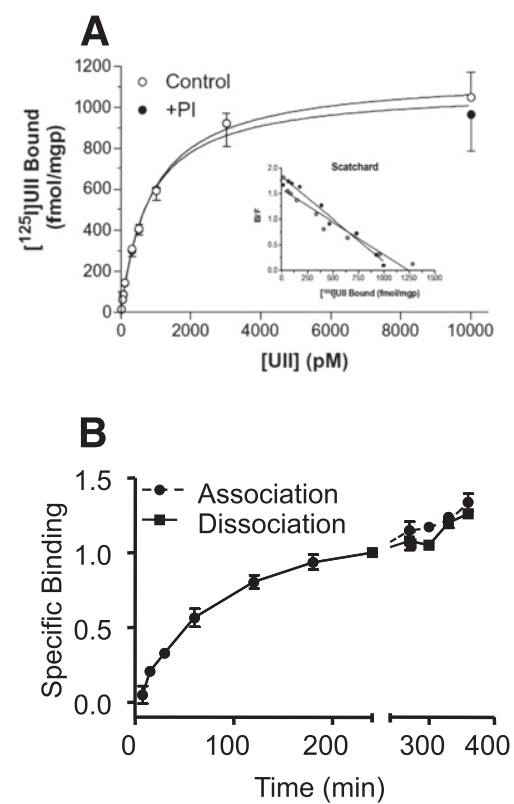

Fig. 12. $\left[{ }^{125}\right.$ I] human UII binding to recombinant human UT. (A) $\left[{ }^{125} \mathrm{I}\right] \mathrm{UII}$ binding is presented with Scatchard analysis of the binding isotherm. Addition of a peptidase inhibitor cocktail (+PI; i.e., amastatin, bestatin, phosphoramidon, and captopril) does not affect binding. (B) Addition of an excess of unlabeled UII (dotted line) fails to induce radioligand dissociation. [Reprinted from Song et al. (2006b). Used with permission.]

described in rat with high concentrations of UT mRNA in the septum, hippocampus, amygdala, hypothalamus, cerebellum, medulla oblongata, and spinal cord (Dubessy et al., 2008). In the anterior horn of the spinal cord, intense expression of UT is observed in motor neurons (Liu et al., 1999; Sun et al., 2014).

In the human CNS, UT mRNA is present in the cerebral cortex, hypothalamus, and medulla oblongata (Totsune et al., 2001), whereas, in the cynomolgus monkey, UT mRNA is found in the spinal cord but not in the cerebral cortex and cerebellum (Elshourbagy et al., 2002). In addition, UII peptide is also detected in the CSF of pregnant women (Cowley et al., 2005). The occurrence of UII binding sites has also been reported in the human brain (Maguire et al., 2000).

In the European flounder, the UT gene is strongly expressed in the spinal cord and in the caudal neurosecretory system (Lu et al., 2006). In the flounder and the orange-spotted grouper Epinephelus coioides, UT transcripts are also present in all regions of the brain including the forebrain, midbrain, hypothalamus, and hindbrain (Lu et al., 2006; Sun et al., 2014).

\section{F. Distribution of Urotensin II Receptor in Peripheral Organs}

The localization of UT mRNA and UT protein has been investigated by RNase protection assay, Northern blot analysis, RT-PCR, immunohistochemistry, and binding experiments. Early reports on the characterization of rat and bovine GPR14/SERN, now renamed UT (see section III.A), revealed that, in mammals, this receptor is actively expressed in the retina and heart muscle (Marchese et al., 1995; Tal et al., 1995). Subsequent studies showed that UT mRNA is widely expressed in peripheral organs such as the eye, heart, pancreas, lung, and skeletal muscle (Ames et al., 1999; Liu et al., 1999; Davenport and Maguire, 2000; Dubessy et al., 2008; Wang et al., 2009). In particular, in mouse, the highest expression of UT mRNA is observed in the lung (Dubessy et al., 2008), suggesting a role of UII/URP in respiratory function. Consistent with this hypothesis, UII induces in vitro a concentration-dependent contraction of airways and pulmonary blood vessels from the cynomolgus monkey (Hay et al., 2000).

In the cardiovascular system, the UT gene is expressed in the atrium, ventricle, coronary artery, thoracic aorta, left internal thoracic artery, great saphenous vein, and umbilical vein (Ames et al., 1999; Davenport and Maguire, 2000; Matsushita et al., 2001; Zhang et al., 2007). Autoradiographic analysis indicates that $\left[{ }^{125} \mathrm{I}\right] \mathrm{UII}$ binds to rat aorta and human left ventricle and coronary artery (Maguire et al., 2000). At the cellular level, UT-like immunoreactivity is observed in arterial and venous smooth muscle cells and cardiomyocytes (Maguire et al., 2008).

The UT transcript is found in the kidney of human (Ames et al., 1999; Lehner et al., 2007), rat (Gartlon et al., 2001; Hirose et al., 2009; Mori et al., 2009; Forty and Ashton, 2013), and mouse (Lehner et al., 2007). In the rat kidney, the UT gene is expressed in glomerular arterioles, thin ascending limbs, and inner medullary collecting ducts (Song et al., 2006a; Forty and Ashton, 2013). Quantitative receptor autoradiography confirms the presence of $\left[{ }^{125} \mathrm{I}\right] \mathrm{UII}$ binding in the human kidney cortex (Maguire et al., 2000) and in the rat kidney medulla (Disa et al., 2006). At the cellular level, UT-like immunoreactivity is located in renal tubular cells, vascular smooth muscle cells, and vascular endothelial cells of the rat kidney (Mori et al., 2009).

In the human endocrine system, UT mRNA is expressed in the adrenal gland (Takahashi et al., 2003) and pancreas (Ames et al., 1999). Immunohistochemical staining indicates that the UT protein occurs in the human adrenal medulla (Morimoto et al., 2008). UT mRNA is also expressed in the rat testis.

In the European flounder and the killfish Fundulus heteroclitus, UT mRNA is expressed in heart, ovary, bladder, kidney, pituitary, and gill (Lu et al., 2006; Evans et al., 2011). In the flounder and the grouper, UT-like immunoreactivity is evident in vascular elements irrigating osmoregulatory tissues such as kidney glomeruli and collecting ducts and the primary and secondary lamellae of the gill (Lu et al., 2006; Sun et al., 2014).

\section{G. Urotensin II Receptor in Tumor Cells}

The UII gene is expressed in a number of human cell lines including T98G glioblastoma cells, IMR-32 neuroblastoma cells, NB69 neuroblastoma cells, BeWo 
choriocarcinoma cells, SW-13 adrenocortical carcinoma cells, DLD-1 colorectal adenocarcinoma cells, and HeLa cervical cancer cells (Takahashi et al., 2001). The UT gene is also expressed in pheochromocytomas, adrenocortical adenomas (including adenomas with primary aldosteronism, adenomas with Cushing syndrome, and nonfunctioning adenomas), adrenocortical carcinomas, ganglioneuroblastoma, and neuroblastomas (Takahashi et al., 2003; Zeng et al., 2006). Of note, all these cell lines except NB69 neuroblastoma cells also express UII mRNA (Takahashi et al., 2001, 2003). Functional human UT has been characterized in rhabdomyosarcoma SJRH30 and TE671 cell lines (Douglas et al., 2004b; Batuwangala et al., 2009a). Both UT mRNA and UT protein are present in human lung adenocarcinoma A549 cells and exogenous UII activates proliferation of these cells in vitro and in vivo (Wu et al., 2010). UII-evoked lung adenocarcinoma growth is likely mediated through the nuclear factor $\kappa \mathrm{B}$ pathway (Zhou et al., 2012). Abundant expression of UT mRNA and UT protein is observed in the interstitial nodular lesions of patients with lymphangioleiomyomatosis, whereas UT mRNA is not expressed in normal human lungs (Kristof et al., 2010). UT mRNA expression is significantly elevated in androgen-dependent $\mathrm{LNCaP}$ prostate cancer cells and reduced in androgen-independent PC3 and DU145 prostate cancer cells (Grieco et al., 2011). Interestingly, there is a significant correlation between UT expression and the prognosis of human prostate adenocarcinoma, suggesting the potential use of UT as a prognostic marker for prostate cancer (Grieco et al., 2011). Collectively, these findings indicate that further studies should be pursued on the role of UT in the pathogenesis of various cancers as well as its potential as a diagnostic and prognostic marker.

\section{H. Phylogenetic Evolution of Urotensin II Receptor}

As mentioned above (see section III.A), UT exhibits the highest degree of sequence identity with somatostatin, opioid, and galanin receptors. Consistent with this observation, phylogenetic analysis shows that all of these receptors group into the same clade, called the $\gamma$-group of rhodopsin receptors (Mirabeau and Joly, 2013). The close evolutionary relationships between UII- and somatostatin-related peptides (Parmentier et al., 2011; see section II.J.3) on the one hand and between UT and somatostatin receptors on the other hand are consistent with the hypothesis that all these peptides, together with their cognate receptors, coevolved from a single ancestral ligand-receptor pair (Tostivint et al., 2006, 2014).

Although the UII family encompasses several members (i.e., two in tetrapods and up to five in teleosts), until recently only one UII/URP receptor had been identified. However, in a recent study, Larhammar et al. (2012) provide evidence that UT also belongs to a multigenic family and show that the vertebrate ancestor likely possessed five distinct UT subtypes. They propose that the single ancestral UT gene was quadrupled in $2 \mathrm{R}$ and that one of these copies underwent a local duplication (Fig. 13). It now appears that all five UT subtypes have been preserved in some reptile species, notably in the anole lizard (Anolis carolinensis), whereas in teleosts and birds, for instance, only four are still present. In contrast, placental mammals have lost four of the five ancestral UT genes (Fig. 13). These new data reveal a totally unexpected complexity of the urotensinergic system in vertebrates (Tostivint et al., 2014). Further studies are now needed to grasp the full biologic significance of such a complexity, particularly in teleosts where many ligands and receptors coexist. In any event, it is now clear that the relative simplicity of the urotensinergic system in placental mammals (i.e., two ligands for only one receptor) should no longer be viewed as a general rule.

\section{Biologic and Pharmacologic Effects of Urotensin II and Urotensin II-Related Peptide}

\section{A. Effects of Urotensin II/Urotensin II-Related Peptide in the Central Nervous System}

The widespread distribution of UT in the brain and spinal cord indicates that UII and URP may regulate various neurophysiological and behavioral activities. As a matter of fact, central administration of UII induces a number of biologic effects (Watson and May, 2004; do Rego et al., 2005; Nothacker and Clark, 2005; Vaudry et al., 2010).

1. Action on Rapid Eye Movement Sleep. The presence of UT mRNA and UII binding sites in cholinergic neurons of the pedunculopontine tegmental nucleus (PPT) and the lateral dorsal tegmental area (Clark et al., 2001), two structures of the pons-midbrain transition area involved in the control of rapid eye movement (REM) sleep (Baghdoyan et al., 1984; Webster and Jones, 1988; Quattrochi et al., 1989; Steriade and McCarley, 1990), lends credence to the idea that the UII system may be implicated in the regulation of the sleep-wake cycle. Consistent with this hypothesis, intracerebroventricular administration of UII or local bilateral injection of UII into the PPT increases the number of REM sleep episodes in rat (Huitron-Resendiz et al., 2005; de Lecea and Bourgin, 2008). Interestingly, only a low dose $(0.6 \mathrm{pmol})$ of UII significantly augments the amount of REM sleep, whereas a 10-fold higher dose is ineffective. The UT antagonist SB-710411 blocks the UII-induced REM sleep response. Whole cell recording from rat brain slices revealed that UII triggers cholinergic PPT neurons by activating a slow inward current (Huitron-Resendiz et al., 2005).

High concentrations of UT mRNA and UII binding sites are also observed in the locus coeruleus (Jégou et al., 2006), a structure involved in the regulation of the sleep-wake cycle (Jacobs, 1985). In rat brain slices, UII 


\section{Actinopterygians}

Danio rerio
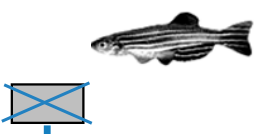

UT1

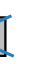

1 UT3 UT4

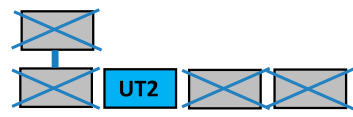

|

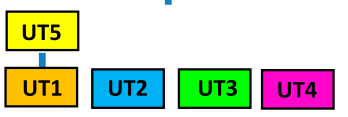

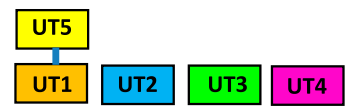
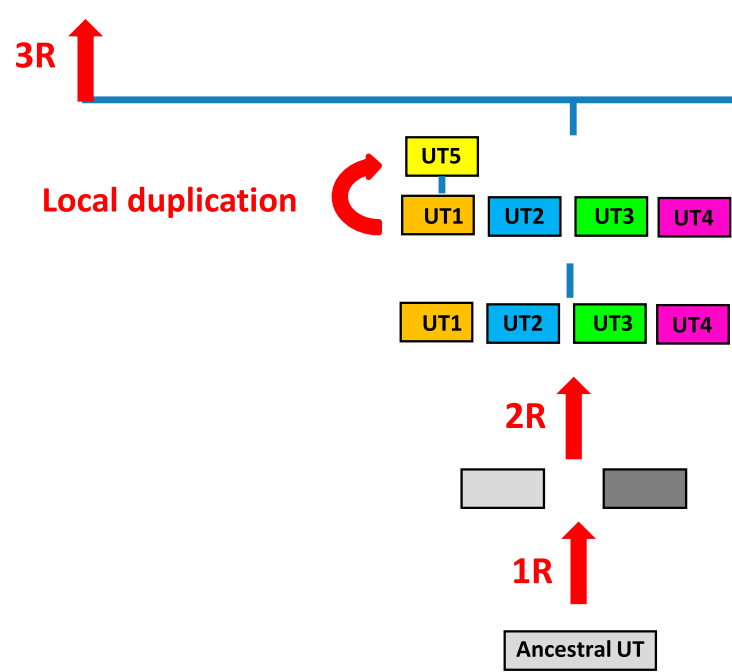

Fig. 13. A proposed evolutionary model for the UT gene family. The names of the different paralogous genes are given in the boxes. Crossed-out boxes represent lost genes. R, rounds of the whole-genome duplication. [Adapted from Tostivint et al. (2014).]

stimulates the release of norepinephrine in a concentration-dependent manner, and this effect is blocked by the UT antagonist UFP-803 (Ono et al., 2008). The UIIevoked norepinephrine release is also inhibited by the central-type benzodiazepine agonist midazolam (Kawaguchi et al., 2009), suggesting that the effect of UII on REM sleep may be mediated, at least in part, through interaction with the $\mathrm{GABA}_{\mathrm{A}}$ receptor. In addition, UII triggers the release of three other wakefulness-promoting neurotransmitters, i.e., dopamine, serotonin, and histamine (Ono et al., 2008).

2. Action on Food Intake and Energy Homeostasis. The UT gene is actively expressed in brain regions that are known to control feeding behavior, both in the hypothalamus, i.e., the arcuate nucleus and the

\section{Tetrapods}

Gallus gallus

Homo sapiens

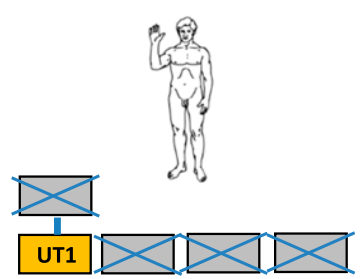


Concurrently, intracerebroventricular administration of UII stimulates the expression of the genes encoding the uncoupling proteins UCP1 and UCP3 in brown adipose tissue and causes an increase in sympathetic nerve activity (Yasuda et al., 2012). In unanesthetized sheep, intracerebroventricular infusion of UII causes a marked increase of plasma glucose (Watson and May, 2004; Hood et al., 2005). Collectively, these observations indicate that UII may act centrally to regulate food intake and energy expenditure, but the neuronal systems mediating these effects are still unknown.

In the marine snail Aplysia californica, the UII-related peptide (see section II.J.2) modifies the electrophysiological activity of neurons that play a role in satiety and/or aversive signaling (Romanova et al., 2012), supporting the view that the involvement of UII in the control of feeding behavior has been conserved during evolution from molluscs to rodents.

3. Action on Cardiovascular Activity. A high density of UT mRNA is present in magnocellular neurons of the paraventricular and supraoptic nuclei and in discrete regions of the medulla oblongata and pons that are involved in the control of the multisynaptic cardiovascular reflex arc, including the nucleus of the solitary tract, the dorsal nucleus of the vagus, the ambiguus nucleus, the gigantocellular and paragigantocellular reticular nuclei, the locus coeruleus, and the parabrachial nuclei (Jégou et al., 2006). This observation suggests that UII/URP may act centrally to regulate cardiovascular activity. In normotensive rats, intracerebroventricular administration of 1-10 nmol UII provokes an increase in arterial blood pressure and heart rate within 5 minutes after the onset of injection (Lin et al., 2003a) and the pressure action is exaggerated in hypertensive rat (Lin et al., 2003b). Similarly, in sheep, intracerebroventricular administration of UII $(0.2 \mathrm{nmol} / \mathrm{kg})$ provokes a prolonged increase in heart rate, cardiac output, and blood pressure (Watson et al., 2003; Hood et al., 2005). In rat, the nicotinic receptor antagonist pentolinium abrogates the pressor and tachycardic responses to intracerebroventricularly administered UII (Lin et al., 2003a), whereas in sheep, the $\beta$-adrenoreceptor blocker propranolol suppresses the cardiac responses to intracerebroventricularly injected UII (Hood et al., 2005). These findings indicate that the central cardiac actions of UII are mediated through cholinergic and/or adrenergic neuronal pathways. Intracerebroventricular injection of UII also causes a robust increase in cortical blood flow (Huitron-Resendiz et al., 2005; Chuquet et al., 2008). After induction of cerebral ischemia by occlusion of the right cerebral artery in rat, intracerebroventricular injection of UII induces a significant increase of hemispheric infarction volume, suggesting that UII exacerbates brain damage caused by an ischemic insult (Chuquet et al., 2008). Local administration of UII in discrete brain nuclei produces differential cardiovascular responses. For instance, microinjection of UII into the paraventricular or arcuate nucleus of the rat hypothalamus significantly increases arterial blood pressure and heart rate ( $\mathrm{Lu}$ et al., 2002). In contrast, microinjection of UII into the A1 (noradrenergic cells) area of the medulla oblongata induces a dose-related depressor and bradycardic response (Lu et al., 2002). In normotensive rats, pentolinium suppresses hypertension and tachycardia induced by intracerebroventricularly injected UII (Lin et al., 2003a), indicating that the central cardiovascular action of UII is mediated through activation of the sympathetic system. The fact that the hypertensive effect of UII is significantly greater in SHR than in WKY (Lin et al., 2003b) provides further evidence for a role of UII in the pathogenesis of hypertension. In unanesthetized trout and eel, intracerebroventricular injection of UII evokes an increase in arterial blood pressure and heart rate (Lancien et al., 2004; Nobata et al., 2011; Le Mével et al., 1996, 2008, 2012). In these two teleost fish species, the central vasopressor action of UII is mimicked by URPs, but the duration of the effect of URPs is shorter (Nobata et al., 2011; Le Mével et al., 2013).

4. Action on Locomotor Activity. The high expression of UII and URP mRNAs in motoneurons of the brainstem and spinal cord (Dun et al., 2001; Chartrel et al., 1996, 2004; Coulouarn et al., 1998, 1999, 2001; Pelletier et al., 2002, 2005; Dubessy et al., 2008) and the presence of UT mRNA and UT protein in various regions of the CNS implicated in the regulation of motor activity and arousal, such as the cortex, thalamus, amygdala, striatum, nucleus accumbens, motor nuclei of the brainstem, and spinal cord (Ames et al., 1999; Liu et al., 1999; Clark et al., 2001; Gartlon et al., 2001; Jégou et al., 2006; Bruzzone et al., 2010) strongly suggest that UII/URP may affect locomotor activity. Indeed, intracerebroventricular injection of UII in mouse $(10 \mathrm{nmol})$ and rat (5-15 nmol) induces a dosedependent increase of ambulatory movements (Gartlon et al., 2001; Clark et al., 2005; do Rego et al., 2005, 2008) (Fig. 14). In rat, UII excites mesopontine cholinergic neurons (Clark et al., 2005). In mouse cervical spinal synaptosomes, UII induces a concentration-dependent stimulation of acetylcholine release (Bruzzone et al., 2010). In frog, UII accelerates spontaneous transmitter release at motor nerve terminals (Brailoiu et al., 2003). These observations indicate that, in mammals and amphibians, UII may control motor functions through modulation of motoneuron activity both centrally within the spinal cord and peripherally at the neuromuscular junction. In unanesthetized trout, intracerebroventricular injection of UII or URPs (5-50 pmol) causes a longlasting increase in motor activity (Lancien et al., 2004; Le Mevel et al., 2013). Of note, the minimum effective doses of UII/URPs influencing locomotion in trout are 10 times lower than those necessary to affect respiratory or cardiovascular parameters (Lancien et al., 2004).

5. Action on Anxiety and Depression. The UT gene is expressed in brain regions involved in the control of 

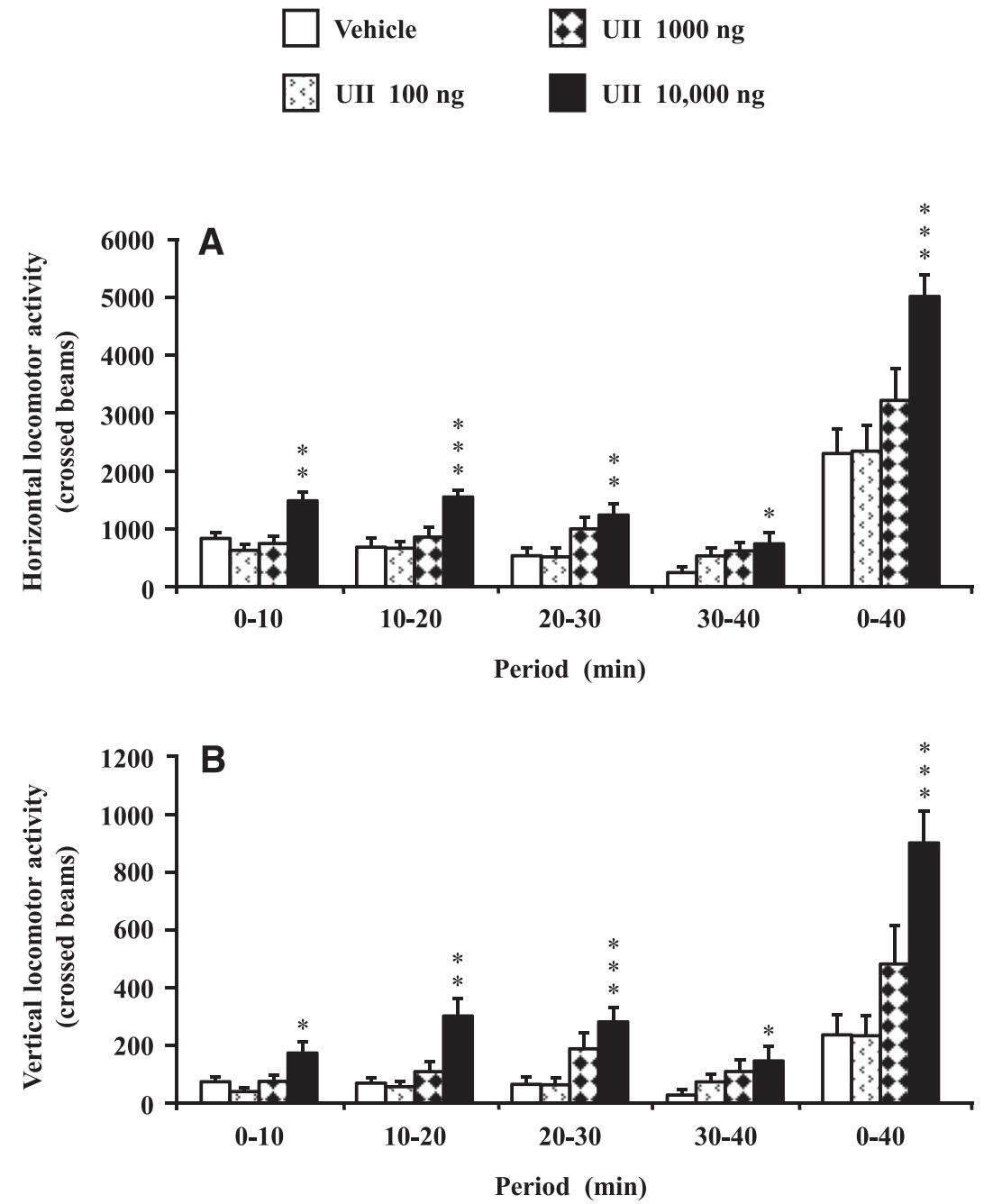

Fig. 14. Effect of UII on locomotor activity. Mice were given intracerebroventricular injections of vehicle or graded doses of UII (10-10,000 ng/mouse) and the horizontal (A) and vertical (B) components of motor activity were measured for four consecutive periods of 10 minutes. Mean \pm S.E.M. of data from 14 mice per group. Dunnett's $t$ test $\left(* P<0.005\right.$; ${ }^{* *} P<0.01$; $\left.* * * P<0.001\right)$. [Reprinted from do Rego et al. (2005). Used with permission.]

motivation, vigilance, and arousal such as the bed nucleus of the stria terminalis, the locus coeruleus, the ventral tegmental area, the laterodorsal tegmental nucleus, and the nucleus ambiguus (Clark et al., 2001; Gartlon et al., 2001; Jégou et al., 2006; Hunt et al., 2010). Intracerebroventricular injection of 15 pmol-3 nmol UII in mice causes anxiogenic-like effects as assessed in the black-and-white, hole-board, and elevated plus maze tests (Matsumoto et al., 2004; do Rego et al., 2005, 2008) (Fig. 15). The anxiogenic action of UII is attenuated by central-type benzodiazepine receptor antagonists (Kawaguchi et al., 2009). UT mRNA and UII binding sites also occur in brain regions involved in the pathophysiology of mood disorders such as the limbic system (i.e., cerebral cortex, nucleus accumbens, amygdala, hippocampus), thalamic nuclei, and striatum (Gartlon et al., 2001; Matsushita et al., 2001; Totsune et al., 2001; Jégou et al., 2006). Intracerebroventricular injection of UII in mice causes an increase of the immobilization time in the tail suspension test and the forced swimming test (do Rego et al., 2005), two classic tests used to assess depressive-like behavior. Because otherwise UII induces hyperlocomotion in mice (do Rego et al., 2005), the prolonged immobility time observed in the forced swimming and tail suspension tests cannot be accounted for by nonspecific effects on locomotor activity.

6. Action on Ventilation. In trout, intracerebroventricular injection of $0.5 \mathrm{nmol}$ UII or URP1 induces a strong increase in the ventilation amplitude and ventilation frequency (Le Mével et al., 2008, 2013).

7. Neuroendocrine Actions. The expression of UT mRNA in hypothalamic nuclei, notably in the arcuate nucleus, the supraoptic nucleus, the ventromedial hypothalamic nucleus, the magnocellular aspect of the paraventricular nucleus, and the median preoptic nucleus (Jégou et al., 2006) provides the anatomic substrate for neuroendocrine actions of UII. In support of this hypothesis, intracerebroventricular administration of UII $(0.2 \mathrm{nmol} / \mathrm{kg})$ in unanesthetized ewes provokes a marked increase in plasma adrenocorticotropin (ACTH) and adrenaline levels (Watson et al., 

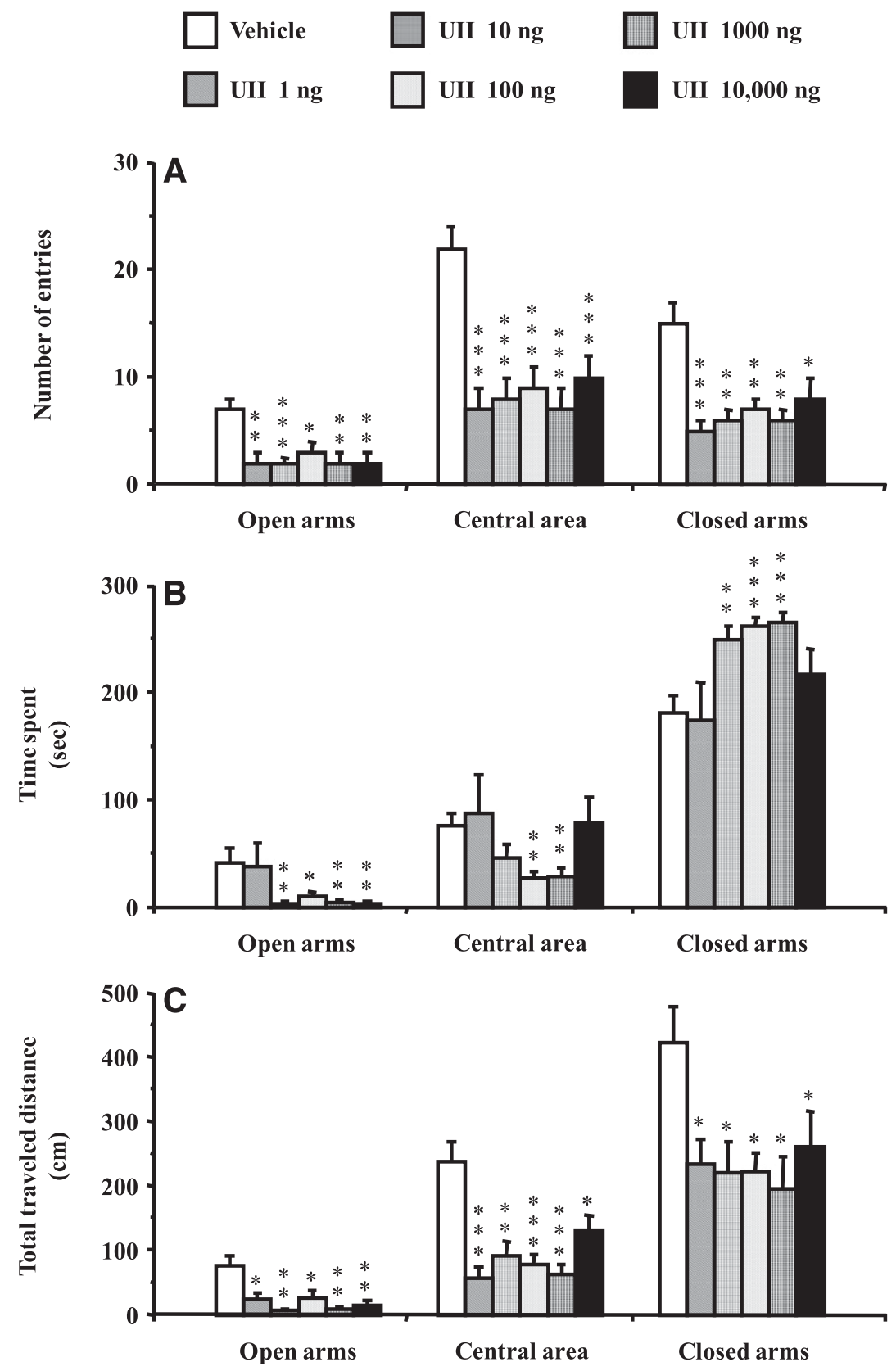

Fig. 15. Effect of UII on anxiety-like behavior. Mice were given intracerebroventricular injections of vehicle or graded doses of UII (1-10,000 $\mathrm{ng} /$ mouse) and were placed at the center of an elevated plus-maze 10 minutes later. The number of entries (A), the time spent (B), and the distance traveled (C) in the open arms, in the central area, and in the closed arms of the maze were measured for 5 minutes. Mean \pm S.E.M. of data from 10 to 20 mice per group. Dunnett's $t$ test $(* P<0.05 ; * * P<0.01 ; * * P<0.001)$. [Reprinted from do Rego et al. (2005). Used with permission.]

2003). In contrast, intravenous injection of UII (2-40 $\mathrm{nmol} / \mathrm{kg}$ ) does not significantly affect ACTH secretion (Watson et al., 2003), indicating that UII acts centrally to stimulate ACTH secretion. Similarly, in rat, intracerebroventricular injection of UII causes an increase of plasma cortisol level (Watson et al., 2008). The anxiogenic-like activity of UII (do Rego et al., 2008) is consistent with a central effect of UII on the hypothalamo-pituitary-adrenal axis. The expression of UT mRNA in parvocellular neurons of the paraventricular nucleus (Jégou et al., 2006) suggests that UII-induced ACTH secretion may be ascribed to a direct stimulatory action on corticotropin-releasing hormone-producing neurons. Consistent with this notion, intracerebroventricular injected UII causes an increase of Fos immunoreactivity in the paraventricular nucleus that contains a dense population of corticotropin-releasing hormone neurons (Watson et al., 2008).

In fish, UII exerts neuroendocrine actions at different levels of the hypothalamo-pituitary complex. Thus, at the hypothalamic level, UII stimulates mRNA expression of growth hormone-releasing hormone and inhibits mRNA expression of the two isoforms of somatostatin, SS1 and SS2, in the orange-spotted grouper 
(Sun et al., 2014). At the pituitary level, UII inhibits prolactin secretion in tilapia (Grau et al., 1982; Rivas et al., 1986) and stimulates growth hormone mRNA expression in grouper (Sun et al., 2014).

\section{B. Effect of Urotensin II / Urotensin II-Related Peptide on the Cardiovascular System}

The most studied aspect of UII is its vascular activity (Camarda et al., 2002b; Kompa et al., 2004; Barrette and Schwertani, 2012; Zemanciková and Török, 2013). Although previously thought to be endothelin-1, UII has been demonstrated to be the most potent physiologic vasoconstrictor peptide (Ames et al., 1999). Both endothelium-dependent vasorelaxation and endotheliumindependent vasoconstriction mediated by UII have been demonstrated in rat-isolated aorta (Gibson, 1987). Despite being characterized as the most potent isolated vasoconstrictor, the constrictive effects of UII are variable and appear to be dependent on the vascular bed (Itoh et al., 1987, 1988) and the species from which it is isolated (Douglas et al., 2000b). In addition to its potent vasoactive effects, UII has several other crucial roles in cardiovascular physiology and pathophysiology, many of which have only begun to be identified in recent years. Under normal physiologic conditions, UII/UT binding is integral in the control of vascular tone, blood pressure, and maintaining blood glucose levels (Douglas and Ohlstein, 2000; Douglas et al., 2000b; Loirand et al., 2008). The physiologic roles of UII also include mediating the release of endothelialderived vasodilators, such as NO, and thus controlling the contraction and relaxation of vascular smooth muscle cells (Itoh et al., 1987; Gardiner et al., 2001; Stirrat et al., 2001). The pathologic roles for the UT receptor system are still emerging. There is evidence implicating this system in conditions such as congestive heart failure, atherosclerosis and coronary artery disease, and both systemic and pulmonary hypertension, cirrhosis, and chronic renal failure, among others. There is also evidence suggesting that positive and negative inotropy, arrhythmias, cardiomyocyte hypertrophy, vascular smooth muscle cell proliferation, extracellular matrix production, and hyperpermeability of endothelial cells are among some of the other cardiovascular effects of the urotensinergic system in pathophysiological conditions (Russell, 2004). This section will provide an overview of what is currently known about the physiologic and pathophysiological roles of UII and URP in the cardiovascular system, with particular emphasis on the implications in cardiovascular disease.

1. Remodeling of Vascular Tissue. UII promotes the formation of the extracellular matrix and proliferation of various cardiovascular cell types (Matsushita et al., 2001, 2003; Sauzeau et al., 2001; Watanabe et al., 2001b; Papadopoulos et al., 2008; Albertin et al., 2009; Guidolin et al., 2010; Dai et al., 2011; Xu et al., 2012). For instance, UII stimulates proliferation of vascular smooth muscle cells via epidermal growth factor receptor transactivation (Tsai et al., 2009). The effect of UII on smooth muscle cells growth is abrogated by the Rho-kinase inhibitor Y-27632 and by the membranepermeant RhoA inhibitor TAT-C3 (Sauzeau et al., 2001), indicating that the growth-stimulating effect of UII is mediated through activation of the small GTPase RhoA and its downstream effector Rho-kinase.

UII also promotes proliferation of bone marrowderived endothelial progenitor cells (Xu et al., 2012). In both rat and human endothelial cells, UII exerts a proangiogenic action in vitro that is comparable to that of the reference angiogenic cytokine fibroblast growth factor-2 (Spinazzi et al., 2006; Albertin et al., 2009). In human umbilical vein endothelial cells, UII increases mRNA and protein expression of the proangiogenic factors vascular endothelial growth factor, endothelin-1, and adrenomedullin (Albertin et al., 2011).

In neonatal rat cardiac fibroblasts, UII increases the expression of mRNAs for procollagens type I and III and fibronectin (Tzanidis et al., 2003). UII also stimulates proliferation of neonatal cardiac fibroblasts and this effect is suppressed by the UT antagonist SB-611812 (Bousette et al., 2006b). In these cells, UII promotes transforming growth factor- $\beta 1$ (TGF- $\beta 1$ ) expression and UII-induced collagen synthesis is blocked by a TGF- $\beta 1$ neutralizing antibody (Dai et al., 2007), indicating that TGF- $\beta 1$ mediates the profibrotic effects of UII. Altogether, these observations give credence to the notion that UII plays a role in tissue remodeling associated with cardiovascular diseases.

2. Regulation of Vascular Tone. Initial studies of UII demonstrated a potent vasoconstrictor activity on isolated arteries from fish, birds, and mammals (Muramatsu and Kobayashi, 1979; Gibson et al., 1986; Bottrill et al., 2000) (Fig. 16). Similarly, UII causes vasoconstriction on human coronary, mammary, and radial arteries with their endothelia removed (Maguire et al., 2000; Paysant et al., 2001). In an in vivo study in human subjects, Böhm and Pernow (2002) observed potent vasoconstrictor activity upon local administration of UII. However, a great amount of heterogeneity of vasoactive responses to UII has been observed among vascular beds from different species, as well as different regions within the same species (Medakovic et al., 1975; Douglas et al., 2000b; Camarda et al., 2002b). Potent vasodilation in response to UII has been frequently observed (Gibson, 1987; Stirrat et al., 2001). Interestingly, in a review by Desai et al. (2008) it is suggested that the vasoactivity of UII is dependent on blood vessel diameter: smaller arteries of $0.07 \mathrm{~mm}$ in diameter, whose responses are thought to be more endothelium mediated, vasodilate in response to UII, whereas arteries $0.07-0.25 \mathrm{~mm}$ in diameter show a more attenuated response and large vessels with a $0.25 \mathrm{~mm}$ diameter, whose responses are thought to be more smooth muscle mediated, show no response (MacLean et al., 2000; 
A (a)

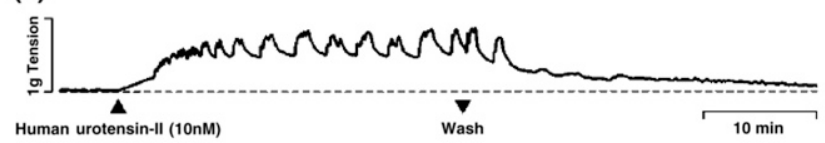

(b)

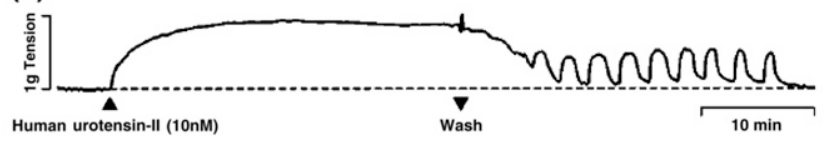

(c)
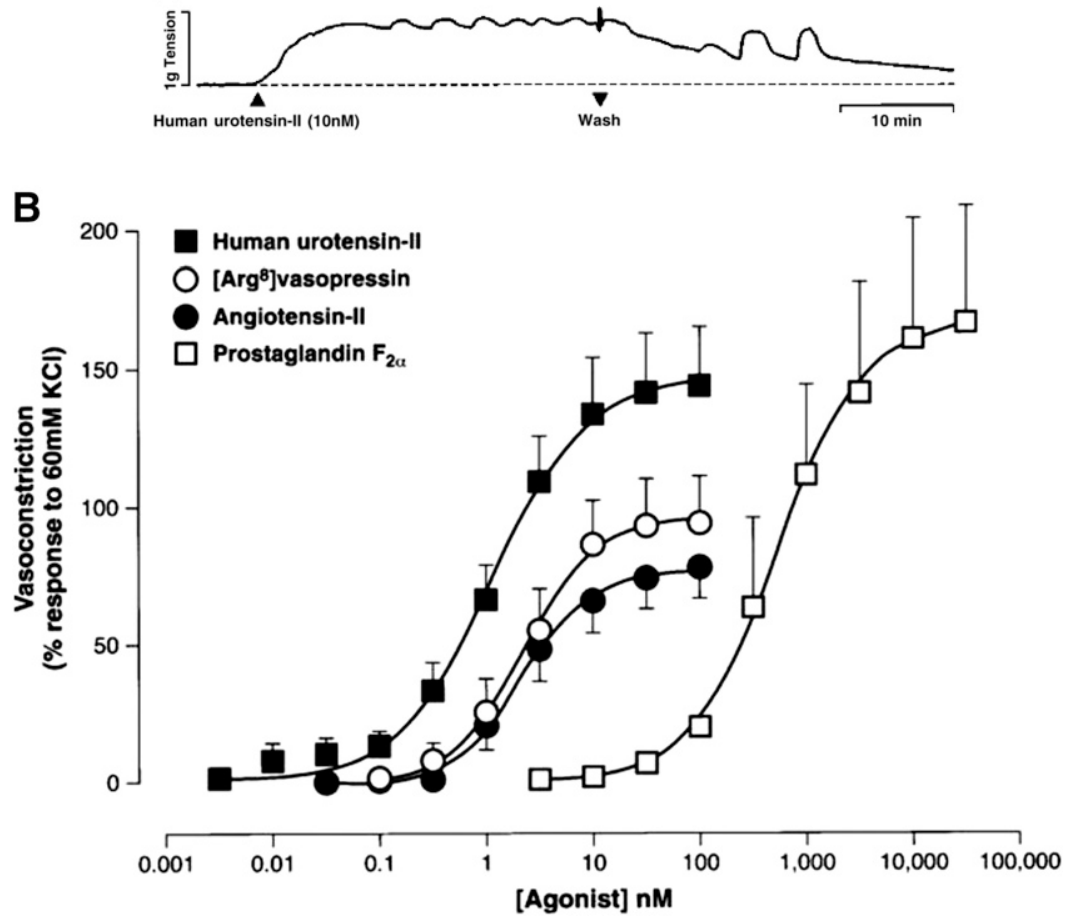

Fig. 16. Effect of UII and other vasoactive agents on isolated descending rat aorta. Human UII provokes a concentration-dependent contraction of aortic rings. (A) Representative experimental traces illustrating the contractile responses of aortic rings from three separate rats upon exposure to $10 \mathrm{nM}$ UII. Contraction was sustained and tone did not return to basal levels for $>30$ minutes after removal of peptide from the organ bath. Also evident are the cyclical changes in tone frequency observed upon (a) addition or (b) removal of UII to or from [or both (c)] the organ bath. (B) Human UII was both efficacious and potent compared with [ $\left.\mathrm{Arg}^{8}\right]$ vasopressin, angiotensin II, and prostaglandin $\mathrm{PGF}_{2 \alpha}$. [Reprinted from Douglas et al. (2000). Used with permission.]

Stirrat et al., 2001; Bennett et al., 2004). However, another study reports that UII has no vasoconstrictor action in human arteries and veins of varying calibers from different vascular beds (Hillier et al., 2001). The absence of effect of UII on forearm resistance vessels has been confirmed in vivo (Wilkinson et al., 2002; Cheriyan et al., 2009). Properties of the signal transduction cascade of the UT receptor system could be contributing to the differential vasoactive effects of UII (see section III.B). When the UII peptide binds UT in vascular smooth muscle cells, this leads to dissociation of the $\alpha \beta \gamma-\mathrm{G}$ protein complex and activation of $\mathrm{G} \alpha_{\mathrm{q} / 11}$. The activated $\mathrm{G} \alpha_{\mathrm{q} / 11}$ causes the PLC-mediated hydrolysis of phosphatidylinositol-4-5 bisphosphate into $\mathrm{IP}_{3}$ and diacylglycerol. $\mathrm{IP}_{3}$ can then bind to its receptors on endoplasmic/sarcoplasmic reticula, causing the increase in intracellular $\mathrm{Ca}^{2+}$ underlying contraction (see section III.B). In the endothelium-mediated vasodilation caused by UII, UT activation on the endothelium leads to the release of $\mathrm{NO}$ and endothelium-derived hyperpolarizing factor, causing vasodilation (McDonald et al., 2007). Differences in expression of UT in vessels of different sizes and locations may also contribute to the variability in response to UII (Onan et al., 2004a). Interestingly, through its two receptor subtypes, endothelin-1 also mediates endothelium-independent vasoconstriction and endothelium-dependent vasoconstriction (Maguire et al., 2000). Despite being the most potent vasoconstrictor, UII is often described as having the most variable responses (Russell and Molenaar, 2004) and the least efficacy compared with other vasoconstrictors such as endothelin-1, angiotensin II, and noradrenaline (Douglas et al., 2000a; Maguire et al., 2000; Camarda et al., 2002b). Finally, URP has been demonstrated to be a less potent vasoconstrictor (Chatenet et al., 2004) and vasodilator (Prosser et al., 2006) than UII in rat, despite having the same binding affinity to the UT receptor.

The action of UII on vascular tone has also been explored in submammalian vertebrates. In the bullfrog 
Rana catesbeiana, now renamed Lithobates catesbeianus, UII induces a concentration-dependent contraction of vascular rings from the proximal and distal regions of the left and right systemic arches (Yano et al., 1995). In vivo, UII causes a marked reduction of cardiac output that is not accompanied by a fall in arterial blood pressure, confirming that UII increases systemic vascular resistance (Yano et al., 1995; Conlon et al., 1996). In vascular rings prepared from trout celiacomesenteric and branchial arteries, UII produces robust contractions (Le Mével et al., 1996). In unanesthetized trout, intra-arterial administration of UII provokes a dose-dependent increase in arterial blood pressure associated with a decrease in heart rate (Le Mével et al., 1996). Collectively, these data indicate that, in amphibians as in fish, the pressor effects of UII are mediated predominantly by an increase in systemic vascular resistance.

3. Regulation of Myocardial Contractility. The direct effects of UII on human myocardial contractility have been studied in strips of myocardium isolated from human patients that were stimulated to contract at $60 \mathrm{beats} / \mathrm{min}$. Application of UII increases the contractile force in the right atrium and right ventricle, identifying UII as the most potent inotropic agent to date, surpassing endothelin-1, serotonin, and noradrenaline (Russell et al., 2001). UII displays similar contractile activity on myocardial strips isolated from rats (Gong et al., 2004). In vivo studies in cynomolgus monkeys and anesthetized rats have shown that acute systemic infusion of UII mediates a drop in mean arterial blood pressure, which is contradictory to the supposed positive inotropic effects of UII (Ames et al., 1999; Hassan et al., 2005). A potential explanation for the observed variability in contractile responses to UII administration is that the drop in blood pressure and contractility could be due to coronary artery constriction caused by UII (Desai et al., 2008).

4. Role in Hypertension. The status of UII as the most potent endogenous vasoconstrictor suggests a potential role in essential hypertension (Krum and Kemp, 2007; Desai et al., 2008). Hypertensive patients were found to have elevated levels of UII compared with normotensive controls in a study by Cheung et al. (2004), where UII was directly related to systolic blood pressure. Hypertensive survivors of myocardial infarction also have significantly elevated plasma UII levels after exercise compared with similar patients without hypertension (Rdzanek et al., 2006). A study by Thompson et al. (2003) was first to measure UII concentrations in CSF and found CSF UII levels to be lower than those of plasma and, remarkably, found a significant positive correlation between CSF UII concentrations and mean arterial blood pressure. After demonstrating that URP and UT expression are upregulated in the kidneys of rats with chronic renal failure or hypertension (Mori et al., 2009), Hirose et al. (2009) went on to examine the gene expression of UII, URP, and UT in the heart and aorta of hypertensive rats and found an increased expression of the entire urotensinergic system (Hirose et al., 2009). A development in the study of the urotensinergic system in hypertension is the study by Behm et al. (2004a) that reports a hypertensive cat model to be useful in monitoring classic systemic hypertensive responses and the effects of UII administration and UT antagonism on these parameters.

Given the accumulating evidence for a role of the urotensinergic system in systemic hypertension, studies have emerged on the roles in pulmonary hypertension. On the one hand, human UII is a potent vasoconstrictor in pulmonary arteries isolated from hypoxic rats, and this response increases at the onset of pulmonary hypertension (MacLean et al., 2000). On the other hand, pulmonary arteries isolated from humans did not respond to UII (MacLean et al., 2000; Stirrat et al., 2001). Although plasma and lung concentrations of UII are unchanged in hypoxic rats, there was an observed pulmonary pressure-induced increase in UT expression in the right ventricle (Zhang et al., 2002). In another rat model of pulmonary hypertension, UII immunoreactive staining was upregulated in endothelial cells and smooth muscle cells of small pulmonary arteries (Qi et al., 2004). To determine a more direct role for UT in pulmonary hypertension, a recent study by Onat et al. (2013) used the UT antagonist palosuran in a rat model for pulmonary hypertension and observed significant decreases in mean pulmonary arterial pressure, right ventricular hypertrophy, and right ventricular myocardial infarction. There are limitations to this study, because the palosuran inhibitor also decreased endothelin-1 and TGF- $\beta$ levels. More selective inhibitors and further research will continue to provide insight into the direct roles of the urotensinergic system in pulmonary hypertension and other cardiovascular pathologies.

5. Role in Atherosclerosis. Atherosclerosis is a leading cause of death in Western societies and is a major contributing factor to several cardiovascular diseases. Thus determining the role of the urotensinergic system in atherosclerosis is a critical area of study (Pakala, 2008). Bousette et al. (2004) were first to demonstrate that atherosclerotic lesions of the human carotid arteries and aorta have increased expression of UII and UT compared with healthy vessels. More specifically, using immunohistochemistry, strong UII immunoreactivity was observed in endothelial, smooth muscle, and inflammatory cells, particularly in the intima, in both carotid and aortic plaques. Using quantitative real time RT-PCR analysis, they demonstrated that UII production mainly occurs in leukocytes, whereas UT expression is mediated primarily by monocytes and macrophages (Bousette et al., 2004). This suggests that inflammatory cells play an important role in the UT-dependent atherosclerotic function. In a later study, the same group found elevated levels of UII mRNA and protein in atherosclerotic coronary arteries 
compared with normal coronary arteries, with UII expression being highest in endothelial cells in areas with inflammatory or fibrofatty lesions (Hassan et al., 2005). Similarly, in another study, UII expression was reported to be localized to areas of macrophage infiltration in atherosclerotic coronary arteries (Maguire et al., 2004). Elevated UII levels have also been observed in human plasma of patients with atherosclerosis (Heringlake et al., 2004; Lapp et al., 2004; Loirand et al., 2008). UII alone and synergistically with oxidized low-density lipoprotein (LDL) and serotonin also enhances vascular smooth muscle cell proliferation, a key process for the intimal thickening stage of atherosclerosis (Watanabe et al., 2001a,b). This is of great clinical significance, because oxidized LDL is a major contributing factor to atherosclerotic plaque formation. Furthermore, UII has also been linked to increased foam cell formation in atherosclerosis (Watanabe et al., 2005). Acyl-coenzyme A:cholesterol acyltransferase-1 (ACAT-1), is a key enzyme in cholesterol homeostasis that functions to convert intracellular free cholesterol into cholesterol ester for storage in lipid droplets. ACAT-1 is important in the formation of foam cells, which form early in atherosclerotic lesions by macrophages continuously taking up oxidized LDL via scavenger receptors. The accumulation of these macrophage-derived foam cells contributes to the necrotic fibrofatty cores seen in atherosclerotic lesions (Bousette and Giaid, 2006). The stimulating effects of UII on foam cell formation seem to involve various intracellular signaling pathways, because they were inhibited by selective UT antagonist urantide, protein kinase $\mathrm{C}$ inhibitor rottlerin, MEK inhibitor PD98059, Rho kinase inhibitor Y27632, c-Src protein tyrosine kinase inhibitor PP2, and G protein inactivator GDP- $\beta$-S (Watanabe et al., 2005). In recent years, significant evidence has begun to emerge about the roles of the urotensinergic system in atherosclerosis by the use of genetic inhibition and the development of new pharmacological inhibitors. A recent study by You et al. (2012) demonstrates that UII gene deletion in atherosclerotic mice, as well as the use of the UT antagonist SB657510, ameliorates many features of atherosclerosis, including reducing serum cytokines and adipokines, improving aortic atherosclerosis, reducing weight gain and fat deposition, decreasing blood pressure, and improving glucose tolerance. After observing increased UII expression in diabetes-associated atherosclerotic mice and humans, Watson et al. (2013) demonstrated that the same UT antagonist, SB657510, attenuated diabetes-associated plaque development. Interestingly, Bousette et al. (2009) observed that genetic deletion of UT on ApoE knockout mice (a model for atherosclerosis) increased atherosclerosis as well as serum insulin and lipids in these mice. It is suggested that UT deletion in these mice downregulates ACAT-1 expression, ultimately decreasing receptor-mediated lipoprotein uptake in the liver. This increases hyperlipidemia, decreases hepatic steatosis and, along with UT-KO-associated hypertension, is thought to contribute to the increase in atherosclerosis seen in these mice. The further development of pharmacological agents capable of interfering with the urotensinergic system and their use in animal models will contribute to a better understanding of the roles of UII and URP in atherosclerosis as well as the development of novel therapeutic approaches.

6. Role in Heart Failure. Under physiologic conditions, UII expression is strongest in the CNS but is significantly increased in the heart in cardiovascular disease states (Bousette and Giaid, 2006; Khan et al., 2007). Both UII and UT expression increase significantly in patients with end-stage congestive heart failure (CHF), particularly in cardiomyocytes and to a lesser extent in vascular smooth muscle cells, endothelial cells, and inflammatory cells (Douglas et al., 2002). There is a correlation between UII levels and cardiac dysfunction, because the previously mentioned study observed an inverse relationship between UII levels and ejection fraction (Douglas et al., 2002). This increase in UII seen in cardiac dysfunction is supported by several studies demonstrating elevated plasma UII levels in patients with $\mathrm{CHF}$ (Ng et al., 2002; Richards et al., 2002; Russell et al., 2003) or acute myocardial infarction (Khan et al., 2007). In studies where disease data were separated by etiology, UII levels in plasma increased similarly in both ischemic and nonischemic CHF (Douglas et al., 2002; Russell et al., 2003). The inverse relationship between UII and ejection fraction in CHF patients is supported by additional studies by Gruson et al. (2006). Conversely, there have also been studies showing no difference in plasma UII in CHF patients compared with healthy controls (Dschietzig et al., 2002; Jołda-Mydłowska et al., 2006), potentially due to differences in patient populations (Bousette and Giaid, 2006). Recently, Jani et al. (2013) developed a solid phase extraction technique such that both plasma UII and URP can be differentially isolated and assayed separately. Given the structural similarity between UII and URP, this ensures the specificity of both measurements. Using this newly developed technique, Jani et al. (2013) observed significant increases in both UII and URP plasma levels in patients with acute heart failure compared with healthy controls, suggesting roles for the entire urotensinergic system in acute heart failure. This is supported by a study by Nakayama et al. (2008) that demonstrates an increase in gene expression of URP, UII, and UT in the hearts of rats with $\mathrm{CHF}$.

Although there is accumulating evidence associating plasma UII levels with cardiac dysfunction (Totsune et al., 2001, 2004), current studies aim to elucidate functional roles for the urotensinergic system in heart failure. In a study by Lim et al. (2004), a noninvasive iontophoresis technique was used to examine the 
effects of UII on cutaneous blood flow in healthy and CHF patients. Although UII administration caused vasodilation in healthy patients, in patients with $\mathrm{CHF}$, UII caused vasoconstriction, indicated by reduced blood flow in skin microcirculation. Because endothelial dysfunction is a common feature of CHF (Katz, 1997) and several studies have shown UII to have differential endothelium-dependent and independent vasoactive effects (Gibson, 1987; Lim et al., 2004), this suggests that the functional state of the endothelium in $\mathrm{CHF}$ is a critical consideration in determining the effect of the urotensinergic system in CHF. Using selective UT receptor antagonist SB-611812 in rats after coronary artery ligation, Bousette et al. (2006a) demonstrated significantly improved cardiac dysfunction. Specifically, blocking UT led to decreases in left ventricular end diastolic pressure, lung edema, right ventricular systolic pressure, central venous pressure, cardiomyocyte hypertrophy, and ventricular dilatation. A subsequent study in a rat model of ischemic CHF showed that SB-611812 administration attenuates cardiac remodeling (Bousette et al., 2006b). SB-611812-mediated UT blockage decreases myocardial fibrillar collagen deposition and leads to a reduced ratio of collagen type 1 to type III (Bousette et al., 2006b), which has been previously linked to decreased diastolic dysfunction (Nishikawa et al., 2001). This is consistent with previous work demonstrating the fibrotic effects of UII in vitro and in vivo. Tzanidis et al. (2003) demonstrated that incubation of cardiac fibroblasts with UII leads to increased expression of fibronectin, type I and type III procollagen mRNAs, and significant collagen peptide synthesis upon overexpression of recombinant UT. This suggests that the fibrotic role of UII in myocardial remodeling would be enhanced in diseased states where increased UT has been repeatedly demonstrated (Russell, 2004). There is an increasing amount of evidence implicating UII in cardiac hypertrophy. Overexpression of UII and UT in rat cardiomyocytes increases cardiomyocyte growth (Zou et al., 2001), enhances sarcomere organization (Zou et al., 2001) and produces a hypertrophic phenotype (Tzanidis et al., 2003; Onan et al., 2004b). In addition to demonstrating UII-mediated hypertrophic effects, Johns et al. (2004) found that UII-stimulated cardiac myocytes secreted inflammatory cytokine IL-6, suggesting a potential proinflammatory role for UII in heart failure.

\section{Effect of Urotensin II / Urotensin II-Related Peptide on the Urogenital Tract}

The fact that UII is produced and released by human (Nothacker et al., 1999; Shenouda et al., 2002; Matsushita et al., 2003) and monkey kidney (Elshourbagy et al., 2002), the expression of UT mRNA in the rat kidney (Song et al., 2006a) and the presence of [ $\left.{ }^{125} \mathrm{I}\right]$ UII binding sites in the human (Maguire et al., 2000), cat (Aiyar et al., 2005), and rat kidney (Disa et al., 2006) indicate that the urotensinergic system may be implicated in physiologic regulation of renal function and/or renal pathology. Indeed, UII infusion causes a marked reduction in glomerular filtration rate, urine flow, and sodium excretion rate (Abdel-Razik et al., 2008). UII immunoreactivity is present in the glomerular basement membrane, glomerular mesangium, and Bowman capsule of children with membranoproliferative glomerulonephritis and membranous glomerulonephritis. In the kidney of diabetic patients, UII and UT gene expression are markedly increased (Langham et al., 2004). UII and UT mRNA levels are also significantly elevated in the kidney medulla of SHR, and the effects of UII on renal blood flow and glomerular filtration rate are stronger in SHR than in WKY (Abdel-Razik et al., 2008), supporting a role for UII in renal pathophysiology.

The URP gene is overexpressed in a mouse model of obstructive nephropathy called "megabladder," which results from lack of bladder smooth muscle differentiation (Singh et al., 2008), suggesting that URP may play a critical role in bladder smooth muscle development. In frog, UII produces a concentration-dependent increase in the frequency of contraction of bladder strips (Yano et al., 1994). Similarly, in trout, UII induces a spasmosgenic action on the urinary bladder (Lederis, 1970).

The UII gene is expressed in the human corpus cavernosum (HCC), and UT is present in endothelial cells of HCC (d'Emmanuele di Villa Bianca et al., 2010). In rat, intracavernous injection of UII causes an increase in intracavernous pressure without affecting systemic blood pressure (d'Emmanuele di Villa Bianca et al., 2010). In HCC tissue, UII causes an endotheliumdependent relaxation involving the NO pathway (Bianca et al., 2012). These observations suggest that the UII/UT system may represent a novel therapeutic target to treat erectile dysfunction.

\section{Effect of Urotensin II / Urotensin II-Related Peptide on the Gastrointestinal Tract}

The genes encoding UII and/or URP mRNAs are expressed in the human (Coulouarn et al., 1998; Sugo et al., 2003; Ong et al., 2005), rat (Sugo et al., 2003), and mouse intestine (Dubessy et al., 2008), and the UT gene is expressed in the mouse intestine and colon (Elshourbagy et al., 2002). UII provokes concentration-dependent contractions of guinea pig ileal segments via activation of ganglionic cholinergic neurons (Horie et al., 2003). The contractile response is blocked by cyclooxygenase and phospholipase $\mathrm{A}_{2}$ inhibitors (Horie et al., 2005), indicating that the effect of UII on myenteric neurons is mediated through prostaglandin biosynthesis. Moreover, UII potently relaxes the mouse anococcygeus muscle (Gibson et al., 1984), suggesting that UII may play a role in the control of defecation.

In isolated bullfrog longitudinal ileal strips, UII provokes a concentration-dependent increase in the 
frequency and strength of contractions (Yano et al., 1994). Pretreatment of the tissues with indomethacin significantly reduces the response to UII (Yano et al., 1994), indicating that prostaglandins mediate the spasmogenic action of UII in the frog ileum. The ability of UII to induce contractions of the fish hindgut has been exploited to set up bioassays that have been used successfully to monitor chromatographic separation of fish UII (Zelnik and Lederis, 1973; Chan et al., 1978; Pearson et al., 1980). Thus, purified UII fractions from Catostomus commersonii (Zelnik and Lederis, 1973) or Gillichthys mirabilis urophysial extracts (Chan et al., 1978) induce contractions of trout rectal strips in a concentration-dependent manner.

In addition to its spasmogenic action, UII stimulates the transport of sodium and chloride ions across the goby posterior intestinal epithelium (Loretz, 1990; Loretz et al., 1983, 1985), lowers $\left[\mathrm{Ca}^{2+}\right]_{\mathrm{i}}$ in isolated goby enterocytes (Loretz and Assad, 1986), and increases water absorption in intestinal sacs from seawater-adapted tilapia (Mainoya and Bern, 1982). Electrophysiological studies indicate that UII exerts a dual effect on the isolated posterior intestine of freshwater-adapted European eel Anguilla anguilla: UII reduces short-circuit current and transepithelial potential difference at concentrations ranging from 10 to $100 \mathrm{nM}$ and increases these parameters at a concentration of $500 \mathrm{nM}$ (Baldisserotto and Mimura, 1997). Altogether, these observations substantiate a role of UII in osmoregulation in fish.

\section{E. Effect of Urotensin II / Urotensin II-Related Peptide on the Pancreas}

The UT gene is expressed in the human (Ames et al., 1999; Douglas and Ohlstein, 2000), monkey, and mouse pancreas (Elshourbagy et al., 2002). The UII gene is also expressed in the human and rat pancreas (Coulouarn et al., 1998; Ames et al., 1999; Sugo et al., 2003), and the evidence of the presence of the UII peptide has been found in a rat pancreas extract by reversed-phase HPLC analysis combined with radioimmunoassay detection (Silvestre et al., 2004), suggesting that UII may control pancreatic activity. The effect of UII on the endocrine pancreas has been studied using an in situ perfused rat pancreas model (Silvestre et al., 1986). It was first observed that synthetic frog UII, at doses of 10 and $100 \mathrm{nM}$, significantly reduces glucose-evoked insulin release but does not affect glucagon and somatostatin secretion (Silvestre et al., 2001). Frog UII also inhibits the insulin response to arginine (Silvestre et al., 2001). It was subsequently shown that rat UII provokes a concentration-dependent inhibition of glucose-induced insulin secretion with an $\mathrm{IC}_{50}$ of $0.12 \mathrm{nM}$ (Silvestre et al., 2004, Liu and Zhu, 2010). Rat UII also attenuates insulin secretion elicited by various secretagogues that act on pancreatic $\beta$-cells through diverse signaling pathways (Silvestre et al., 2004, 2009). Thus, UII inhibits the insulin response to the cholinergic agonist carbachol that activates polyphosphoinositide turnover (Gilon and Henquin, 2001), glucagon-like peptide-1 that stimulates the adenylyl cyclase/cyclic AMP pathway (Delmeire et al., 2003), the dihydropyridine BAY K 8644 that induces $\mathrm{Ca}^{2+}$ influx through L-type $\mathrm{Ca}^{2+}$ channels (Hess et al., 1984), and the sulfonylurea tolbutamide that closes ATP-dependent $\mathrm{K}^{+}$channels (Henquin et al., 1992). Consistent with these observations, it was previously reported that the insulinostatic effect of somatostatin could be ascribed both to decreased formation of cyclic adenosine monophosphate (Sharp, 1996) and inhibition of the intracellular $\mathrm{Ca}^{2+}$ response to various insulin secretagogues (Nilsson et al., 1989). The inhibitory effect of UII on glucose-induced insulin secretion is blocked by the UT antagonists palosuran and urantide but not by a somatostatin antagonist (Marco et al., 2008). Reciprocally, palosuran does not reverse the insulinostatic effect of somatostatin (Marco et al., 2008). Interestingly, both palosuran and urantide potentiate glucose-evoked insulin release, indicating that endogenous UII exerts a tonic inhibitory action upon $\beta$-cell secretory activity (Marco et al., 2008).

Elevated UII levels have been detected in the plasma of diabetic patients (Totsune et al., 2003, 2004; Krum and Gilbert, 2003; Suguro et al., 2008), particularly in individuals presenting with metabolic syndrome (Ong et al., 2008; Oguri et al., 2009; Gruson et al., 2010b). In addition, overexpression of UII and UT has been reported in the kidney of diabetic patients (Langham et al., 2004). The UII and UT genes are upregulated in both the aorta and kidney of nonobese diabetic rats (Tian et al., 2008; Xie and Liu, 2009). Genetic studies have shown that single nucleotide polymorphisms (SNPs) in the UII gene are associated with type 2 diabetes mellitus (T2DM) in the Northern Chinese (Sun et al., 2002, Zhu et al., 2002; Tan et al., 2006), Hong Kong Chinese (Ong et al., 2006), Japanese (Wenyi et al., 2003; Suzuki et al., 2004), Turkish (Okumus et al., 2012), and Spanish populations (Sáez et al., 2011). In particular, the SNP $3836 \mathrm{C} \rightarrow \mathrm{T}(\mathrm{S} 89 \mathrm{~N})$ found in the Japanese and Hong Kong populations has been associated with elevated plasma UII level, higher plasma insulin, insulin resistance, and susceptibility of developing T2DM (Wenyi et al., 2003; Suzuki et al., 2004; Ong et al., 2006). SNPs have also been reported in the UT promoter in the Japanese population, but no significant association with T2DM was found (Suzuki et al., 2004). In bovine, 5 SNPs have been identified for the UII gene and 14 SNPs for the UT gene, and a significant association with fat deposition and fatty acid composition was reported (Jiang et al., 2008). In the coho salmon Oncorhynchus kisutch, UII enhances glucose mobilization, increases liver glucose-G-phosphatase activity, and stimulates glycogene synthetase activity (Sheridan et al., 1987).

The genetic association between SNPs in the UII gene and T2DM suggests that UT antagonists may have 
beneficial effects for the treatment of diabetes and metabolic syndrome. As a matter of fact, treatment of streptozotocin-induced diabetic rats with palosuran (Clozel et al., 2004) improves survival, increases serum insulin concentration, reduces glycemia, attenuates albuminuria, and prevents renal tubular degeneration (Clozel et al., 2006). However, clinical trials led to divergent results (Desai et al., 2008; Tsoukas et al., 2011). One study indicates that, in hypertensive T2DM patients affected by nephropathy, palosuran $(125 \mathrm{mg}$ twice daily) reduces albuminuria, suggesting that blockage of UT could be a therapeutic approach for the treatment of diabetic nephropathy (Sidharta et al., 2006). However, the authors subsequently found that palosuran does not improve insulin secretion, insulin sensitivity, and glycemia in T2DM (Sidharta et al., 2009). In addition, Clozel et al. (2006) conducted a series of three clinical proof-of-concept studies in diabetic nephropathy patients that did not reveal major efficacy of palosuran at a relatively high dose (300 mg/kg per day). The lack of effect of palosuran on albuminuria, blood pressure, glomerular filtration rate, and renal plasma flow in patients with T2DM nephropathy was recently confirmed by the PROLONG study group (Vogt et al., 2010).

\section{F. Effect of Urotensin II / Urotensin II-Related Peptide on the Liver}

The liver is a documented site of UII and URP production in human (Coulouarn et al., 1998; Sugo et al., 2003) and sheep (Charles et al., 2005). In cirrhotic bile duct-ligated rats, increased expression of UII and UT is observed in hepatic tissue and portal veins (Trebicka et al., 2008). In cirrhotic patients, plasma UII concentration is elevated in the hepatic vein compared with the hepatic portal vein (Heller et al., 2002). Patients with chronic liver disease exhibit high serum UII levels that are associated with the severity of the disease and the extent of portal hypertension (Kemp et al., 2007). The expression of UT mRNA and UT protein is also significantly increased in the liver of patients with cirrhosis and portal hypertension (Liu et al., 2010a). Taken together, these observations indicate that the liver is a source of UII production, particularly in pathophysiological conditions, and that the urotensinergic system may play a role in cirrhosis and portal hypertension.

\section{G. Effect of Urotensin II / Urotensin II-Related Peptide on the Adrenal Gland}

Intracerebroventricular injection of UII significantly increases plasma levels of adrenaline, ACTH, and cortisol in unanesthetized sheep (Watson et al., 2003) and corticosterone in rat (Watson et al., 2008). Expression of UII mRNA, but not URP mRNA, has been observed in the mouse and rat adrenal gland (Sugo et al., 2003; Dubessy et al., 2008) and in human adrenocortical and adrenomedullary tissues (Takahashi et al., 2003; Zeng et al., 2006; Giuliani et al., 2009). Genome-wide microarray experiments have shown that the UII gene is downregulated in the adrenal gland of SHR, stroke-prone SHR, and malignant stroke-prone SHR (Ashenagar et al., 2010). Expression of UT mRNA has also been reported in the mouse and monkey adrenal gland (Elshourbagy et al., 2002) and in human adrenal tissue (Takahashi et al., 2003; Zeng et al., 2006; Giuliani et al., 2009). Immunohistochemical experiments have also shown the presence of the UII peptide in the human adrenal medulla (Morimoto et al., 2008). UII and UT mRNAs are both present in freshly dispersed and cultured rat adrenocortical cells (Albertin et al., 2006). These observations suggest that UII may act as a paracrine factor, produced either by the adrenal cortex or the adrenal medulla, regulating corticosteroid secretion. In agreement with this hypothesis, UII induces a concentration-dependent inhibition of basal corticosterone secretion from cultured rat adrenocortical cells but does not affect ACTH-evoked corticosterone secretion (Albertin et al., 2006).

The UII and UT genes are expressed in cortisolproducing adenoma, aldosterone-producing adenoma, carcinoma, and pheochromocytoma (Takahashi et al., 2001, 2003; Zeng et al., 2006). UII and UT mRNAs are also expressed in PC12 rat pheochromocytoma cells (Aita et al., 2010). The presence of the UII peptide and UT protein has been confirmed in human adrenocortical and adrenomedullary tumors by immunoblot analysis and immunohistochemistry (Takahashi et al., 2001; Morimoto et al., 2008; Giuliani et al., 2009). Consistent with these data, UII stimulates proliferation of human adrenocortical carcinoma cells (Takahashi et al., 2003) and pheochromocytoma cells (Zeng et al., 2006; Aita et al., 2010) in a concentrationdependent manner.

In the frog Pelophylax ridibundus, UII has no effect on corticosterone and aldosterone secretion from perifused interrenal tissue. In addition, UII does not modify ACTH- and angiotensin II-induced corticosteroid secretion (Feuilloley et al., 1994). In rainbow trout and European flounder, UII stimulates cortisol secretion in vitro by perifused interrenal tissue derived from seawater-adapted fish but does not affect cortisol secretion in tissue derived from freshwater-adapted fish (Arnold-Reed and Balment, 1994; Kelsall and Balment, 1998). In vivo, intra-arterial infusion of UII in seawater-adapted flounder causes a dose-dependent increase in plasma cortisol levels (Kelsall and Balment, 1998).

\section{Conclusions and Perspectives}

Since the discovery 15 years ago of the potent vasoconstrictor and biologic effects of UII, substantial research has been performed to understand the role of UII in human physiology and pathophysiology. Toward 
this goal, high affinity and selective peptidic and nonpeptidic receptor agonists and antagonists have been developed to further elucidate the pharmacology and biology of UII. Clearly, because of their physiochemical and pharmacokinetic properties, nonpeptidic UII antagonists are attractive alternatives to peptidic antagonists, and they offer the opportunity to evaluate the role of UII in chronic disorders. These pharmacological tools have been employed to explore the role of endogenous UII in pathophysiology. The most studied clinical indications include hypertension, heart failure, renal disease, atherosclerosis, asthma, pulmonary hypertension, and diabetes. Although these compounds have been studied in a variety of preclinical animal models with encouraging results, UT antagonists have yet to be systematically and comprehensively studied in human diseases (Gilbert et al., 2004). There is still a paucity of human investigation with UT antagonists, and the clinical studies that have been conducted have not fully clarified the understanding of the role of UII in human pathophysiology.

For example, a clinical study by Vogt et al. (2010) examined the effects of the UT antagonist palosuran in hypertensive patients with diabetic nephropathy. Contrary to preclinical data, a 4-week treatment of subjects with palosuran did not affect blood pressure, glomerular filtration rate, renal hemodynamics, or albuminuria. Hence, these results do not support a role of UII in the control of blood pressure or renal function in patients with diabetic nephropathy. Also, the UT antagonist GSK1440115 was tested recently in a phase $1 \mathrm{~B}$ clinical study in asthma patients. Again, contrary to preclinical data, acute UT antagonism did not induce bronchodilation or protect against methacholineinduced bronchospasm (Portnoy et al., 2013). This clinical study suggested that antagonism of UII is not likely to provide benefit as an acute bronchodilator in asthmatic patients. In addition, there are contradictory results in the literature on effects of exogenously administered UII on cardiovascular function, as well as regional differences in the vasoconstrictor response to UII. Moreover, vasopressor effects of UII may have differential cardiovascular consequences depending on the disease state. Clearly, more work needs to be performed, because clinical research has not revealed an unambiguous role of UII in human disease.

Despite UII being recognized as the most potent vasoconstrictor identified so far, a definitive role for UII in cardiovascular disease is still under investigation. The major challenge for the future will be clinical demonstration of efficacy of receptor antagonists in human pathophysiology, and then UT may emerge as an important therapeutic target. Pharmacological intervention through the now currently orally active UT antagonists will help provide a rational approach to understanding the role of UII in pathophysiology.

\section{Acknowledgments}

The authors thank J. Michael Conlon (Faculty of Medicine and Health Science, UAE University, United Arab Emirates), JeanClaude do Rego (Institut National de la Santé et de la Recherche Médicale U905, Institute for Research and Innovation in Biomedicine, University of Rouen, France), and Dan Larhammar (Department of Neuroscience, Uppsala University, Sweden) for valuable discussion, and Catherine Beau for skillful secretarial assistance. The authors dedicate this review to Howard A. Bern, the "father" of urotensin II, who died in 2012, and to Stephen A. Douglas, who died in 2009, for his enormous contribution to the elucidation of the pathophysiological roles of urotensin II.

\section{Authorship Contributions}

Wrote or contributed to the writing of the manuscript: H. Vaudry, Leprince, Chatenet, Fournier, Lambert, Le Mével, Ohlstein, Schwertani, Tostivint, D. Vaudry.

\section{References}

Abdel-Razik AE, Balment RJ, and Ashton N (2008) Enhanced renal sensitivity of the spontaneously hypertensive rat to urotensin II. Am J Physiol Renal Physiol 295: F1239-F1247.

Aita Y, Kasahara T, Isobe K, Kawakami Y, and Takekoshi K (2010) Effect of urotensin II on PC12 rat pheochromocytoma cells. J Neuroendocrinol 22:83-91.

Aiyar N, Johns DG, Ao Z, Disa J, Behm DJ, Foley JJ, Buckley PT, Sarau HM, van-derKeyl HK, Elshourbagy NA, et al. (2005) Cloning and pharmacological characterization of the cat urotensin-II receptor (UT). Biochem Pharmacol 69:1069-1079.

Albertin G, Casale V, Ziolkowska A, Spinazzi R, Malendowicz LK, Rossi GP and Nussdorfer GG (2006) Urotensin-II and UII-receptor expression and function in the rat adrenal cortex. Int J Mol Med 17:1111-1115.

Albertin G, Guidolin D, Sorato E, Oselladore B, Tortorella C, and Ribatti D (2011) Urotensin-II-stimulated expression of pro-angiogenic factors in human vascular endothelial cells. Regul Pept 172:16-22.

Albertin G, Guidolin D, Sorato E, Spinazzi R, Mascarin A, Oselladore B, Montopoli M, Antonello M, and Ribatti D (2009) Pro-angiogenic activity of Urotensin-II on different human vascular endothelial cell populations. Regul Pept 157:64-71.

Alexander SP, Mathie A, and Peters JA(2011) Guide to receptors and channels (GRAC), 5th edition. Br J Pharmacol 164:S1-S324.

Altenburger JM, Fossey V, Galtier D, and Petit F (2009) inventors, Sanofi Aventis, assignee. 5,6-Bisaryl-2-pyridinecarboxamide and 5,6-bisaryl-2-pyrazinecarboxamide derivatives, their preparation and their therapeutic application as urotensin II receptor antagonists. Patent WO 2009-115665. 2009 Sep 24.

Altenburger A, Fossey V, Lassalle G, Petit F, and Vernières JC (2008) inventors, Sanofi Aventis, assignee. 5,6-Bisaryl-2-pyridinecarboxamide derivatives, their preparation and their therapeutic application as urotensin II receptor antagonists. Patent FR 2904827. 2008 Feb 15.

Altenburger JM, Fossey V, and Petit F (2011) inventors, Sanofi Aventis, assignee. Derivates of 5,6-isaryl-2-pyrimidinecarboxamide, their preparation and their therapeutic use as urotensin II receptor antagonists. Patent WO 2011/007090. 2011 Jan 20

Ames RS, Sarau HM, Chambers JK, Willette RN, Aiyar NV, Romanic AM, Louden CS, Foley JJ, Sauermelch CF, Coatney RW, et al. (1999) Human urotensin-II is a potent vasoconstrictor and agonist for the orphan receptor GPR14. Nature 401: $282-286$.

Arnold-Reed DE and Balment RJ (1994) Peptide hormones influence in vitro interrenal secretion of cortisol in the trout, Oncorhynchus mykiss. Gen Comp Endocrinol 96:85-91.

Artenstein AW and Opal SM (2011) Proprotein convertases in health and disease. $N$ Engl J Med 365:2507-2518.

Ashenagar MS, Tabuchi M, Kinoshita K, Ooshima K, Niwa A, Watanabe Y, Yoshida M, Shimada K, Yasunaga T, Yamanishi H, et al. (2010) Gene expression in the adrenal glands of three spontaneously hypertensive rat substrains. Mol Med Rep 3: 213-222.

Baghdoyan HA, Monaco AP, Rodrigo-Angulo ML, Assens F, McCarley RW, and Hobson JA (1984) Microinjection of neostigmine into the pontine reticular formation of cats enhances desynchronized sleep signs. J Pharmacol Exp Ther 231: 173-180.

Balat A, Karakök M, Yilmaz K, and Kibar Y (2007) Urotensin-II immunoreactivity in children with chronic glomerulonephritis. Ren Fail 29:573-578.

Baldisserotto B and Mimura OM (1997) Changes in the electrophysiological parameters of the posterior intestine of Anguilla anguilla (Pisces) induced by oxytocin, urotensin II and aldosterone. Braz J Med Biol Res 30:35-39.

Barrette PO and Schwertani AG (2012) A closer look at the role of urotensin II in the metabolic syndrome. Front Endocrinol (Lausanne) 3:165.

Batuwangala MS, Calo G, Guerrini R, Ng LL, McDonald J, and Lambert DG (2009a) Desensitisation of native and recombinant human urotensin-II receptors. Naunyn Schmiedebergs Arch Pharmacol 380:451-457.

Batuwangala M, Camarda V, McDonald J, Marzola E, Lambert DG, Ng LL, Calo' G, Regoli D, Trapella C, Guerrini R, et al. (2009b) Structure-activity relationship study on Tyr9 of urotensin-II(4-11): identification of a partial agonist of the UT receptor. Peptides 30:1130-1136.

Behm DJ, Doe CP, Johns DG, Maniscalco K, Stankus GP, Wibberley A, Willette RN, and Douglas SA (2004a) Urotensin-II: a novel systemic hypertensive factor in the cat. Naunyn Schmiedebergs Arch Pharmacol 369:274-280. 
Behm DJ, Herold CL, Camarda V, Aiyar NV, and Douglas SA (2004b) Differential agonistic and antagonistic effects of the urotensin-II ligand SB-710411 at rodent and primate UT receptors. Eur J Pharmacol 492:113-116.

Behm DJ, Herold CL, Ohlstein EH, Knight SD, Dhanak D, and Douglas SA (2002) Pharmacological characterization of SB-710411 (Cpa-c[D-Cys-Pal-D-Trp-Lys-ValCys]-Cpa-amide), a novel peptidic urotensin-II receptor antagonist. $\mathrm{Br} J$ Pharmacol 137:449-458.

Behm DJ, Stankus G, Doe CP, Willette RN, Sarau HM, Foley JJ, Schmidt DB, Nuthulaganti P, Fornwald JA, Ames RS, et al. (2006) The peptidic urotensin-II receptor ligand GSK248451 possesses less intrinsic activity than the low-efficacy partial agonists SB-710411 and urantide in native mammalian tissues and recombinant cell systems. Br J Pharmacol 148:173-190.

Bennett RT, Jones RD, Morice AH, Smith CF, and Cowen ME (2004) Vasoconstrictive effects of endothelin-1, endothelin-3, and urotensin II in isolated perfused human lungs and isolated human pulmonary arteries. Thorax 59:401-407.

Bern HA, Pearson D, Larson BA, and Nishioka RS (1985) Neurohormones from fish tails: the caudal neurosecretory system. I. "Urophysiology" and the caudal neurosecretory system of fishes. Recent Prog Horm Res 41:533-552.

Bhaskaran R, Arunkumar AI, and Yu C (1994) NMR and dynamical simulated annealing studies on the solution conformation of urotensin II. Biochim Biophys Acta 1199:115-122.

Bianca Rd, Mitidieri E, Fusco F, D’Aiuto E, Grieco P, Novellino E, Imbimbo C, Mirone V, Cirino G, and Sorrentino R (2012) Endogenous urotensin II selectively modulates erectile function through eNOS. PLoS ONE 7:e31019.

Böhm F and Pernow J (2002) Urotensin II evokes potent vasoconstriction in humans in vivo. $\mathrm{Br} J$ Pharmacol 135:25-27.

Boivin S, Guilhaudis L, Milazzo I, Oulyadi H, Davoust D, and Fournier A (2006) Characterization of urotensin-II receptor structural domains involved in the recognition of U-II, URP, and urantide. Biochemistry 45:5993-6002.

Boivin S, Ségalas-Milazzo I, Guilhaudis L, Oulyadi H, Fournier A, and Davoust D (2008) Solution structure of urotensin-II receptor extracellular loop III and characterization of its interaction with urotensin-II. Peptides 29:700-710.

Bottrill FE, Douglas SA, Hiley CR, and White R (2000) Human urotensin-II is an endothelium-dependent vasodilator in rat small arteries. $\mathrm{Br} J$ Pharmacol 130 : 1865-1870.

Boucard AA, Sauvé SS, Guillemette G, Escher E, and Leduc R (2003) Photolabelling the rat urotensin II/GPR14 receptor identifies a ligand-binding site in the fourth transmembrane domain. Biochem $J$ 370:829-838.

Bousette N and Giaid A (2006) Urotensin-II and cardiovascular diseases. Curr Hypertens Rep 8:479-483.

Bousette N, D'Orleans-Juste P, Kiss RS, You Z, Genest J, Al-Ramli W, Qureshi ST, Gramolini A, Behm D, Ohlstein EH, et al. (2009) Urotensin II receptor knockout mice on an ApoE knockout background fed a high-fat diet exhibit an enhanced hyperlipidemic and atherosclerotic phenotype. Circ Res 105:686-695, 19, 695

Bousette N, Hu F, Ohlstein EH, Dhanak D, Douglas SA, and Giaid A (2006a) Urotensin-II blockade with SB-611812 attenuates cardiac dysfunction in a rat model of coronary artery ligation. J Mol Cell Cardiol 41:285-295.

Bousette N, Patel L, Douglas SA, Ohlstein EH, and Giaid A (2004) Increased expression of urotensin II and its cognate receptor GPR14 in atherosclerotic lesions of the human aorta. Atherosclerosis 176:117-123.

Bousette N, Pottinger J, Ramli W, Ohlstein EH, Dhanak D, Douglas SA, and Giaid A (2006b) Urotensin-II receptor blockade with SB-611812 attenuates cardiac remodeling in experimental ischemic heart disease. Peptides 27:2919-2926.

Brailoiu E, Brailoiu GC, Miyamoto MD, and Dun NJ (2003) The vasoactive peptide urotensin II stimulates spontaneous release from frog motor nerve terminals. $\mathrm{Br} J$ Pharmacol 138:1580-1588.

Brailoiu E, Jiang X, Brailoiu GC, Yang J, Chang JK, Wang H, and Dun NJ (2008) State-dependent calcium mobilization by urotensin-II in cultured human endothelial cells. Peptides 29:721-726.

Brazeau P, Vale W, Burgus R, Ling N, Butcher M, Rivier J, and Guillemin R (1973) Hypothalamic polypeptide that inhibits the secretion of immunoreactive pituitary growth hormone. Science 179:77-79.

Brkovic A, Hattenberger A, Kostenis E, Klabunde T, Flohr S, Kurz M, Bourgault S, and Fournier A (2003) Functional and binding characterizations of urotensin II-related peptides in human and rat urotensin II-receptor assay. J Pharmacol Exp Ther 306:1200-1209.

Bruzzone F, Cervetto C, Mazzotta MC, Bianchini P, Ronzitti E, Leprince J, Diaspro A, Maura G, Vallarino M, Vaudry H, et al. (2010) Urotensin II receptor and acetylcholine release from mouse cervical spinal cord nerve terminals. Neuroscience 170:67-77.

Bucharles C, Bizet P, Arthaud S, Arabo A, Leprince J, Lefranc B, Cartier D, Anouar Y, and Lihrmann I (2014) Concordant localization of functional urotensin II and urotensin II-related peptide binding sites in the rat brain: Atypical occurrence close to the fourth ventricle. J Comp Neurol 522:2634-2649.

Camarda V, Guerrini R, Kostenis E, Rizzi A, Calò G, Hattenberger A, Zucchini M, Salvadori S, and Regoli D (2002a) A new ligand for the urotensin II receptor. $B r J$ Pharmacol 137:311-314

Camarda V, Rizzi A, Calò G, Gendron G, Perron SI, Kostenis E, Zamboni P, Mascoli F, and Regoli D (2002b) Effects of human urotensin II in isolated vessels of various species; comparison with other vasoactive agents. Naunyn Schmiedebergs Arch Pharmacol 365:141-149.

Camarda V, Song W, Marzola E, Spagnol M, Guerrini R, Salvadori S, Regoli D, Thompson JP, Rowbotham DJ, Behm DJ, et al. (2004) Urantide mimics urotensinII induced calcium release in cells expressing recombinant UT receptors. Eur $J$ Pharmacol 498:83-86.

Camarda V, Spagnol M, Song W, Vergura R, Roth AL, Thompson JP, Rowbotham DJ, Guerrini R, Marzola E, Salvadori S, et al. (2006) In vitro and in vivo pharmacological characterization of the novel UT receptor ligand [Pen5,DTrp7,Dab8]urotensin II(4-11) (UFP-803). Br J Pharmacol 147:92-100.

Carotenuto A, Auriemma L, Merlino F, Yousif AM, Marasco D, Limatola A, Campiglia P, Gomez-Monterrey I, Santicioli P, Meini S, et al. (2014) Lead optimization of P5U and urantide: discovery of novel potent ligands at the urotensin-II receptor. $J$ Med Chem 57:5965-5974.

Carotenuto A, Grieco P, Campiglia P, Novellino E, and Rovero P (2004a) Unraveling the active conformation of urotensin II. J Med Chem 47:1652-1661.

Carotenuto A, Grieco P, Novellino E, and Rovero P (2004b) Urotensin-II receptor peptide agonists. Med Res Rev 24:577-588.

Carotenuto A, Grieco P, Rovero P, and Novellino E (2006) Urotensin-II receptor antagonists. Curr Med Chem 13:267-275.

Castel H, Diallo M, Chatenet D, Leprince J, Desrues L, Schouft MT, Fontaine M, Dubessy C, Lihrmann I, Scalbert E, et al. (2006) Biochemical and functional characterization of high-affinity urotensin II receptors in rat cortical astrocytes. $J$ Neurochem 99:582-595.

Chan DKO (1975) Cardiovascular and renal effects of urotensins, I and II in the eel, Anguilla rostrata. Gen Comp Endocrinol 27:52-61.

Chan DK, Gunther R, and Bern HA (1978) The isolated trout rectum bioassay for urotensin II: assessment for specificity and precision. Gen Comp Endocrinol 34:347-359.

Charles CJ, Rademaker MT, Richards AM, and Yandle TG (2005) Urotensin II: evidence for cardiac, hepatic and renal production. Peptides 26:2211-2214.

Chartrel N, Conlon JM, Collin F, Braun B, Waugh D, Vallarino M, Lahrichi SL, Rivier JE, and Vaudry H (1996) Urotensin II in the central nervous system of the frog Rana ridibunda: immunohistochemical localization and biochemical characterization. J Comp Neurol 364:324-339.

Chartrel N, Dujardin C, Anouar Y, Leprince J, Decker A, Clerens S, Do-Régo JC, Vandesande F, Llorens-Cortes C, Costentin J, et al. (2003) Identification of $26 \mathrm{RFa}$ a hypothalamic neuropeptide of the RFamide peptide family with orexigenic activity. Proc Natl Acad Sci USA 100:15247-15252.

Chartrel N, Leprince J, Dujardin C, Chatenet D, Tollemer H, Baroncini M, Balment RJ, Beauvillain JC, and Vaudry H (2004) Biochemical characterization and immunohistochemical localization of urotensin II in the human brainstem and spinal cord. J Neurochem 91:110-118.

Chatenet D, Dubessy C, Boularan C, Scalbert E, Pfeiffer B, Renard P, Lihrmann I, Pacaud P, Tonon MC, Vaudry H, et al. (2006) Structure-activity relationships of a novel series of urotensin II analogues: identification of a urotensin II antagonist. $J$ Med Chem 49:7234-7238.

Chatenet D, Dubessy C, Leprince J, Boularan C, Carlier L, Ségalas-Milazzo I, Guilhaudis L, Oulyadi H, Davoust D, Scalbert E, et al. (2004) Structure-activity relationships and structural conformation of a novel urotensin II-related peptide. Peptides 25:1819-1830.

Chatenet D, Folch B, Feytens D, Létourneau M, Tourwé D, Doucet N, and Fournier A (2013a) Development and pharmacological characterization of conformationally constrained urotensin II-related peptide agonists. J Med Chem 56:9612-9622.

Chatenet D, Létourneau M, Nguyen QT, Doan ND, Dupuis J, and Fournier A (2013b) Discovery of new antagonists aimed at discriminating UII and URP-mediated biological activities: insight into UII and URP receptor activation. $\mathrm{Br} J$ Pharmacol 168:807-821.

Chatenet D, Nguyen QT, Létourneau M, Dupuis J, and Fournier A (2012) Urocontrin, a novel UT receptor ligand with a unique pharmacological profile. Biochem Pharmacol 83:608-615.

Chatenet D, Nguyen TT, Létourneau M, and Fournier A (2013c) Update on the urotensinergic system: new trends in receptor localization, activation, and drug design. Front Endocrinol (Lausanne) 3:174 10.3389/fendo.2012.00174.

Chen EW and Chiu AY (1992) Early stages in the development of spinal motor neurons. J Comp Neurol 320:291-303.

Chen YL, Liu JC, Loh SH, Chen CH, Hong CY, Chen JJ, and Cheng TH (2008) Involvement of reactive oxygen species in urotensin II-induced proliferation of cardiac fibroblasts. Eur J Pharmacol 593:24-29.

Chen YH, Zhao MW, Yao WZ, Pang YZ, and Tang CS (2004) The signal transduction pathway in the proliferation of airway smooth muscle cells induced by urotensin II. Chin Med J (Engl) 117:37-41.

Cheriyan J, Burton TJ, Bradley TJ, Wallace SM, Mäki-Petäjä KM, Mackenzie IS, McEniery CM, Brown J, and Wilkinson IB (2009) The effects of urotensin II and urantide on forearm blood flow and systemic haemodynamics in humans. Br J Clin Pharmacol 68:518-523.

Cheung BM, Leung R, Man YB, and Wong LY (2004) Plasma concentration of urotensin II is raised in hypertension. J Hypertens 22:1341-1344.

Chuquet J, Lecrux C, Chatenet D, Leprince J, Chazalviel L, Roussel S, MacKenzie ET, Vaudry H, and Touzani O (2008) Effects of urotensin-II on cerebral blood flow and ischemia in anesthetized rats. Exp Neurol 210:577-584.

Clark SD, Nothacker HP, Blaha CD, Tyler CJ, Duangdao DM, Grupke SL, Helton DR, Leonard CS, and Civelli O (2005) Urotensin II acts as a modulator of mesopontine cholinergic neurons. Brain Res 1059:139-148.

Clark SD, Nothacker HP, Wang Z, Saito Y, Leslie FM, and Civelli O (2001) The urotensin II receptor is expressed in the cholinergic mesopontine tegmentum of the rat. Brain Res 923:120-127.

Clozel M, Binkert C, Birker-Robaczewska M, Boukhadra C, Ding SS, Fischli W, Hess P, Mathys B, Morrison K, Müller C, et al. (2004) Pharmacology of the urotensin-II receptor antagonist palosuran (ACT-058362; 1-[2-(4-benzyl-4-hydroxy-piperidin-1-yl)ethyl]-3-(2-methyl-quinolin-4-yl)-urea sulfate salt): first demonstration of a pathophysiological role of the urotensin System. J Pharmacol Exp Ther 311:204-212.

Clozel M, Hess P, Qiu C, Ding SS, and Rey M (2006) The urotensin-II receptor antagonist palosuran improves pancreatic and renal function in diabetic rats. $J$ Pharmacol Exp Ther 316:1115-1121.

Conlon JM (2000) Singular contributions of fish neuroendocrinology to mammalian regulatory peptide research. Regul Pept 93:3-12.

Conlon JM (2008) Liberation of urotensin II from the teleost urophysis: an historical overview. Peptides 29:651-657.

Conlon JM, Arnold-Reed D, and Balment RJ (1990) Post-translational processing of prepro-urotensin II. FEBS Lett 266:37-40.

Conlon JM, Kolodziejek J, and Nowotny N (2009) Antimicrobial peptides from the skins of North American frogs. Biochim Biophys Acta 1788:1556-1563. 
Conlon JM, O'Harte F, Smith DD, Balment RJ, and Hazon N (1992a) Purification and characterization of urotensin II and parvalbumin from an elasmobranch fish, Scyliorhinus canicula (common dogfish). Neuroendocrinology 55:230-235.

Conlon JM, O'Harte F, Smith DD, Tonon MC, and Vaudry H (1992b) Isolation and primary structure of urotensin II from the brain of a tetrapod, the frog Rana ridibunda. Biochem Biophys Res Commun 188:578-583.

Conlon JM, Tostivint H, and Vaudry H (1997) Somatostatin- and urotensin II-related peptides: molecular diversity and evolutionary perspectives. Regul Pept 69:95-103.

Conlon JM, Yano K, Waugh D, and Hazon N (1996) Distribution and molecular forms of urotensin II and its role in cardiovascular regulation in vertebrates. J Exp Zool 275:226-238.

Cosenzi A (2008) Non peptidic urotensin II antagonists: perspectives for a new class of drugs. Cardiovasc Hematol Agents Med Chem 6:80-91.

Coulouarn Y, Fernex C, Jégou S, Henderson CE, Vaudry H, and Lihrmann I (2001) Specific expression of the urotensin II gene in sacral motoneurons of developing rat spinal cord. Mech Dev 101:187-190.

Coulouarn Y, Jégou S, Tostivint H, Vaudry H, and Lihrmann I (1999) Cloning, sequence analysis and tissue distribution of the mouse and rat urotensin II precursors. FEBS Lett 457:28-32.

Coulouarn Y, Lihrmann I, Jegou S, Anouar Y, Tostivint H, Beauvillain JC, Conlon JM, Bern HA, and Vaudry H (1998) Cloning of the cDNA encoding the urotensin II precursor in frog and human reveals intense expression of the urotensin II gene in motoneurons of the spinal cord. Proc Natl Acad Sci USA 95:15803-15808.

Cowley E, Thompson JP, Sharpe P, Waugh J, Ali N, and Lambert DG (2005) Effects of pre-eclampsia on maternal plasma, cerebrospinal fluid, and umbilical cord urotensin II concentrations: a pilot study. Br J Anaesth 95:495-499.

Coy DH, Rossowski WJ, Cheng BL, Hocart SJ, and Taylor JE (2000) Novel urotensin II (UII) antagonists point to multiple receptor involvement in UII bioactivity. 13th Internationl Symposium on Regulatory Peptides; 2000 Oct 22-26; Cairns, QLD, Australia.

Coy DH, Rossowski WJ, Cheng BL, and Taylor JE (2002) Structural requirements at the N-terminus of urotensin II octapeptides. Peptides 23:2259-2264.

Croston GE, Olsson R, Currier EA, Burstein ES, Weiner D, Nash N, Severance D, Allenmark SG, Thunberg L, Ma JN, et al. (2002) Discovery of the first nonpeptide agonist of the GPR14/urotensin-II receptor: 3-(4-chlorophenyl)-3-(2- (dimethylamino) ethyl)isochroman-1-one (AC-7954). J Med Chem 45:4950-4953.

Dahlgren U (1914) The electric motor nerve centers in the skates (RAJIDAe). Science 40:862-863.

Dai HY, He T, Li XL, Xu WL, and Ge ZM (2011) Urotensin-2 promotes collagen synthesis via ERK1/2-dependent and ERK1/2-independent TGF- $\beta 1$ in neonatal cardiac fibroblasts. Cell Biol Int 35:93-98.

Dai HY, Kang WQ, Wang X, Yu XJ, Li ZH, Tang MX, Xu DL, Li CW, Zhang Y, and Ge ZM (2007) The involvement of transforming growth factor-beta1 secretion in urotensin II-induced collagen synthesis in neonatal cardiac fibroblasts. Regul Pept 140:88-93.

Davenport AP and Maguire JJ (2000) Urotensin II: fish neuropeptide catches orphan receptor. Trends Pharmacol Sci 21:80-82.

Decatur WA, Hall JA, Smith JJ, Li W, and Sower SA (2013) Insight from the lamprey genome: glimpsing early vertebrate development via neuroendocrine-associated genes and shared synteny of gonadotropin-releasing hormone (GnRH). Gen Comp Endocrinol 192:237-245

de Lecea L and Bourgin P (2008) Neuropeptide interactions and REM sleep: a role for Urotensin II? Peptides 29:845-851.

de Lecea L, Criado JR, Prospero-Garcia O, Gautvik KM, Schweitzer P, Danielson PE, Dunlop CL, Siggins GR, Henriksen SJ, and Sutcliffe JG (1996) A cortical neuropeptide with neuronal depressant and sleep-modulating properties. Nature 381:242-245.

Delmeire D, Flamez D, Hinke SA, Cali JJ, Pipeleers D, and Schuit F (2003) Type VIII adenylyl cyclase in rat beta cells: coincidence signal detector/generator for glucose and GLP-1. Diabetologia 46:1383-1393.

d'Emmanuele di Villa Bianca R, Cirino G, Mitidieri E, Coletta C, Grassia G, Roviezzo F, Grieco P, Novellino E, Imbimbo C, Mirone V, et al. (2010) Urotensin II: a novel target in human corpus cavernosum. $J$ Sex Med 7:1778-1786.

Desai N, Sajjad J, and Frishman WH (2008) Urotensin II: a new pharmacologic target in the treatment of cardiovascular disease. Cardiol Rev 16:142-153.

Desrues L, Lefebvre T, Lecointre C, Schouft MT, Leprince J, Compère V, Morin F, Proust F, Gandolfo P, Tonon MC, et al. (2012) Down-regulation of GABA(A) receptor via promiscuity with the vasoactive peptide urotensin II receptor. Potential involvement in astrocyte plasticity. PLOS ONE 7:e36319.

Dhanak D, Gallagher TF, and Knight SD (2002) inventors, Smithkline Beecham Corp., USA, assignee. Preparation of sulfonamides as antagonists of urotensin II. Patent WO 2002-090353. 2002 Nov 14

Dhanak D and Knight SD (2002) inventors, Smithkline Beecham Corp., USA, assignee. Preparation of quinolones as urotensin-II receptor antagonists. Patent WO 2002-047456. 2002 Jun 20

Dhanak D, Knight SD, Warren GL, Jin J, Widdowson KL, and Keenan RM (2001) inventors, Smithkline Beecham Corp., USA, assignee. Pyrrolidine derivative urotensin II receptor antagonists, their preparation, and therapeutic use. Patent WO 2001045700. 2001 Jun 28.

Diallo M, Jarry M, Desrues L, Castel H, Chatenet D, Leprince J, Vaudry H, Tonon MC, and Gandolfo P (2008) [Orn5]URP acts as a pure antagonist of urotensinergic receptors in rat cortical astrocytes. Peptides 29:813-819.

Disa J, Floyd LE, Edwards RM, Douglas SA, and Aiyar NV (2006) Identification and characterization of binding sites for human urotensin-II in Sprague-Dawley rat renal medulla using quantitative receptor autoradiography. Peptides $\mathbf{2 7}$ : 1532-1537.

Djordjevic T, BelAiba RS, Bonello S, Pfeilschifter J, Hess J, and Görlach A (2005) Human urotensin II is a novel activator of NADPH oxidase in human pulmonary artery smooth muscle cells. Arterioscler Thromb Vasc Biol 25:519-525.

Doan ND, Nguyen TT, Létourneau M, Turcotte K, Fournier A, and Chatenet D (2012) Biochemical and pharmacological characterization of nuclear urotensin-II binding sites in rat heart. Br J Pharmacol 166:243-257. do Rego JC, Leprince J, Scalbert E, Vaudry H, and Costentin J (2008) Behavioral actions of urotensin-II. Peptides 29:838-844.

do Rego JC, Chatenet D, Orta MH, Naudin B, Le Cudennec C, Leprince J, Scalbert E Vaudry H, and Costentin J (2005) Behavioral effects of urotensin-II centrally administered in mice. Psychopharmacology (Berl) 183:103-117.

Douglas SA, Ashton DJ, Sauermelch CF, Coatney RW, Ohlstein DH, Ruffolo MR, Ohlstein EH, Aiyar NV, and Willette RN (2000a) Human urotensin-II is a potent vasoactive peptide: pharmacological characterization in the rat, mouse, dog and primate. J Cardiovasc Pharmacol 36(5, Suppl 1)S163-S166.

Douglas SA, Behm DJ, Aiyar NV, Naselsky D, Disa J, Brooks DP, Ohlstein EH, Gleason JG, Sarau HM, Foley JJ, et al. (2005) Nonpeptidic urotensin-II receptor antagonists I: in vitro pharmacological characterization of SB-706375. Br J Pharmacol 145:620-635.

Douglas SA, Dhanak D, and Johns DG (2004a) From 'gills to pills': urotensin-II as a regulator of mammalian cardiorenal function. Trends Pharmacol Sci 25:76-85.

Douglas SA, Naselsky D, Ao Z, Disa J, Herold CL, Lynch F, and Aiyar NV (2004b) Identification and pharmacological characterization of native, functional human urotensin-II receptors in rhabdomyosarcoma cell lines. $\mathrm{Br} J$ Pharmacol 142: 921-932.

Douglas SA and Ohlstein EH (2000) Human urotensin-II, the most potent mammalian vasoconstrictor identified to date, as a therapeutic target for the management of cardiovascular disease. Trends Cardiovasc Med 10:229-237.

Douglas SA, Sulpizio AC, Piercy V, Sarau HM, Ames RS, Aiyar NV, Ohlstein EH, and Willette RN (2000b) Differential vasoconstrictor activity of human urotensin-II in vascular tissue isolated from the rat, mouse, dog, pig, marmoset and cynomolgus monkey. Br J Pharmacol 131:1262-1274

Douglas SA, Tayara L, Ohlstein EH, Halawa N, and Giaid A (2002) Congestive heart failure and expression of myocardial urotensin II. Lancet 359:1990-1997.

Dschietzig T, Bartsch C, Pregla R, Zurbrügg HR, Armbruster FP, Richter C, Laule M, Romeyke E, Neubert C, Voelter W, et al. (2002) Plasma levels and cardiovascular gene expression of urotensin-II in human heart failure. Regul Pept 110:33-38

Du AT, Onan D, Dinh DT, Lew MJ, Ziogas J, Aguilar MI, Pattenden LK, Thomas WG (2010) Ligand-supported purification of the urotensin-II receptor. Mol Pharmacol 78:639-647.

Dubessy C, Cartier D, Lectez B, Bucharles C, Chartrel N, Montero-Hadjadje M, Bizet $\mathrm{P}$, Chatenet D, Tostivint H, Scalbert E, et al. (2008) Characterization of urotensin II, distribution of urotensin II, urotensin II-related peptide and UT receptor mRNAs in mouse: evidence of urotensin II at the neuromuscular junction. $J$ Neurochem 107:361-374.

Dun SL, Brailoiu GC, Yang J, Chang JK, and Dun NJ (2001) Urotensin II-immunoreactivity in the brainstem and spinal cord of the rat. Neurosci Lett 305:9-12.

Egginger JG, Camus A, and Calas A (2006) Urotensin-II expression in the mouse spinal cord. J Chem Neuroanat 31:146-154.

Elshourbagy NA, Douglas SA, Shabon U, Harrison S, Duddy G, Sechler JL, Ao Z Maleeff BE, Naselsky D, Disa J, et al. (2002) Molecular and pharmacologica characterization of genes encoding urotensin-II peptides and their cognate G-protein-coupled receptors from the mouse and monkey. Br J Pharmacol 136:9-22.

Enami M (1959) The morphology and functional significance of the caudal neurosecretory system of fishes, in Comparative Endocrinology (Gorbman A ed) pp 697-724, Wiley, New York

Evans DH, Hyndman KA, Cornwell E, and Buchanan P (2011) Urotensin II and its receptor in the killifish gill: regulators of $\mathrm{NaCl}$ extrusion. $J$ Exp Biol 214: 3985-3991.

Feuilloley M, Lesouhaitier O, Delarue C, De Marchis S, Conlon JM, Bern HA, and Vaudry $H$ (1994) In vitro study of the effect of urotensin II on corticosteroid secretion in the frog Rana ridibunda. J Steroid Biochem Mol Biol 48:287-292.

Filipeanu CM, Brailoiu E, Le Dun S, and Dun NJ (2002) Urotensin-II regulates intracellular calcium in dissociated rat spinal cord neurons. J Neurochem 83: 879-884.

Flohr S, Kurz M, Kostenis E, Brkovich A, Fournier A, and Klabunde T (2002) Identification of nonpeptidic urotensin II receptor antagonists by virtual screening based on a pharmacophore model derived from structure-activity relationships and nuclear magnetic resonance studies on urotensin II. J Med Chem 45:1799-1805.

Foister S, Taylor LL, Feng JJ, Chen WL, Lin A, Cheng FC, Smith AB 3rd, and Hirschmann R (2006) Design and synthesis of potent cystine-free cyclic hexapeptide agonists at the human urotensin receptor. Org Lett 8:1799-1802.

Forty EJ and Ashton N (2013) The urotensin system is up-regulated in the prehypertensive spontaneously hypertensive rat. PLoS ONE 8:e83317.

Fredriksson R and Schiöth HB (2005) The repertoire of G-protein-coupled receptors in fully sequenced genomes. Mol Pharmacol 67:1414-1425.

Fridberg G and Bern HA (1968) The urophysis and the caudal neurosecretory system of fishes. Biol Rev Camb Philos Soc 43:175-199.

Gardiner SM, March JE, Kemp PA, Davenport AP, and Bennett T (2001) Depressor and regionally-selective vasodilator effects of human and rat urotensin II in conscious rats. Br J Pharmacol 132:1625-1629.

Gartlon J, Parker F, Harrison DC, Douglas SA, Ashmeade TE, Riley GJ, Hughes ZA, Taylor SG, Munton RP, Hagan JJ, et al. (2001) Central effects of urotensin-II following ICV administration in rats. Psychopharmacology (Berl) 155:426-433.

Gibson A (1987) Complex effects of Gillichthys urotensin II on rat aortic strips. $\mathrm{Br} J$ Pharmacol 91:205-212.

Gibson A, Bern HA, Ginsburg M, and Botting JH (1984) Neuropeptide-induced contraction and relaxation of the mouse anococcygeus muscle. Proc Natl Acad Sci USA 81:625-629.

Gibson A, Conyers S, and Bern HA (1988) The influence of urotensin II on calcium flux in rat aorta. $J$ Pharm Pharmacol 40:893-895.

Gibson A, Wallace P, and Bern HA (1986) Cardiovascular effects of urotensin II in anesthetized and pithed rats. Gen Comp Endocrinol 64:435-439.

Gilbert RE, Douglas SA, and Krum H (2004) Urotensin-II as a novel therapeutic target in the clinical management of cardiorenal disease. Curr Opin Investig Drugs 5:276-282. 
Gilon P and Henquin JC (2001) Mechanisms and physiological significance of the cholinergic control of pancreatic beta-cell function. Endocr Rev 22:565-604.

Giuliani L, Lenzini L, Antonello M, Aldighieri E, Belloni AS, Fassina A, GomezSanchez C, and Rossi GP (2009) Expression and functional role of urotensin-II and its receptor in the adrenal cortex and medulla: novel insights for the pathophysiology of primary aldosteronism. J Clin Endocrinol Metab 94:684-690.

Gong H, Ma H, Liu M, Zhou B, Zhang G, Chen Z, Jiang G, Yan Y, Yang C, Kanda M, et al. (2011) Urotensin II inhibits the proliferation but not the differentiation of cardiac side population cells. Peptides 32:1035-1041.

Gong H, Wang YX, Zhu YZ, Wang WW, Wang MJ, Yao T, and Zhu YC (2004) Cellular distribution of GPR14 and the positive inotropic role of urotensin II in the myocardium in adult rat. $J$ Appl Physiol 97:2228-2235.

González GC, Martinez-Padrón M, Lederis K, and Lukowiak K (1992) Distribution and coexistence of urotensin I and urotensin II peptides in the cerebral ganglia of Aplysia californica. Peptides 13:695-703.

Grau EG, Nishioka RS, and Bern HA (1982) Effects of somatostatin and urotensin II on tilapia pituitary prolactin release and interactions between somatostatin, osmotic pressure $\mathrm{Ca}++$, and adenosine $33^{\prime}, 5^{\prime}$-monophosphate in prolactin release in vitro. Endocrinology 110:910-915.

Gray GA, Jones MR, and Sharif I (2001) Human urotensin II increases coronary perfusion pressure in the isolated rat heart: potentiation by nitric oxide synthase and cyclooxygenase inhibition. Life Sci 69:175-180.

Grieco P, Carotenuto A, Campiglia P, Gomez-Monterrey I, Auriemma L, Sala M, Marcozzi C, d'Emmanuele di Villa Bianca R, Brancaccio D, Rovero P, et al. (2009) New insight into the binding mode of peptide ligands at Urotensin-II receptor: structure-activity relationships study on P5U and urantide. J Med Chem 52: 3927-3940

Grieco P, Carotenuto A, Campiglia P, Marinelli L, Lama T, Patacchini R, Santicioli P, Maggi CA, Rovero P, and Novellino E (2005) Urotensin-II receptor ligands. From agonist to antagonist activity. J Med Chem 48:7290-7297.

Grieco P, Carotenuto A, Campiglia P, Zampelli E, Patacchini R, Maggi CA, Novellino $\mathrm{E}$, and Rovero $\mathrm{P}$ (2002a) A new, potent urotensin II receptor peptide agonist containing a Pen residue at the disulfide bridge. J Med Chem 45:4391-4394.

Grieco P, Carotenuto A, Patacchini R, Maggi CA, Novellino E, and Rovero P (2002b) Design, synthesis, conformational analysis, and biological studies of urotensin-II lactam analogues. Bioorg Med Chem 10:3731-3739.

Grieco P, Franco R, Bozzuto G, Toccacieli L, Sgambato A, Marra M, Zappavigna S, Migaldi M, Rossi G, Striano S, et al. (2011) Urotensin II receptor predicts the clinical outcome of prostate cancer patients and is involved in the regulation of motility of prostate adenocarcinoma cells. J Cell Biochem 112:341-353.

Gruson D, Ginion A, Decroly N, Lause P, Vanoverschelde JL, Ketelslegers JM, Bertrand L, and Thissen JP (2010a) Urotensin II induction of adult cardiomyocytes hypertrophy involves the Akt/GSK-3ß signaling pathway. Peptides 31:1326-1333.

Gruson D, Rousseau MF, Ahn SA, van Linden F, and Ketelslegers JM (2006) Circulating urotensin II levels in moderate to severe congestive heart failure: its relations with myocardial function and well established neurohormonal markers. Peptides 27:1527-1531.

Gruson D, Rousseau MF, Ketelslegers JM, and Hermans MP (2010b) Raised plasma urotensin II in type 2 diabetes patients is associated with the metabolic syndrome phenotype. J Clin Hypertens (Greenwich) 12:653-660.

Guerrini R, Camarda V, Marzola E, Arduin M, Calo G, Spagnol M, Rizzi A, Salvadori $\mathrm{S}$, and Regoli D (2005) Structure-activity relationship study on human urotensin II. $J$ Pept Sci 11:85-90.

Guidolin D, Albertin G, Oselladore B, Sorato E, Rebuffat P, Mascarin A, and Ribatti $\mathrm{D}$ (2010) The pro-angiogenic activity of urotensin-II on human vascular endothelial cells involves ERK1/2 and PI3K signaling pathways. Regul Pept 162:26-32.

Hassan GS, Douglas SA, Ohlstein EH, and Giaid A (2005) Expression of urotensin-II in human coronary atherosclerosis. Peptides 26:2464-2472.

Hay DW, Luttmann MA, and Douglas SA (2000) Human urotensin-II is a potent spasmogen of primate airway smooth muscle. $\mathrm{Br} J$ Pharmacol 131:10-12.

Hazon N, Bjenning C, and Conlon JM (1993) Cardiovascular actions of dogfish urotensin II in the dogfish Scyliorhinus canicula. Am J Physiol 265:R573-R576.

Heller J, Schepke M, Neef M, Woitas R, Rabe C, and Sauerbruch T (2002) Increased urotensin II plasma levels in patients with cirrhosis and portal hypertension. $J$ Hepatol 37:767-772.

Henquin JC, Debuyser A, Drews G, and Plant TD (1992) Regulation of K+ permeability and membrane potential in insulin-secretin cells, in Nutrient Regulation of Insulin Secretion (Flatt PR ed) pp 173-191, Portland Press, London.

Heringlake M, Kox T, Uzun O, Will B, Bahlmann L, Klaus S, Eleftheriadis S, Armbruster FP, Franz N, and Kraatz E (2004) The relationship between urotensin II plasma immunoreactivity and left ventricular filling pressures in coronary artery disease. Regul Pept 121:129-136.

Herold CL, Behm DJ, Buckley PT, Foley JJ, Wixted WE, Sarau HM, and Douglas SA (2003) The neuromedin B receptor antagonist, BIM-23127, is a potent antagonist at human and rat urotensin-II receptors. Br J Pharmacol 139:203-207.

Hess P, Lansman JB, and Tsien RW (1984) Different modes of Ca channel gating behaviour favoured by dihydropyridine Ca agonists and antagonists. Nature $\mathbf{3 1 1}$ 538-544

Hillier C, Berry C, Petrie MC, O’Dwyer PJ, Hamilton C, Brown A, and McMurray J (2001) Effects of urotensin II in human arteries and veins of varying caliber. Circulation 103:1378-1381.

Hirose T, Takahashi K, Mori N, Nakayama T, Kikuya M, Ohkubo T, Kohzuki M, Totsune K, and Imai Y (2009) Increased expression of urotensin II, urotensin II-related peptide and urotensin II receptor mRNAs in the cardiovascular organs of hypertensive rats: comparison with endothelin-1. Peptides 30:1124-1129.

Holleran BJ, Beaulieu ME, Proulx CD, Lavigne P, Escher E, and Leduc R (2007) Photolabelling the urotensin II receptor reveals distinct agonist- and partialagonist-binding sites. Biochem $J$ 402:51-61.

Holleran BJ, Domazet I, Beaulieu ME, Yan LP, Guillemette G, Lavigne P, Escher E, and Leduc $\mathrm{R}$ (2009) Identification of transmembrane domain 6 \& 7 residues that contribute to the binding pocket of the urotensin II receptor. Biochem Pharmacol 77:1374-1382.

Hood SG, Watson AM, and May CN (2005) Cardiac actions of central but not peripheral urotensin II are prevented by beta-adrenoceptor blockade. Peptides 26: $1248-1256$

Horie S, Tsurumaki Y, Someya A, Hirabayashi T, Saito T, Okuma Y, Nomura Y, and Murayama T (2005) Involvement of cyclooxygenase-dependent pathway in contraction of isolated ileum by urotensin II. Peptides 26:323-329.

Horie S, Yasuda S, Tsurumaki Y, Someya A, Saito T, Okuma Y, Nomura Y, Hirabayashi T, and Murayama T (2003) Contraction of isolated guinea-pig ileum by urotensin II via activation of ganglionic cholinergic neurons and acetylcholine release. Neuropharmacology 45:1019-1027.

Huitron-Resendiz S, Kristensen MP, Sánchez-Alavez M, Clark SD, Grupke SL, Tyler C, Suzuki C, Nothacker HP, Civelli O, Criado JR, et al. (2005) Urotensin II modulates rapid eye movement sleep through activation of brainstem cholinergic neurons. $J$ Neurosci 25:5465-5474.

Hunt BD, Ng LL, and Lambert DG (2010) A rat brain atlas of urotensin-II receptor expression and a review of central urotensin-II effects. Naunyn Schmiedebergs Arch Pharmacol 382:1-31.

Ichikawa T, Lederis K, and Kobayashi H (1984) Primary structures of multiple forms of urotensin II in the urophysis of the carp, Cyprinus carpio. Gen Comp Endocrinol 55:133-141.

Ishihata A, Sakai M, and Katano Y (2006) Vascular contractile effect of urotensin II in young and aged rats: influence of aging and contribution of endothelial nitric oxide. Peptides 27:80-86.

Itoh H, Itoh Y, Rivier J, and Lederis K (1987) Contraction of major artery segments of rat by fish neuropeptide urotensin II. Am J Physiol 252:R361-R366.

Itoh H, McMaster D, and Lederis K (1988) Functional receptors for fish neuropeptide urotensin II in major rat arteries. Eur J Pharmacol 149:61-66.

Jacobs BL (1985) Overview of the activity of brain monoaminergic neurons across the sleep-wake cycle, in Sleep: Neurotransmitters and Neuromodulators (Wauquier A, Monti JM, Gaillard JM, and Radulovacki M eds) pp 1-14, Raven Press, New York.

Jani PP, Narayan H, and Ng LL (2013) The differential extraction and immunoluminometric assay of Urotensin II and Urotensin-related peptide in heart failure. Peptides 40:72-76.

Jarry M, Diallo M, Lecointre C, Desrues L, Tokay T, Chatenet D, Leprince J, Rossi O, Vaudry H, Tonon MC, et al. (2010) The vasoactive peptides urotensin II and urotensin II-related peptide regulate astrocyte activity through common and distinct mechanisms: involvement in cell proliferation. Biochem J 428:113-124

Javitch JA, Shi L, and Liapakis G (2002) Use of the substituted cysteine accessibility method to study the structure and function of $\mathrm{G}$ protein-coupled receptors. Methods Enzymol 343:137-156.

Jégou S, Cartier D, Dubessy C, Gonzalez BJ, Chatenet D, Tostivint H, Scalbert E, Leprince J, Vaudry H, and Lihrmann I (2006) Localization of the urotensin II receptor in the rat central nervous system. J Comp Neurol 495:21-36.

Jiang Z, Michal JJ, Tobey DJ, Wang Z, Macneil MD, and Magnuson NS (2008) Comparative understanding of UTS2 and UTS2R genes for their involvement in type 2 diabetes mellitus. Int $J$ Biol Sci 4:96-102.

Jin J, Dhanak D, Knight SD, Widdowson K, Aiyar N, Naselsky D, Sarau HM, Foley JJ, Schmidt DB, Bennett CD, et al. (2005) Aminoalkoxybenzyl pyrrolidines as nove human urotensin-II receptor antagonists. Bioorg Med Chem Lett 15:3229-3232.

Johns DG, Ao Z, Naselsky D, Herold CL, Maniscalco K, Sarov-Blat L, Steplewski K, Aiyar N, and Douglas SA (2004) Urotensin-II-mediated cardiomyocyte hypertrophy: effect of receptor antagonism and role of inflammatory mediators. Naunyn Schmiedebergs Arch Pharmacol 370:238-250.

Jołda-Mydłowska B, Salomon P, and Mazurek W (2006) [Plasma urotensin II level in patients with chronic congestive heart failure]. Pol Arch Med Wewn 116: $1125-1136$

Katz SD (1997) Mechanisms and implications of endothelial dysfunction in congestive heart failure. Curr Opin Cardiol 12:259-264.

Kawaguchi Y, Ono T, Kudo M, Kushikata T, Hashiba E, Yoshida H, Kudo T, Furukawa K, Douglas SA, and Hirota K (2009) The effects of benzodiazepines on urotensin II-stimulated norepinephrine release from rat cerebrocortical slices. Anesth Analg 108:1177-1181.

Kawauchi H, Kawazoe I, Tsubokawa M, Kishida M, and Baker BI (1983) Characterization of melanin-concentrating hormone in chum salmon pituitaries. Nature 305:321-323.

Kelsall CJ and Balment RJ (1998) Native urotensins influence cortisol secretion and plasma cortisol concentration in the euryhaline flounder, platichthys flesus. Gen Comp Endocrinol 112:210-219.

Kemp W, Krum H, Colman J, Bailey M, Yandle T, Richards M, and Roberts S (2007) Urotensin II: a novel vasoactive mediator linked to chronic liver disease and portal hypertension. Liver Int 27:1232-1239.

Kessler RJ and Wu C (2009) inventors, Encysive Pharmaceuticals Inc., USA, assignee. Quinoline derivatives as urotensin-II receptor antagonists and their preparation, pharmaceutical compositions and use in the treatment of diseases. Patent WO 2009-053895. 2009 Apr 30

Khan SQ, Bhandari SS, Quinn P, Davies JE, and Ng LL (2007) Urotensin II is raised in acute myocardial infarction and low levels predict risk of adverse clinical outcome in humans. Int $J$ Cardiol 117:323-328.

Kim SK, Li Y, Park C, Abrol R, and Goddard WA 3rd (2010) Prediction of the threedimensional structure for the rat urotensin II receptor, and comparison of the antagonist binding sites and binding selectivity between human and rat receptors from atomistic simulations. ChemMedChem 5:1594-1608.

Kinney WA, Almond HR Jr, Qi J, Smith CE, Santulli RJ, de Garavilla L, AndradeGordon P, Cho DS, Everson AM, Feinstein MA, et al. (2002) Structure-function analysis of urotensin II and its use in the construction of a ligand-receptor working model. Angew Chem Int Ed Engl 41:2940-2944.

Kirchmair R, Hogue-Angeletti R, Gutierrez J, Fischer-Colbrie R, and Winkler H (1993) Secretoneurin-a neuropeptide generated in brain, adrenal medulla and 
other endocrine tissues by proteolytic processing of secretogranin II (chromogranin C). Neuroscience 53:359-365.

Kobayashi Y, Lederis K, Rivier J, Ko D, McMaster D, and Poulin P (1986) Radioimmunoassays for fish tail neuropeptides: II. Development of a specific and sensitive assay for and the occurrence of immunoreactive urotensin II in the central nervous system and blood of Catostomus commersoni. J Pharmacol Methods 15:321-333.

Kompa AR, Thomas WG, See F, Tzanidis A, Hannan RD, and Krum H (2004) Cardiovascular role of urotensin II: effect of chronic infusion in the rat. Peptides 25:1783-1788.

Konno N, Fujii Y, Imae H, Kaiya H, Mukuda T, Miyazato M, Matsuda K, and Uchiyama M (2013) Urotensin II receptor (UTR) exists in hyaline chondrocytes: a study of peripheral distribution of UTR in the African clawed frog, Xenopus laevis. Gen Comp Endocrinol 185:44-56.

Kriegsfeld LJ, Mei DF, Bentley GE, Ubuka T, Mason AO, Inoue K, Ukena K, Tsutsui K, and Silver R (2006) Identification and characterization of a gonadotropin-inhibitory system in the brains of mammals. Proc Natl Acad Sci USA 103:2410-2415.

Kristof AS, You Z, Han YS, and Giaid A (2010) Protein expression of urotensin II, urotensin-related peptide and their receptor in the lungs of patients with lymphangioleiomyomatosis. Peptides 31:1511-1516.

Krum H and Gilbert RE (2003) Urotensin II: a new player in vascular and myocardial disease? Clin Sci (Lond) 104:65-67.

Krum H and Kemp W (2007) Therapeutic potential of blockade of the urotensin II system in systemic hypertension. Curr Hypertens Rep 9:53-58.

Labarrère P, Chatenet D, Leprince J, Marionneau C, Loirand G, Tonon MC, Dubessy C, Scalbert E, Pfeiffer B, Renard P, et al. (2003) Structure-activity relationships of human urotensin II and related analogues on rat aortic ring contraction. $J$ Enzyme Inhib Med Chem 18:77-88.

Lancien F, Leprince J, Mimassi N, Mabin D, Vaudry H, and Le Mével JC (2004) Central effects of native urotensin II on motor activity, ventilatory movements, and heart rate in the trout Oncorhynchus mykiss. Brain Res 1023:167-174.

Langham RG, Kelly DJ, Gow RM, Zhang Y, Dowling JK, Thomson NM, and Gilbert $\mathrm{RE}$ (2004) Increased expression of urotensin II and urotensin II receptor in human diabetic nephropathy. Am J Kidney Dis 44:826-831.

Lapp H, Boerrigter G, Costello-Boerrigter LC, Jaekel K, Scheffold T, Krakau I, Schramm M, Guelker H, and Stasch JP (2004) Elevated plasma human urotensinII-like immunoreactivity in ischemic cardiomyopathy. Int J Cardiol 94:93-97.

Larhammar D, Bergqvist C, Sundström G, and Ocampo Daza D (2012) Evolution of receptors for somatostatin and urotensin II. 26th Conference of European Comparative Endocrinologists; 2012 Aug 21-25; Zurich, Switzerland. pp A13.5.

Lavecchia A, Cosconati S, and Novellino E (2005) Architecture of the human urotensin II receptor: comparison of the binding domains of peptide and non-peptide urotensin II agonists. J Med Chem 48:2480-2492.

Lawson EC, Luci DK, Ghosh S, Kinney WA, Reynolds CH, Qi J, Smith CE, Wang Y, Minor LK, Haertlein BJ, et al. (2009) Nonpeptide urotensin-II receptor antagonists: a new ligand class based on piperazino-phthalimide and piperazino-isoindolinone subunits. J Med Chem 52:7432-7445.

Lederis K (1970) Teleost urophysis. II. Biological characterization of the bladdercontracting activity. Gen Comp Endocrinol 14:427-437.

Lederis K, Letter A, McMaster D, Moore G, and Schlesinger D (1982) Complete amino acid sequence of urotensin I, a hypotensive and corticotropin-releasing neuropeptide from Catostomus. Science 218:162-165.

Lehmann F, Currier EA, Clemons B, Hansen LK, Olsson R, Hacksell U, and Luthman K (2009) Novel and potent small-molecule urotensin II receptor agonists. Bioorg Med Chem 17:4657-4665.

Lehmann F, Currier EA, Olsson R, Hacksell U, and Luthman K (2005) Isochromanonebased urotensin-II receptor agonists. Bioorg Med Chem 13:3057-3068.

Lehmann F, Pettersen A, Currier EA, Sherbukhin V, Olsson R, Hacksell U, and Luthman K (2006) Novel potent and efficacious nonpeptidic urotensin II receptor agonists. J Med Chem 49:2232-2240.

Lehner U, Velić A, Schroter R, Schlatter E, and Sindić A (2007) Ligands and signaling of the G-protein-coupled receptor GPR14, expressed in human kidney cells. Cell Physiol Biochem 20:181-192.

Le Mével JC, Lancien F, Mimassi N, and Conlon JM (2012) Brain neuropeptides in central ventilatory and cardiovascular regulation in trout. Front Endocrinol (Lausanne) 3:124 10.3389/fendo.2012.00124

Le Mével JC, Lancien F, Mimassi N, Leprince J, Conlon JM, and Vaudry H (2008) Central and peripheral cardiovascular, ventilatory, and motor effects of trout urotensin-II in the trout. Peptides 29:830-837.

Le Mével JC, Leprince J, Lancien F, Mimassi N, and Vaudry H (2013) Cardioventilatory and locomotor effects of centrally administered urotensin II and urotensin II-related peptides in the unanesthetized trout. 17th International Congress of Comparative Endocrinology; 2013 Jul 15-19; Barcelona. Abst P-131.

Le Mével JC, Olson KR, Conklin D, Waugh D, Smith DD, Vaudry H, and Conlon JM (1996) Cardiovascular actions of trout urotensin II in the conscious trout, Oncorhynchus mykiss. Am J Physiol 271:R1335-R1343.

Leprince J, Chatenet D, Dubessy C, Fournier A, Pfeiffer B, Scalbert E, Renard P, Pacaud P, Oulyadi H, Ségalas-Milazzo I, et al. (2008) Structure-activity relationships of urotensin II and URP. Peptides 29:658-673.

Lescot E, Bureau R, and Rault S (2008a) Nonpeptide Urotensin-II receptor agonists and antagonists: review and structure-activity relationships. Peptides 29:680-690.

Lescot E, Sopkova-de Oliveira Santos J, Colloc'h N, Rodrigo J, Milazzo-Segalas I, Bureau $R$, and Rault S (2008b) Three-dimensional model of the human urotensin-II receptor: docking of human urotensin-II and nonpeptide antagonists in the binding site and comparison with an antagonist pharmacophore model. Proteins 73:173-184.

Lescot E, Sopkova-de Oliveira Santos J, Dubessy C, Oulyadi H, Lesnard A, Vaudry H, Bureau R, and Rault S (2007) Definition of new pharmacophores for nonpeptide antagonists of human urotensin-II. Comparison with the 3D-structure of human urotensin-II and URP. J Chem Inf Model 47:602-612.

Lihrmann I, Tostivint H, Bern H, and Vaudry H (2013) Urotensin II peptides, in Handbook of Biologically Active Peptides, 2nd ed (Kastin ED ed), pp 957-965, Academic Press, New York.
Lim M, Honisett S, Sparkes CD, Komesaroff P, Kompa A, and Krum H (2004) Differential effect of urotensin II on vascular tone in normal subjects and patients with chronic heart failure. Circulation 109:1212-1214

Lin Y, Tsuchihashi T, Matsumura K, Abe I, and Iida M (2003a) Central cardiovascular action of urotensin II in conscious rats. J Hypertens 21:159-165.

Lin Y, Tsuchihashi T, Matsumura K, Fukuhara M, Ohya Y, Fujii K, and Iida M (2003b) Central cardiovascular action of urotensin II in spontaneously hypertensive rats. Hypertens Res 26:839-845.

Liu D, Chen J, Wang J, Zhang Z, Ma X, Jia J, and Wang Y (2010a) Increased expression of urotensin II and GPR14 in patients with cirrhosis and portal hypertension. Int $J$ Mol Med 25:845-851.

Liu F and Zhu YC (2010) Urotensin II inhibits glucokinase expression and glucoseinduced insulin secretion. Sheng Li Xue Bao 62:129-136.

Liu JC, Chen CH, Chen JJ, and Cheng TH (2009) Urotensin II induces rat cardiomyocyte hypertrophy via the transient oxidization of Src homology 2-containing tyrosine phosphatase and transactivation of epidermal growth factor receptor. Mol Pharmacol 76:1186-1195.

Liu Q, Pong SS, Zeng Z, Zhang Q, Howard AD, Williams DL Jr, Davidoff M, Wang R, Austin CP, McDonald TP, et al. (1999) Identification of urotensin II as the endogenous ligand for the orphan G-protein-coupled receptor GPR14. Biochem Biophys Res Commun 266:174-178.

Liu Y, Lu D, Zhang Y, Li S, Liu X, and Lin H (2010b) The evolution of somatostatin in vertebrates. Gene 463:21-28.

Loirand G, Rolli-Derkinderen M, and Pacaud P (2008) Urotensin II and atherosclerosis. Peptides 29:778-782.

Loretz CA (1990) Recognition by goby intestine of a somatostatin analog, SMS 201-995. J Exp Zool Suppl 4:31-36.

Loretz CA and Assad JA (1986) Urotensin II lowers cytoplasmic free calcium concentration in goby enterocytes: measurements using quin2. Gen Comp Endocrinol 64:355-361.

Loretz CA and Bern HA (1981) Stimulation of sodium transport across the teleost urinary bladder by urotensin II. Gen Comp Endocrinol 43:325-330.

Loretz C, Bern HA, Foskett JK, and Mainoya JR (1982) The caudal neurosecretory system and osmoregulation in fish, in Neurosecretion: Molecules, Cells, Systems (Farner DS and Ledens K eds), pp 319-328, Plenum Press, New York.

Loretz CA, Freel RW, and Bern HA (1983) Specificity of response of intestinal ion transport systems to a pair of natural peptide hormone analogs: somatostatin and urotensin II. Gen Comp Endocrinol 52:198-206.

Loretz CA, Howard ME, and Siegel AJ (1985) Ion transport in goby intestine: cellular mechanism of urotensin II stimulation. Am J Physiol 249:G284-G293.

$\mathrm{Lu}$ W, Abdel-Razik AE, Ashton N, and Balment RJ (2008) Urotensin II: lessons from comparative studies for general endocrinology. Gen Comp Endocrinol 157:14-20.

Lu W, Greenwood M, Dow L, Yuill J, Worthington J, Brierley MJ, McCrohan CR, Riccardi D, and Balment RJ (2006) Molecular characterization and expression of urotensin II and its receptor in the flounder (Platichthys flesus): a hormone system supporting body fluid homeostasis in euryhaline fish. Endocrinology 147:3692-3708.

$\mathrm{Lu}$ Y, Zou CJ, Huang DW, and Tang CS (2002) Cardiovascular effects of urotensin II in different brain areas. Peptides 23:1631-1635.

MacLean MR, Alexander D, Stirrat A, Gallagher M, Douglas SA, Ohlstein EH, Morecroft I, and Polland K (2000) Contractile responses to human urotensin-II in rat and human pulmonary arteries: effect of endothelial factors and chronic hypoxia in the rat $B r J$ Pharmacol 130:201-204.

Maguire JJ, Kuc RE, and Davenport AP (2000) Orphan-receptor ligand human urotensin II: receptor localization in human tissues and comparison of vasoconstrictor responses with endothelin-1. Br J Pharmacol 131:441-446.

Maguire JJ, Kuc RE, Kleinz MJ, and Davenport AP (2008) Immunocytochemical localization of the urotensin-II receptor, UT, to rat and human tissues: relevance to function. Peptides 29:735-742.

Maguire JJ, Kuc RE, Wiley KE, Kleinz MJ, and Davenport AP (2004) Cellular distribution of immunoreactive urotensin-II in human tissues with evidence of increased expression in atherosclerosis and a greater constrictor response of small compared to large coronary arteries. Peptides 25:1767-1774.

Mainoya JR and Bern HA (1982) Effects of teleost urotensins on intestinal absorption of water and Nacl in tilapia, sarotherodon mossambicus, adapted to fresh water or seawater. Gen Comp Endocrinol 47:54-58.

Mainoya JR and Bern HA (1984) Influence of vasoactive intestinal peptide and urotensin II on the absorption of water and $\mathrm{NaCl}$ by the anterior intestine of the tilapia, Sarotherodon mossambicus. Zool Sci 1:100-105.

Malagon MM, Molina M, Gahete MD, Duran-Prado M, Martinez-Fuentes AJ, Alcain FJ, Tonon MC, Leprince J, Vaudry H, Castaño JP, et al. (2008) Urotensin II and urotensin II-related peptide activate somatostatin receptor subtypes 2 and 5 . Peptides 29:711-720.

Marchese A, Heiber M, Nguyen T, Heng HH, Saldivia VR, Cheng R, Murphy PM, Tsui LC, Shi X, Gregor P, et al. (1995) Cloning and chromosomal mapping of three novel genes, GPR9, GPR10, and GPR14, encoding receptors related to interleukin 8, neuropeptide Y, and somatostatin receptors. Genomics 29:335-344.

Marco J, Egido EM, Hernández R, and Silvestre RA (2008) Evidence for endogenous urotensin-II as an inhibitor of insulin secretion. Study in the perfused rat pancreas. Peptides 29:852-858.

Marshall WS and Bern HA (1979) Teleostean urophysis: urotensin II and ion transport across the isolated skin of a marine teleost. Science 204:519-521.

Marshall WS and Bern HA (1981) Active chloride transport by the skin of a marine teleost is stimulated by urotensin I and inhibited by urotensin II. Gen Comp Endocrinol 43:484-491.

Maryanoff BE and Kinney WA (2010) Urotensin-II receptor modulators as potential drugs. J Med Chem 53:2695-2708.

Matsumoto Y, Abe M, Watanabe T, Adachi Y, Yano T, Takahashi H, Sugo T, Mori M, Kitada C, Kurokawa T, et al. (2004) Intracerebroventricular administration of urotensin II promotes anxiogenic-like behaviors in rodents. Neurosci Lett 358: 99-102. 
Matsushita M, Shichiri M, Fukai N, Ozawa N, Yoshimoto T, Takasu N, and Hirata Y (2003) Urotensin II is an autocrine/paracrine growth factor for the porcine renal epithelial cell line, LLCPK1. Endocrinology 144:1825-1831.

Matsushita M, Shichiri M, Imai T, Iwashina M, Tanaka H, Takasu N, and Hirata Y (2001) Co-expression of urotensin II and its receptor (GPR14) in human cardiovascular and renal tissues. J Hypertens 19:2185-2190.

McCrohan CR, Lu W, Brierley MJ, Dow L, and Balment RJ (2007) Fish caudal neurosecretory system: a model for the study of neuroendocrine secretion. Gen Comp Endocrinol 153:243-250.

McDonald J, Batuwangala M, and Lambert DG (2007) Role of urotensin II and its receptor in health and disease. $J$ Anesth 21:378-389.

McMaster D, Belenky MA, Polenov AL, and Lederis K (1992) Isolation and amino acid sequence of urotensin II from the sturgeon Acipenser ruthenus. Gen Comp Endocrinol 87:275-285.

McMaster D, Kobayashi Y, Rivier J, and Lederis K (1986) Characterization of the biologically and antigenically important regions of urotensin II. Proc West Pharmacol Soc 29:205-208.

McMaster D and Lederis K (1983) Isolation and amino acid sequence of two urotensin II peptides from Catostomus commersoni urophyses. Peptides 4:367-373.

Medakovic M, Chan DK, and Lederis K (1975) Pharmacological effects of urotensins. I. Regional vascular effects of urotensins I and II in the rat. Pharmacology 13 409-418.

Merlino F, Di Maro S, Munaim Yousif A, Caraglia M, and Grieco P (2013) Urotensin-II ligands: An overview from peptide to nonpeptide structures. J Amino Acids DOI: $10.1155 / 2013 / 979016$

Mirabeau O and Joly JS (2013) Molecular evolution of peptidergic signaling systems in bilaterians. Proc Natl Acad Sci USA 110:E2028-E2037.

Mori M, Sugo T, Abe M, Shimomura Y, Kurihara M, Kitada C, Kikuchi K, Shintani Y, Kurokawa T, Onda H, et al. (1999) Urotensin II is the endogenous ligand of a G-protein-coupled orphan receptor, SENR (GPR14). Biochem Biophys Res Commun 265:123-129.

Mori N, Hirose T, Nakayama T, Ito O, Kanazawa M, Imai Y, Kohzuki M, Takahashi $\mathrm{K}$, and Totsune K (2009) Increased expression of urotensin II-related peptide and its receptor in kidney with hypertension or renal failure. Peptides 30:400-408.

Morimoto R, Satoh F, Murakami O, Totsune K, Arai Y, Suzuki T, Sasano H, Ito S, and Takahashi K (2008) Immunolocalization of urotensin II and its receptor in human adrenal tumors and attached non-neoplastic adrenal tissues. Peptides 29: 873-880.

Muramatsu I and Kobayashi Y (1979) Effects of urotensins on the cardiovascular system of a teleost fish and a bird. 16th Gunma Symposia on Endocrinology; 1978 May 31-Jun 1; Maebashi, Japan. pp 49-56.

Nakayama T, Hirose T, Totsune K, Mori N, Maruyama Y, Maejima T, Minagawa K, Morimoto R, Asayama K, Kikuya M, et al (2008) Increased gene expression of urotensin II-related peptide in the hearts of rats with congestive heart failure. Peptides 29:801-808

Ng LL, Loke I, O'Brien RJ, Squire IB, and Davies JE (2002) Plasma urotensin in human systolic heart failure. Circulation 106:2877-2880.

Nilsson T, Arkhammar P, Rorsman P, and Berggren PO (1989) Suppression of insulin release by galanin and somatostatin is mediated by a G-protein. An effect involving repolarization and reduction in cytoplasmic free $\mathrm{Ca} 2+$ concentration. J Biol Chem 264:973-980.

Nishikawa N, Masuyama T, Yamamoto K, Sakata Y, Mano T, Miwa T, Sugawara M, and Hori M (2001) Long-term administration of amlodipine prevents decompensation to diastolic heart failure in hypertensive rats. J Am Coll Cardiol 38: $1539-1545$.

Nobata S, Donald JA, Balment RJ, and Takei Y (2011) Potent cardiovascular effects of homologous urotensin II (UII)-related peptide and UII in unanesthetized eels after peripheral and central injections. Am J Physiol Regul Integr Comp Physiol 300:R437-R446

Nothacker HP and Clark S (2005) From heart to mind. The urotensin II system and its evolving neurophysiological role. FEBS J 272:5694-5702.

Nothacker HP, Wang Z, McNeill AM, Saito Y, Merten S, O'Dowd B, Duckles SP, and Civelli O (1999) Identification of the natural ligand of an orphan G-proteincoupled receptor involved in the regulation of vasoconstriction. Nat Cell Biol $\mathbf{1}$ : $383-385$

Oguri M, Kato K, Yokoi K, Itoh T, Yoshida T, Watanabe S, Metoki N, Yoshida H, Satoh K, Aoyagi Y, et al. (2009) Association of genetic variants with myocardial infarction in Japanese individuals with metabolic syndrome. Atherosclerosis 206 486-493.

Ohsako S, Ishida I, Ichikawa T, and Deguchi T (1986) Cloning and sequence analysis of cDNAs encoding precursors of urotensin II-alpha and -gamma. J Neurosci 6 : $2730-2735$

Oka S, Honma Y, Iwanaga T, and Fujita T (1989) Immunohistochemical demonstration of urotensins I and II in the caudal neurosecretory system of the white sturgeon, Acipender transmontanus Richardson. Biomed Res 10 (Suppl 3):329-340.

Okumus S, Igci YZ, Taskin T, Oztuzcu S, Gurler B, Eslik Z, Gogebakan B, Coskun E, Erbagci I, Demiryurek S, et al. (2012) Association between Thr21Met and Ser89 Asn polymorphisms of the urotensin-II (UTS2) gene, diabetes mellitus, and diabetic retinopathy. Curr Eye Res 37:921-929.

Onan D, Hannan RD, and Thomas WG (2004a) Urotensin II: the old kid in town. Trends Endocrinol Metab 15:175-182.

Onan D, Pipolo L, Yang E, Hannan RD, and Thomas WG (2004b) Urotensin II promotes hypertrophy of cardiac myocytes via mitogen-activated protein kinases. $\mathrm{Mol}$ Endocrinol 18:2344-2354.

Onat AM, Pehlivan Y, Turkbeyler IH, Demir T, Kaplan DS, Ceribasi AO, Orkmez M, Tutar E, Taysi S, Sayarlioglu M, et al. (2013) Urotensin inhibition with palosuran could be a promising alternative in pulmonary arterial hypertension. Inflammation 36:405-412.

Ong KL, Lam KS, and Cheung BM (2005) Urotensin II: its function in health and its role in disease. Cardiovasc Drugs Ther 19:65-75.
Ong KL, Wong LY, and Cheung BM (2008) The role of urotensin II in the metabolic syndrome. Peptides 29:859-867.

Ong KL, Wong LY, Man YB, Leung RY, Song YQ, Lam KS, and Cheung BM (2006) Haplotypes in the urotensin II gene and urotensin II receptor gene are associated with insulin resistance and impaired glucose tolerance. Peptides 27:1659-1667.

Ono T, Kawaguchi Y, Kudo M, Kushikata T, Hashiba E, Yoshida H, Kudo T, Furukawa K, Douglas SA, Guerrini R, et al (2008) Urotensin II evokes neurotransmitter release from rat cerebrocortical slices. Neurosci Lett 440:275-279.

Onstott D and Elde R (1986) Immunohistochemical localization of urotensin $\mathrm{I} /$ corticotropin-releasing factor, urotensin II, and serotonin immunoreactivities in the caudal spinal cord of nonteleost fishes. J Comp Neurol 249:205-225.

Owada K, Kawata M, Akaji K, Takagi A, Moriga M, and Kobayashi H (1985) Urotensin II-immunoreactive neurons in the caudal neurosecretory system of freshwater and seawater fish. Cell Tissue Res 239:349-354.

Pakala R (2008) Role of urotensin II in atherosclerotic cardiovascular diseases. Cardiovasc Revasc Med 9:166-178.

Papadopoulos P, Bousette N, and Giaid A (2008) Urotensin-II and cardiovascular remodeling. Peptides 29:764-769.

Parmentier C, Hameury E, Dubessy C, Quan FB, Habert D, Calas A, Vaudry H, Lihrmann I, and Tostivint $\mathrm{H}$ (2011) Occurrence of two distinct urotensin II-related peptides in zebrafish provides new insight into the evolutionary history of the urotensin II gene family. Endocrinology 152:2330-2341.

Parmentier C, Taxi J, Balment R, Nicolas G, and Calas A (2006) Caudal neurosecretory system of the zebrafish: ultrastructural organization and immunocytochemical detection of urotensins. Cell Tissue Res 325:111-124.

Parys JB and De Smedt H (2012) Inositol 1,4,5-trisphosphate and its receptors. Adv Exp Med Biol 740:255-279.

Patacchini R, Santicioli P, Giuliani S, Grieco P, Novellino E, Rovero P, and Maggi CA (2003) Urantide: an ultrapotent urotensin II antagonist peptide in the rat aorta. Br J Pharmacol 140:1155-1158.

Paysant J, Rupin A, Simonet S, Fabiani JN, and Verbeuren TJ (2001) Comparison of the contractile responses of human coronary bypass grafts and monkey arteries to human urotensin-II. Fundam Clin Pharmacol 15:227-231.

Pearson D, Shively JE, Clark BR, Geschwind II, Barkley M, Nishioka RS, and Bern HA (1980) Urotensin II: a somatostatin-like peptide in the caudal neurosecretory system of fishes. Proc Natl Acad Sci USA 77:5021-5024.

Pelletier G, Lihrmann I, Dubessy C, Luu-The V, Vaudry H, and Labrie F (2005) Androgenic down-regulation of urotensin II precursor, urotensin II-related peptide precursor and androgen receptor mRNA in the mouse spinal cord. Neuroscience 132:689-696.

Pelletier G, Lihrmann I, and Vaudry H (2002) Role of androgens in the regulation of urotensin II precursor mRNA expression in the rat brainstem and spinal cord. Neuroscience 115:525-532.

Perkins TD, Bansal S, and Barlow DJ (1990) Molecular modelling and design of analogues of the peptide hormone urotensin II. Biochem Soc Trans 18:918-919.

Petersen TN, Brunak S, von Heijne G, and Nielsen H (2011) SignalP 4.0: discriminating signal peptides from transmembrane regions. Nat Methods 8:785-786.

Phelps PE, Barber RP, and Vaughn JE (1988) Generation patterns of four groups of cholinergic neurons in rat cervical spinal cord: a combined tritiated thymidine autoradiographic and choline acetyltransferase immunocytochemical study. J Comp Neurol 273:459-472.

Portnoy A, Kumar S, Behm DJ, Mahar KM, Noble RB, Throup JP, and Russ SF (2013) Effects of urotensin II receptor antagonist, GSK1440115, in asthma. Front Pharmacol 4:54.

Preininger AM, Meiler J, and Hamm HE (2013) Conformational flexibility and structural dynamics in GPCR-mediated G protein activation: a perspective. $J \mathrm{Mol}$ Biol 425:2288-2298.

Prosser HC, Forster ME, Richards AM, and Pemberton CJ (2008) Urotensin II and urotensin II-related peptide (URP) in cardiac ischemia-reperfusion injury. Peptides 29:770-777.

Prosser HC, Leprince J, Vaudry H, Richards AM, Forster ME, and Pemberton C. (2006) Cardiovascular effects of native and non-native urotensin II and urotensin II-related peptide on rat and salmon hearts. Peptides 27:3261-3268.

Qi J, Du J, Tang X, Li J, Wei B, and Tang C (2004) The upregulation of endothelial nitric oxide synthase and urotensin-II is associated with pulmonary hypertension and vascular diseases in rats produced by aortocaval shunting. Heart Vessels 19:81-88.

Qi JS, Minor LK, Smith C, Hu B, Yang J, Andrade-Gordon P, and Damiano B (2005) Characterization of functional urotensin II receptors in human skeletal muscle myoblasts: comparison with angiotensin II receptors. Peptides 26:683-690.

Quan FB, Bougerol M, Rigour F, Kenigfest NB, and Tostivint H (2012) Characterization of the true ortholog of the urotensin II-related peptide (URP) gene in teleosts. Gen Comp Endocrinol 177:205-212.

Quattrochi JJ, Mamelak AN, Madison RD, Macklis JD, and Hobson JA (1989) Mapping neuronal inputs to REM sleep induction sites with carbachol-fluorescent microspheres. Science 245:984-986.

Rdzanek A, Filipiak KJ, Karpiński G, Grabowski M, and Opolski G (2006) Exercise urotensin II dynamics in myocardial infarction survivors with and without hypertension. Int $J$ Cardiol 110:175-178.

Richards AM, Nicholls MG, Lainchbury JG, Fisher S, and Yandle TG (2002) Plasma urotensin II in heart failure. Lancet 360:545-546.

Rivas RJ, Nishioka RS, and Bern HA (1986) In vitro effects of somatostatin and urotensin II on prolactin and growth hormone secretion in tilapia, Oreochromis mossambicus. Gen Comp Endocrinol 63:245-251.

Rodríguez-Moyano M, Díaz I, Dionisio N, Zhang X, Avila-Medina J, Calderón-Sánchez E, Trebak M, Rosado JA, Ordóñez A, and Smani T (2013) Urotensin-II promotes vascular smooth muscle cell proliferation through store-operated calcium entry and EGFR transactivation. Cardiovasc Res 100:297-306.

Romanova EV, Sasaki K, Alexeeva V, Vilim FS, Jing J, Richmond TA, Weiss KR, and Sweedler JV (2012) Urotensin II in invertebrates: from structure to function in Aplysia californica. PLoS ONE 7:e48764. 
Rossowski WJ, Cheng BL, Taylor JE, Datta R, and Coy DH (2002) Human urotensin II-induced aorta ring contractions are mediated by protein kinase $\mathrm{C}$, tyrosine kinases and Rho-kinase: inhibition by somatostatin receptor antagonists. Eur $J$ Pharmacol 438:159-170.

Russell FD (2004) Emerging roles of urotensin-II in cardiovascular disease. Pharmacol Ther 103:223-243.

Russell FD (2008) Urotensin II in cardiovascular regulation. Vasc Health Risk Manag 4:775-785

Russell FD, Kearns P, Toth I, and Molenaar P (2004) Urotensin-II-converting enzyme activity of furin and trypsin in human cells in vitro. $J$ Pharmacol Exp Ther $\mathbf{3 1 0}$ 209-214.

Russell FD, Meyers D, Galbraith AJ, Bett N, Toth I, Kearns P, and Molenaar P (2003) Elevated plasma levels of human urotensin-II immunoreactivity in congestive heart failure. Am J Physiol Heart Circ Physiol 285:H1576-H1581.

Russell FD and Molenaar P (2004) Cardiovascular actions of human urotensin II-considerations for hypertension. Naunyn Schmiedebergs Arch Pharmacol 369:271-273.

Russell FD, Molenaar P, and O'Brien DM (2001) Cardiostimulant effects of urotensin-II in human heart in vitro. $\mathrm{Br} J$ Pharmacol 132:5-9.

Saetrum Opgaard O, Nothacker H, Ehlert FJ, and Krause DN (2000) Human urotensin II mediates vasoconstriction via an increase in inositol phosphates. Eur J Pharmacol 406:265-271.

Sáez ME, Smani T, Ramírez-Lorca R, Díaz I, Serrano-Ríos M, Ruiz A, and Ordoñez A (2011) Association analysis of urotensin II gene (UTS2) and flanking regions with biochemical parameters related to insulin resistance. PLoS ONE 6:e19327.

Sainsily X, Cabana J, Boulais PE, Holleran BJ, Escher E, Lavigne P, and Leduc R (2013) Identification of transmembrane domain $3,4 \& 5$ residues that contribute to the formation of the ligand-binding pocket of the urotensin-II receptor. Biochem Pharmacol 86:1584-1593.

Sauzeau V, Le Mellionnec E, Bertoglio J, Scalbert E, Pacaud P, and Loirand G (2001) Human urotensin II-induced contraction and arterial smooth muscle cell proliferation are mediated by RhoA and Rho-kinase. Circ Res 88:1102-1104.

Sawada M and Ichinose M (1999) Potentiation of GABA(A) receptor-mediated Cl-current by urotensin peptides in identified Aplysia neurons. J Neurosci Res $\mathbf{5 6}$ $547-552$

Schlüter H, Jankowski J, Rykl J, Thiemann J, Belgardt S, Zidek W, Wittmann B, and Pohl T (2003) Detection of protease activities with the mass-spectrometryassisted enzyme-screening (MES) system. Anal Bioanal Chem 377:1102-1107.

Segain JP, Rolli-Derkinderen M, Gervois N, Raingeard de la Blétière D, Loirand G, and Pacaud P (2007) Urotensin II is a new chemotactic factor for UT receptorexpressing monocytes. J Immunol 179:901-909.

Seidah NG, Sadr MS, Chrétien M, and Mbikay M (2013) The multifaceted proprotein convertases: their unique, redundant, complementary, and opposite functions. J Biol Chem 288:21473-21481.

Shapiro MD, Kronenberg Z, Li C, Domyan ET, Pan H, Campbell M, Tan H, Huff CD, Hu H, Vickrey AI, et al. (2013) Genomic diversity and evolution of the head crest in the rock pigeon. Science 339:1063-1067.

Sharp GW (1996) Mechanisms of inhibition of insulin release. Am J Physiol 271 C1781-C1799.

Shenouda A, Douglas SA, Ohlstein EH, and Giaid A (2002) Localization of urotensinII immunoreactivity in normal human kidneys and renal carcinoma. J Histochem Cytochem 50:885-889.

Sheridan MA, Plisetskaya EM, Bern HA, and Gorbman A (1987) Effects of somatostatin-25 and urotensin II on lipid and carbohydrate metabolism of coho salmon, Oncorhynchus kisutch. Gen Comp Endocrinol 66:405-414.

Sidharta PN, Rave K, Heinemann L, Chiossi E, Krähenbühl S, and Dingemanse J (2009) Effect of the urotensin-II receptor antagonist palosuran on secretion of and sensitivity to insulin in patients with Type 2 diabetes mellitus. $\mathrm{Br} J$ Clin Pharmacol 68:502-510.

Sidharta PN, Wagner FD, Bohnemeier H, Jungnik A, Halabi A, Krähenbühl S, Chadha-Boreham H and Dingemanse J (2006) Pharmacodynamics and pharmacokinetics of the urotensin II receptor antagonist palosuran in macroalbuminuric, diabetic patients. Clin Pharmacol Ther 80:246-256.

Silvestre RA, Egido EM, Hernández R, Leprince J, Chatenet D, Tollemer H, Chartrel $\mathrm{N}$, Vaudry $\mathrm{H}$, and Marco $\mathrm{J}$ (2004) Urotensin-II is present in pancreatic extracts and inhibits insulin release in the perfused rat pancreas. Eur $J$ Endocrinol 151: 803-809

Silvestre RA, Egido EM, Hernández R, and Marco J (2009) Characterization of the insulinostatic effect of urotensin II: a study in the perfused rat pancreas. Regul Pept 153:37-42.

Silvestre RA, Miralles P, Moreno P, Villanueva ML, and Marco J (1986) Somatostatin, insulin and glucagon secretion by the perfused pancreas from the cysteamine-treated rat. Biochem Biophys Res Commun 134:1291-1297.

Silvestre RA, Rodríguez-Gallardo J, Egido EM, and Marco J (2001) Inhibition of insulin release by urotensin II-a study on the perfused rat pancreas. Horm Metab Res 33:379-381.

Singh S, Robinson M, Ismail I, Saha M, Auer H, Kornacker K, Robinson ML, Bates CM, and McHugh KM (2008) Transcriptional profiling of the megabladder mouse: a unique model of bladder dysmorphogenesis. Dev Dyn 237:170-186.

Song W, Abdel-Razik AE, Lu W, Ao Z, Johns DG, Douglas SA, Balment RJ, and Ashton N (2006a) Urotensin II and renal function in the rat. Kidney Int 69 $1360-1368$.

Song W, McDonald J, Camarda V, Calo G, Guerrini R, Marzola E, Thompson JP, Rowbotham DJ, and Lambert DG (2006b) Cell and tissue responses of a range of Urotensin II analogs at cloned and native urotensin II receptors. Evidence for coupling promiscuity. Naunyn Schmiedebergs Arch Pharmacol 373:148-157.

Spinazzi R, Albertin G, Nico B, Guidolin D, Di Liddo R, Rossi GP, Ribatti D, and Nussdorfer GG (2006) Urotensin-II and its receptor (UT-R) are expressed in rat brain endothelial cells, and urotensin-II via UT-R stimulates angiogenesis in vivo and in vitro. Int $J$ Mol Med 18:1107-1112.
Steriade M and McCarley R (1990) Brainstem control of wakefulness and sleep, Plenum Press, New York.

Stirrat A, Gallagher M, Douglas SA, Ohlstein EH, Berry C, Kirk A, Richardson M, and MacLean MR (2001) Potent vasodilator responses to human urotensin-II in human pulmonary and abdominal resistance arteries. Am J Physiol Heart Circ Physiol 280:H925-H928.

Sugden PH, Fuller SJ, Weiss SC, and Clerk A (2008) Glycogen synthase kinase 3 (GSK3) in the heart: a point of integration in hypertrophic signalling and a therapeutic target? A critical analysis. Br J Pharmacol 153 (Suppl 1):S137-S153.

Sugo T, Murakami Y, Shimomura Y, Harada M, Abe M, Ishibashi Y, Kitada C, Miyajima N, Suzuki N, Mori M, et al. (2003) Identification of urotensin II-related peptide as the urotensin II-immunoreactive molecule in the rat brain. Biochem Biophys Res Commun 310:860-868.

Suguro T, Watanabe T, Kodate S, Xu G, Hirano T, Adachi M, and Miyazaki A (2008) Increased plasma urotensin-II levels are associated with diabetic retinopathy and carotid atherosclerosis in Type 2 diabetes. Clin Sci (Lond) 115:327-334.

Sun C, Duan D, Li B, Qin C, Jia J, Wang B, Dong H, and Li W (2014) UII and UT in grouper: cloning and effects on the transcription of hormones related to growth control. J Endocrinol 220:35-48.

Sun HX, Du WN, Zuo J, Wu GD, Shi GB, Shen Y, Qiang BQ, Yao ZJ, Hang JM, Wang $\mathrm{H}$, et al. (2002) The association of two single nucleotide polymorphisms in PRKCZ and UTS2 respectively with type 2 diabetes in Han people of northern China. Zhongguo Yi Xue Ke Xue Yuan Xue Bao 24:223-227.

Suzuki S, Wenyi Z, Hirai M, Hinokio Y, Suzuki C, Yamada T, Yoshizumi S, Suzuki M, Tanizawa Y, Matsutani A, et al. (2004) Genetic variations at urotensin II and urotensin II receptor genes and risk of type 2 diabetes mellitus in Japanese. Peptides 25:1803-1808

Takahashi K, Totsune K, Murakami O, Arihara Z, Noshiro T, Hayashi Y, and Shibahara S (2003) Expression of urotensin II and its receptor in adrenal tumors and stimulation of proliferation of cultured tumor cells by urotensin II. Peptides 24:301-306.

Takahashi K, Totsune K, Murakami O, and Shibahara S (2001) Expression of urotensin II and urotensin II receptor mRNAs in various human tumor cell lines and secretion of urotensin II-like immunoreactivity by SW-13 adrenocortical carcinoma cells. Peptides 22:1175-1179.

Takei Y, Hyodo S, Katafuchi T, and Minamino N (2004a) Novel fish-derived adrenomedullin in mammals: structure and possible function. Peptides 25:1643-1656.

Takei Y, Inoue K, Ogoshi M, Kawahara T, Bannai H, and Miyano S (2004b) Identification of novel adrenomedullin in mammals: a potent cardiovascular and renal regulator. FEBS Lett 556:53-58.

Tal M, Ammar DA, Karpuj M, Krizhanovsky V, Naim M, and Thompson DA (1995) A novel putative neuropeptide receptor expressed in neural tissue, including sensory epithelia. Biochem Biophys Res Commun 209:752-759.

Tamura K, Okazaki M, Tamura M, Isozumi K, Tasaki H, and Nakashima Y (2003) Urotensin II-induced activation of extracellular signal-regulated kinase in cultured vascular smooth muscle cells: involvement of cell adhesion-mediated integrin signaling. Life Sci 72:1049-1060.

Tan YJ, Fan ZT, and Yang HX (2006) Role of urotensin II gene in the genetic susceptibility to gestational diabetes mellitus in northern Chinese women. Zhonghua Fu Chan Ke Za Zhi 41:732-735.

Tarui N, Santo T, Mori M, and Watanabe H (2001) inventors, Takeda Chemical Industries, Ltd., assignee. Quinoline derivatives as vasoactive agents exhibiting orphan receptor GPR14 protein antagonism. Patent WO 2001-066143. 2001 Sep 13.

Tarui N, Santo T, Watanabe H, Aso K, and Ishihara Y (2002) inventors, Takeda Chemical Industries, Ltd., assignee. Preparation of 2,3,4,5-tetrahydro-1H-3benzazepine derivatives as GPR14 antagonists. Patent WO 2002002530. 2002 Jan 10

Tasaki K, Hori M, Ozaki H, Karaki H, and Wakabayashi I (2004) Mechanism of human urotensin II-induced contraction in rat aorta. J Pharmacol Sci 94:376-383. Thompson JP, Watt P, Sanghavi S, Strupish JW, and Lambert DG (2003) A comparison of cerebrospinal fluid and plasma urotensin II concentrations in normotensive and hypertensive patients undergoing urological surgery during spinal anesthesia: a pilot study. Anesth Analg 97:1501-1503.

Tian L, Li C, Qi J, Fu P, Yu X, Li X, and Cai L (2008) Diabetes-induced upregulation of urotensin II and its receptor plays an important role in TGF-beta1-mediated renal fibrosis and dysfunction. Am J Physiol Endocrinol Metab 295:E1234-E1242.

Tostivint H, Joly L, Lihrmann I, Ekker M, and Vaudry H (2004) Chromosomal localization of three somatostatin genes in zebrafish. Evidence that the [Pro2]somatostatin-14 isoform and cortistatin are encoded by orthologous genes. $J \mathrm{Mo}$ Endocrinol 33:R1-R8.

Tostivint H, Joly L, Lihrmann I, Parmentier C, Lebon A, Morisson M, Calas A, Ekker M, and Vaudry H (2006) Comparative genomics provides evidence for close evolutionary relationships between the urotensin II and somatostatin gene families. Proc Natl Acad Sci USA 103:2237-2242.

Tostivint H, Lihrmann I, and Vaudry H (2008) New insight into the molecular evolution of the somatostatin family. Mol Cell Endocrinol 286:5-17.

Tostivint H, Ocampo Daza D, Bergqvist CA, Quan FB, Bougerol M, Lihrmann I, and Larhammar D (2014) Molecular evolution of GPCRs: Somatostatin/urotensin II receptors. J Mol Endocrinol 52:T61-T86.

Tostivint H, Quan FB, Bougerol M, Kenigfest NB, and Lihrmann I (2013) Impact of gene/genome duplications on the evolution of the urotensin II and somatostatin families. Gen Comp Endocrinol 188:110-117.

Totsune K, Takahashi K, Arihara Z, Sone M, Ito S, and Murakami O (2003) Increased plasma urotensin II levels in patients with diabetes mellitus. Clin Sci (Lond) 104:1-5.

Totsune K, Takahashi K, Arihara Z, Sone M, Murakami O, Ito S, Kikuya M, Ohkubo T, Hashimoto J, and Imai Y (2004) Elevated plasma levels of immunoreactive urotensin II and its increased urinary excretion in patients with Type 2 diabetes mellitus: association with progress of diabetic nephropathy. Peptides 25:1809-1814.

Totsune K, Takahashi K, Arihara Z, Sone M, Satoh F, Ito S, Kimura Y, Sasano H, and Murakami O (2001) Role of urotensin II in patients on dialysis. Lancet $\mathbf{3 5 8}$ : $810-811$. 
Trebicka J, Leifeld L, Hennenberg M, Biecker E, Eckhardt A, Fischer N, Pröbsting AS, Clemens C, Lammert F, Sauerbruch T, et al. (2008) Hemodynamic effects of urotensin II and its specific receptor antagonist palosuran in cirrhotic rats. Hepatology 47:1264-1276.

Tsai CS, Loh SH, Liu JC, Lin JW, Chen YL, Chen CH, and Cheng TH (2009) Urotensin II-induced endothelin-1 expression and cell proliferation via epidermal growth factor receptor transactivation in rat aortic smooth muscle cells. Atherosclerosis 206:86-94.

Tsoukas P, Kane E, and Giaid A (2011) Potential clinical implications of the urotensin II receptor antagonists. Front Pharmacol 2:38 10.3389/fphar.2011.00038.

Tsutsui K, Saigoh E, Ukena K, Teranishi H, Fujisawa Y, Kikuchi M, Ishii S, and Sharp PJ (2000) A novel avian hypothalamic peptide inhibiting gonadotropin release. Biochem Biophys Res Commun 275:661-667.

Tzanidis A, Hannan RD, Thomas WG, Onan D, Autelitano DJ, See F, Kelly DJ, Gilbert RE, and Krum H (2003) Direct actions of urotensin II on the heart: implications for cardiac fibrosis and hypertrophy. Circ Res 93:246-253.

Vale W, Spiess J, Rivier C, and Rivier J (1981) Characterization of a 41-residue ovine hypothalamic peptide that stimulates secretion of corticotropin and beta-endorphin. Science 213:1394-1397.

Van de Peer Y, Maere S, and Meyer A (2010) $2 \mathrm{R}$ or not $2 \mathrm{R}$ is not the question anymore. Nat Rev Genet 11:166.

Vaudry H, Chartrel N, and Conlon JM (1992) Isolation of [Pro2,Met13] somatostatin14 and somatostatin-14 from the frog brain reveals the existence of a somatostatin gene family in a tetrapod. Biochem Biophys Res Commun 188:477-482.

Vaudry H and Conlon JM (1991) Identification of a peptide arising from the specific post-translation processing of secretogranin II. FEBS Lett 284:31-33.

Vaudry H, Do Rego JC, Le Mével JC, Chatenet D, Tostivint H, Fournier A, Tonon MC, Pelletier G, Conlon JM, and Leprince J (2010) Urotensin II, from fish to human. Ann N Y Acad Sci 1200:53-66.

Vaughan J, Donaldson C, Bittencourt J, Perrin MH, Lewis K, Sutton S, Chan R, Turnbull AV, Lovejoy D, Rivier C, et al. (1995) Urocortin, a mammalian neuropeptide related to fish urotensin I and to corticotropin-releasing factor. Nature 378:287-292.

Vaughan JM, Fischer WH, Hoeger C, Rivier J, and Vale W (1989) Characterization of melanin-concentrating hormone from rat hypothalamus. Endocrinology 125:1660-1665.

Vergura R, Camarda V, Rizzi A, Spagnol M, Guerrini R, Calo' G, Salvadori S, and Regoli D (2004) Urotensin II stimulates plasma extravasation in mice via UT receptor activation. Naunyn Schmiedebergs Arch Pharmacol 370:347-352.

Vigh B and Vigh-Teichmann I (1998) Actual problems of the cerebrospinal fluidcontacting neurons. Microsc Res Tech 41:57-83.

Vogt L, Chiurchiu C, Chadha-Boreham H, Danaietash P, Dingemanse J, Hadjadj S, Krum H, Navis G, Neuhart E, Parvanova AI, et al.; PROLONG (PROteinuria Lowering with urOteNsin receptor antaGonists) Study Group (2010) Effect of the urotensin receptor antagonist palosuran in hypertensive patients with type 2 diabetic nephropathy. Hypertension 55:1206-1209.

Wang HX, Zeng XJ, Liu Y, Wang J, Lu LQ, Hao G, Zhang LK, and Tang CS (2009) Elevated expression of urotensin II and its receptor in skeletal muscle of diabetic mouse. Regul Pept 154:85-90.

Wang YX, Ding YJ, Zhu YZ, Shi Y, Yao T, and Zhu YC (2007) Role of PKC in the novel synergistic action of urotensin II and angiotensin II and in urotensin II-induced vasoconstriction. Am J Physiol Heart Circ Physiol 292:H348-H359.

Watanabe T, Pakala R, Katagiri T, and Benedict CR (2001a) Synergistic effect of urotensin II with mildly oxidized LDL on DNA synthesis in vascular smooth muscle cells. Circulation 104:16-18.

Watanabe T, Pakala R, Katagiri T, and Benedict CR (2001b) Synergistic effect of urotensin II with serotonin on vascular smooth muscle cell proliferation. J Hypertens 19 $2191-2196$

Watanabe T, Suguro T, Kanome T, Sakamoto Y, Kodate S, Hagiwara T, Hongo S, Hirano T, Adachi M, and Miyazaki A (2005) Human urotensin II accelerates foam cell formation in human monocyte-derived macrophages. Hypertension 46:738-744.

Watson AM, Lambert GW, Smith KJ, and May CN (2003) Urotensin II acts centrally to increase epinephrine and ACTH release and cause potent inotropic and chronotropic actions. Hypertension 42:373-379.

Watson AM and May CN (2004) Urotensin II, a novel peptide in central and peripheral cardiovascular control. Peptides 25:1759-1766.

Watson AM, McKinley MJ, and May CN (2008) Effect of central urotensin II on heart rate, blood pressure and brain Fos immunoreactivity in conscious rats. Neuroscience 155:241-249.

Watson AM, Olukman M, Koulis C, Tu Y, Samijono D, Yuen D, Lee C, Behm DJ, Cooper ME, Jandeleit-Dahm KA, et al. (2013) Urotensin II receptor antagonism confers vasoprotective effects in diabetes associated atherosclerosis: studies in humans and in a mouse model of diabetes. Diabetologia 56:1155-1165.
Waugh D and Conlon JM (1993) Purification and characterization of urotensin II from the brain of a teleost (trout, Oncorhynchus mykiss) and an elasmobranch (skate, Raja rhina). Gen Comp Endocrinol 92:419-427.

Waugh D, Youson J, Mims SD, Sower S, and Conlon JM (1995) Urotensin II from the river lamprey (Lampetra fluviatilis), the sea lamprey (Petromyzon marinus), and the paddlefish (Polyodon spathula). Gen Comp Endocrinol 99:323-332.

Webster HH and Jones BE (1988) Neurotoxic lesions of the dorsolateral pontomesencephalic tegmentum-cholinergic cell area in the cat. II. Effects upon sleepwaking states. Brain Res 458:285-302.

Wenyi Z, Suzuki S, Hirai M, Hinokio Y, Tanizawa Y, Matsutani A, Satoh J, and Oka Y (2003) Role of urotensin II gene in genetic susceptibility to Type 2 diabetes mellitus in Japanese subjects. Diabetologia 46:972-976.

Wilkinson IB, Affolter JT, de Haas SL, Pellegrini MP, Boyd J, Winter MJ, Balment RJ, and Webb DJ (2002) High plasma concentrations of human urotensin II do not alter local or systemic hemodynamics in man. Cardiovasc Res 53:341-347.

Wu YQ, Song Z, Zhou CH, Xing SH, Pei DS, and Zheng JN (2010) Expression of urotensin II and its receptor in human lung adenocarcinoma A549 cells and the effect of urotensin II on lung adenocarcinoma growth in vitro and in vivo. Oncol Rep 24:1179-1184.

Xie N and Liu L (2009) Elevated expression of urotensin II and its receptor in great artery of type 2 diabetes and its significance. Biomed Pharmacother 63:734-741.

$\mathrm{Xu}$ S, Wen H, and Jiang H (2012) Urotensin II promotes the proliferation of endothelial progenitor cells through p38 and p44/42 MAPK activation. Mol Med Rep 6: 197-200.

Yano K, Hicks JW, Vaudry H, and Conlon JM (1995) Cardiovascular actions of frog urotensin II in the frog, Rana catesbeiana. Gen Comp Endocrinol 97:103-110.

Yano K, Vaudry H, and Conlon JM (1994) Spasmogenic actions of frog urotensin II on the bladder and ileum of the frog, Rana catesbeiana. Gen Comp Endocrinol 96: 412-419.

Yasuda T, Masaki T, Gotoh K, Chiba S, Kakuma T, and Yoshimatsu H (2012) Intracerebroventricular administration of urotensin II regulates food intake and sympathetic nerve activity in brown adipose tissue. Peptides 35:131-135.

You Z, Genest J Jr, Barrette PO, Hafiane A, Behm DJ, D'Orleans-Juste P, and Schwertani AG (2012) Genetic and pharmacological manipulation of urotensin II ameliorate the metabolic and atherosclerosis sequalae in mice. Arterioscler Thromb Vasc Biol 32:1809-1816.

Yulis CR and Lederis K (1986) Extraurophyseal distribution of urotensin II immunoreactive neuronal perikarya and their processes. Proc Natl Acad Sci USA 83: 7079-7083.

Yulis CR and Lederis K (1988) Occurrence of an anterior spinal, cerebrospinal fluidcontacting, urotensin II neuronal system in various fish species. Gen Comp Endocrinol 70:301-311.

Zelnik PR and Lederis K (1973) Chromatographic separation of urotensins. Gen Comp Endocrinol 20:392-400.

Zemancíková A and Török J (2013) Urotensin II-a newly discovered modulator of cardiovascular functions in vertebrates. Cesk Fysiol 62:19-25.

Zeng ZP, Liu GQ, Li HZ, Fan XR, Liu DM, Tong AL, Zheng X, and Liu C (2006) The effects of urotensin-II on proliferation of pheochromocytoma cells and mRNA expression of urotensin-II and its receptor in pheochromocytoma tissues. Ann NY Acad Sci 1073:284-289.

Zhang Y, Li J, Cao J, Chen J, Yang J, Zhang Z, Du J, and Tang C (2002) Effect of chronic hypoxia on contents of urotensin II and its functional receptors in rat myocardium. Heart Vessels 16:64-68.

Zhang YG, Li J, Li YG, and Wei RH (2008) Urotensin II induces phenotypic differentiation, migration, and collagen synthesis of adventitial fibroblasts from rat aorta. J Hypertens 26:1119-1126.

Zhang YG, Li YG, Liu BG, Wei RH, Wang DM, Tan XR, Bu DF, Pang YZ, and Tan CS (2007) Urotensin II accelerates cardiac fibrosis and hypertrophy of rats induced by isoproterenol. Acta Pharmacol Sin 28:36-43.

Zhou CH, Wan YY, Chu XH, Song Z, Xing SH, Wu YQ, and Yin XX (2012) Urotensin II contributes to the formation of lung adenocarcinoma inflammatory microenvironment through the NF-кB pathway in tumor-bearing nude mice. Oncol Lett 4 : 1259-1263.

Zhu F, Ji L, and Luo B (2002) The role of urotensin II gene in the genetic susceptibility to type 2 diabetes in Chinese population. Zhonghua Yi Xue Za Zhi (Taipei) 82:1473-1475.

Ziltener P, Mueller C, Haenig B, Scherz MW, and Nayler O (2002) Urotensin II mediates ERK1/2 phosphorylation and proliferation in GPR14-transfected cell lines. J Recept Signal Transduct Res 22:155-168.

Zou Y, Nagai R, and Yamazaki T (2001) Urotensin II induces hypertrophic responses in cultured cardiomyocytes from neonatal rats. FEBS Lett 508:57-60. 